\title{
Glucopsychosine increases cytosolic calcium to induce calpain-mediated apoptosis of acute myeloid leukemia cells.
}

\author{
by \\ Leonard Angka \\ A thesis \\ presented to the University of Waterloo \\ in fulfillment of the \\ thesis requirement for the degree of \\ Master of Science \\ in \\ Pharmacy
}

Waterloo, Ontario, Canada, 2014

CLeonard Angka 2014 


\section{AUTHOR'S DECLARATION}

I hereby declare that I am the sole author of this thesis. This is a true copy of the thesis, including any required final revisions, as accepted by my examiners.

I understand that my thesis may be made electronically available to the public. 


\section{ABSTRACT}

Nutraceuticals (i.e., food-derived bioactive compounds) are a vast and relatively untapped resource for novel anti-cancer drug discovery. Our lab created a unique nutraceutical library and screened these compounds in two human acute myeloid leukemia (AML) cell lines (KG1a and OCI-AML2) and one "normal" prostate cell line (RWPE) for selective anti-cancer activity. Glucopsychosine, a lipid derived from bovine milk, reduced the viability of leukemia cells without altering viability of normal cells at concentrations up to $10 \mu \mathrm{M}$, as measured by the MTS assay. To confirm its activity, glucopsychosine demonstrated a dose response against AML cell lines $(n=3)$ with an EC50 of 3.5-5.0 $\mu \mathrm{M}$ with no effect on the viability of normal bone marrow derived CD34+ cells at concentrations up to $20 \mu \mathrm{M}$, as measured by the Annexin V/Propidium iodide (ANN/PI) assay. Time course analysis showed that glucopsychosine induced apoptosis following 12 hours of incubation, as evidenced by accumulation of ANN+/PI- cells. Apoptosis was further confirmed, using standard apoptotic assays, as glucopsychosine caused DNA fragmentation, caspase activation and PARP cleavage.

Given the observed in vitro effects, we next evaluated glucopsychosine's in vivo antitumor efficacy in leukemia mouse xenografts. NOD/SCID mice $(n=24)$ were subcutaneously injected with OCI-AML2 leukemia cells and then given glucopsychosine $(20 \mathrm{mg} / \mathrm{kg}$ or 40 $\mathrm{mg} / \mathrm{kg}$ ) or a vehicle control every other day for 17 days by intraperitoneal injection. Glucopsychosine delayed tumor growth and reduced tumor weight up to 4 fold $(\mathrm{p}<0.05)$ compared to control without evidence of weight loss or changes in red blood cell counts, 
hemoglobin levels or serum markers of kidney and liver damage. Therefore, glucopsychosine imparted anti-tumor activity without toxicity.

Glucopsychosine caused a significant 2-3 fold increase $(\mathrm{p}<0.001)$ in cytosolic calcium levels at 4-8 hours of incubation, as measured by the fluorescent intracellular dye fluo-3AM and flow cytometry. Since increases in cytosolic calcium can initiate apoptosis through calpain activation, we measured the activity of these calcium dependent proteases using a commercially available activity assay and by Western blotting. Following 6-8 hours of incubation, glucopsychosine resulted in a 3 fold increase in calpain activity $(\mathrm{p}<0.01)$ and active calpain protein levels. Moreover, co-incubation with the calpain inhibitor MDL28170 significantly abrogated calpain activation $(\mathrm{p}<0.01)$ and AML cell death $(\mathrm{p}<0.05)$.

To assess the source of calcium, we measured glucopsychosine's ability to increase cytosolic calcium and induce death following co-incubation of AML cells with verapamil, cyclosporine A or TMB-8, which block increases in cytosolic calcium mediated by surface channels, mitochondria or endoplasmic reticulum, respectively. Only verapamil abrogated glucopsychosine induced increases in cytosolic calcium and toxicity suggesting that the source of calcium in glucopsychosine mediated AML cell death is from the extracellular space. This hypothesis was confirmed as we demonstrated that glucopsychosine-induced apoptosis was absent when AML cells were cultured in calcium free media. Finally, we interrogated publicly available AML gene expression profiling datasets for changes in expression of surface calcium channel subunits in AML patient samples compared to normal hematopoietic cells. Multiple subunits of CACNA1, a voltage dependent plasma membrane calcium channel, are significantly 
$(\mathrm{p}<0.001)$ under-expressed $>1.5$-fold in AML patients compared to normals. Given recent evidence that AML cells possess low intracellular calcium levels and elevated calpain activity, our data suggests that glucopsychosine's mechanism of AML selectivity may be directly related to its ability to target and activate this apoptotic pathway.

Thus, glucopsychosine increases cytosolic calcium to induce calpain mediated apoptosis and displays pre-clinical activity in leukemia mouse xenografts. Glucopsychosine is a lipid derived from bovine milk and given its observed safety profile it could be useful in the treatment of acute myeloid leukemia. 


\section{ACKNOWLEDGEMENTS}

I would like acknowledge and thank my supervisor, Dr. Paul A. Spagnuolo, for his continual support and mentorship. This thesis represents only a small portion of the lessons I have learned while being a part of his lab over the past 2 years. I also had the pleasure of having Dr. Blay and Dr. Beazely on my advisory committee. I greatly appreciate the feedback and encouragement they have given me throughout my Masters. Thanks to Dr. Cutler for his gracefulness in answering even the simplest of questions. I would like to acknowledge those who have contributed to the success of this Masters thesis: Dr. Quadrilatero, Dr. Sukhai, and Dr. Minden, as well as Thomas and Elliott. A special thanks to Sarah Rae for her kind administrative help throughout the program. I have been incredibly fortunate to have had the best labmates (Sarah, Eric, and Kevin). Thank you guys for being more than just labmates and for making grad school not feel like grad school. To \#loveisonyourside, thank you for being an outlet of my expression and joy. To my fellow UW Pharmacy graduate colleagues, thank you for being welcoming and accepting - I believe we have an amazing community full of bright and wonderful people. I would also like to acknowledge my church family and friends - your prayers and support have carried me through these past 2 years. Lastly, I thank my parents and family for believing in me and loving me through whatever decisions I make. 


\section{TABLE OF CONTENTS}

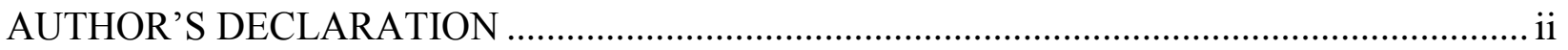

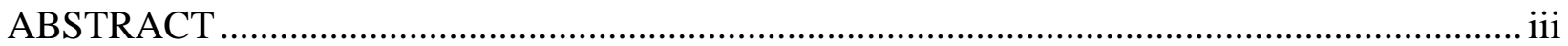

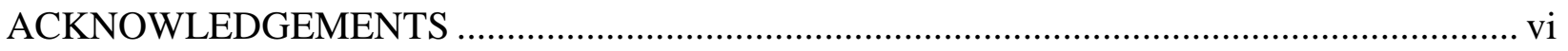

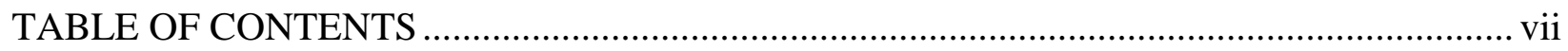

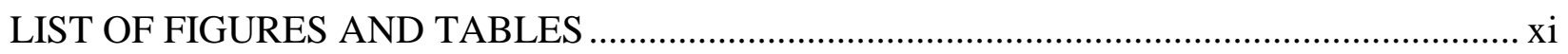

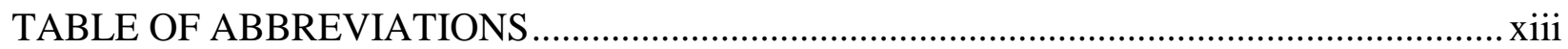

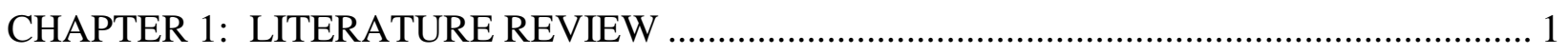

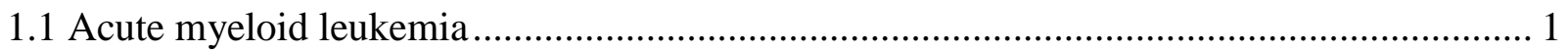

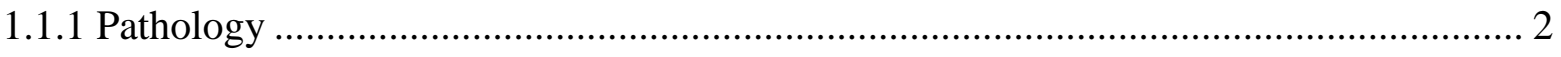

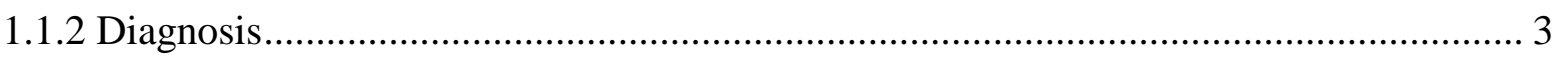

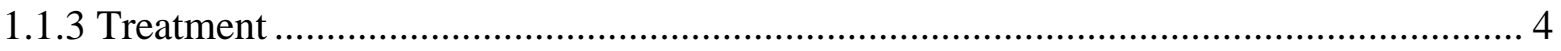

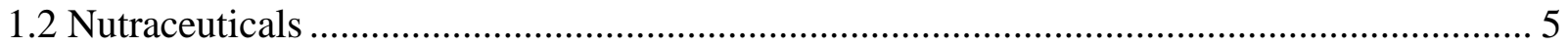

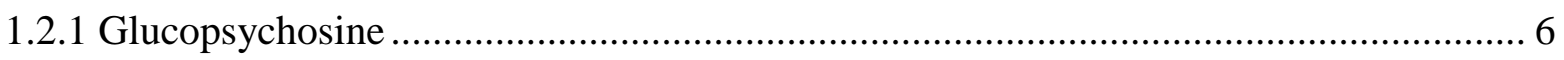

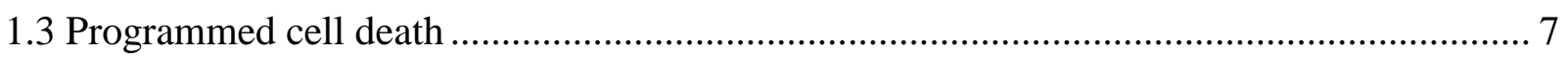

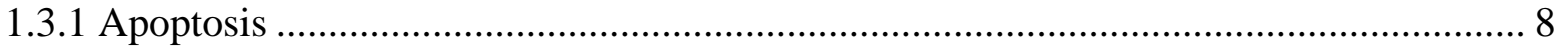

1.3.2 Pathways of apoptosis ............................................................................................ 9

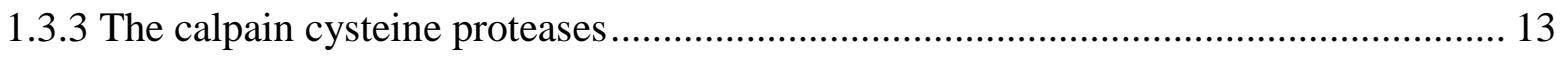

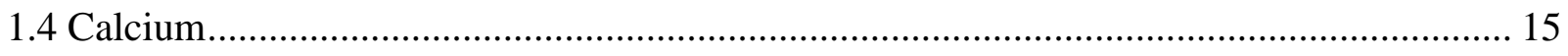

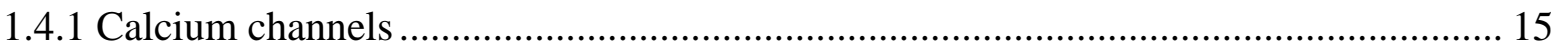

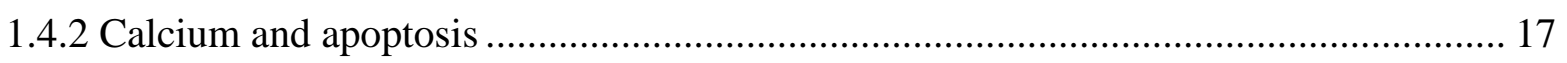

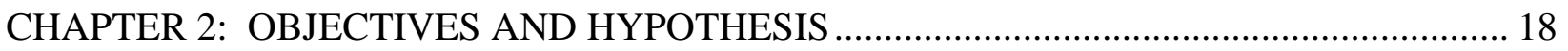


CHAPTER 3: GLUCOPSYCHOSINE INCREASES CYTOSOLIC CALCIUM TO INDUCE CALPAIN-MEDIATED APOPTOSIS OF ACUTE MYELOID LEUKEMIA CELLS.

3.1 Introduction .20

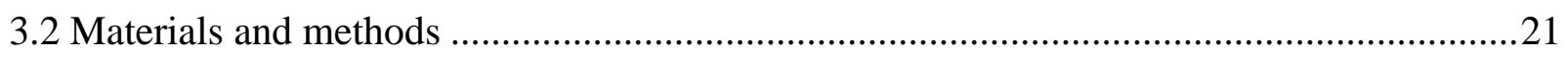

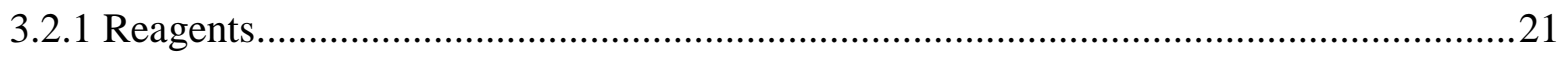

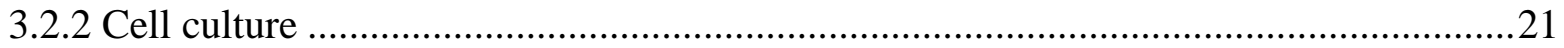

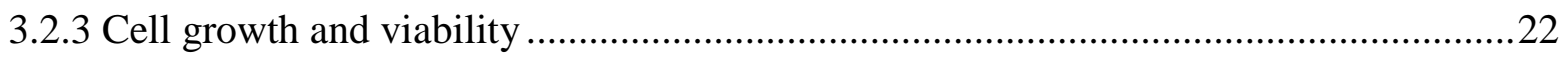

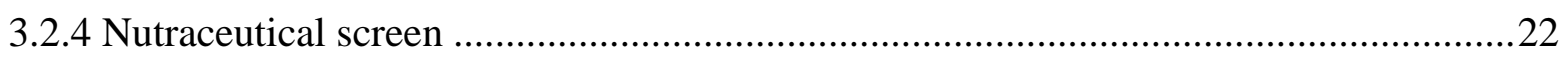

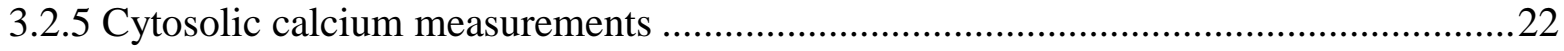

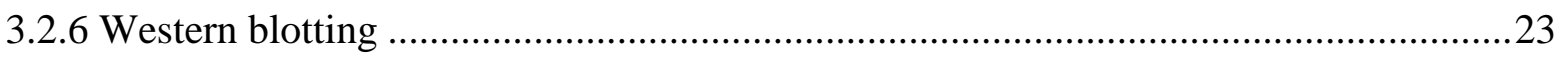

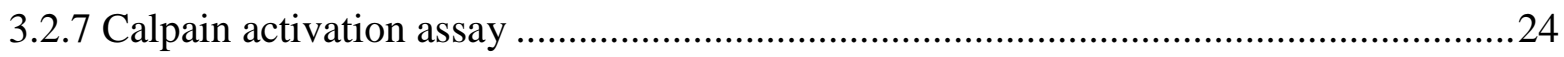

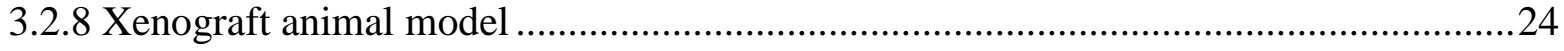

3.2.9 Interrogation of publically available databases .................................................25

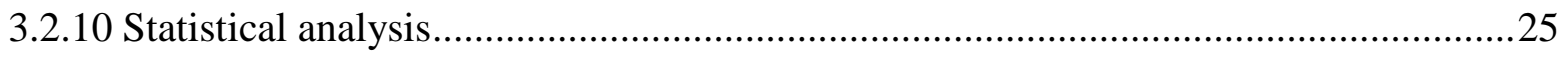

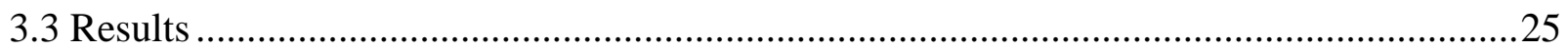

3.3.1 A nutraceutical screen for novel anti-cancer compounds identifies glucopsychosine. .25

3.3.2 Glucopsychosine induces caspase-independent apoptosis .....................................28

3.3.3 Extracellular calcium channels are significantly under-expressed in AML over normal cells

3.3.4 Glucopsychosine increases intracellular calcium to induce calpain-mediated apoptosis

3.3.5 Glucopsychosine-induced apoptosis is mediated by extracellular calcium and not intracellular stores.

3.3.6 Glucopsychosine delays tumor growth and reduces tumor weights in leukemia mouse xenografts

3.4 Discussion 


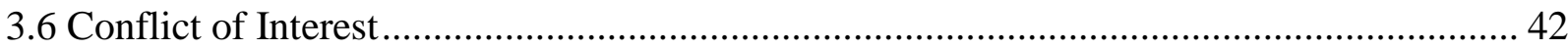

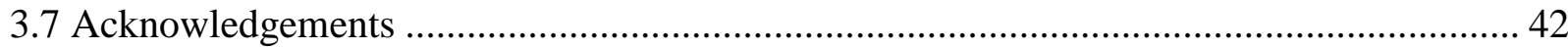

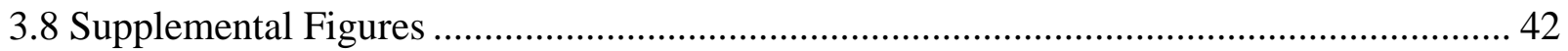

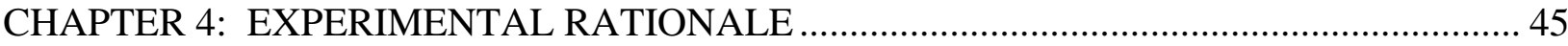

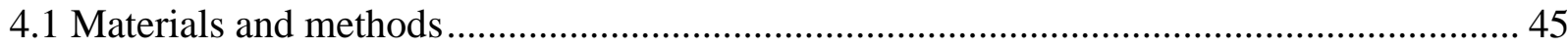

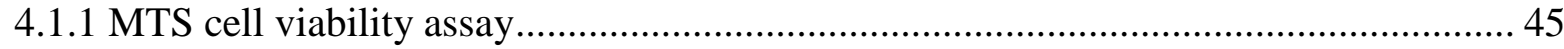

4.1.2 Flow cytometry and Annexin V/propidium iodide (PI) viability assay ........................ 45

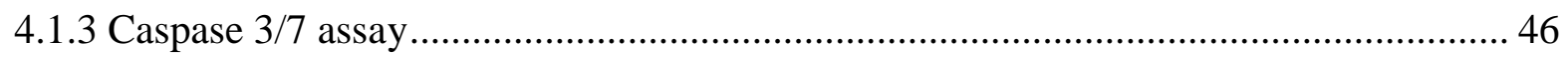

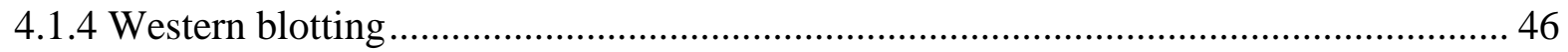

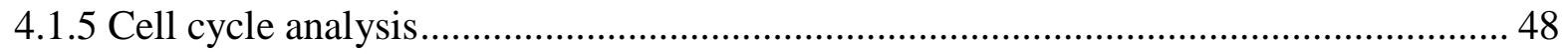

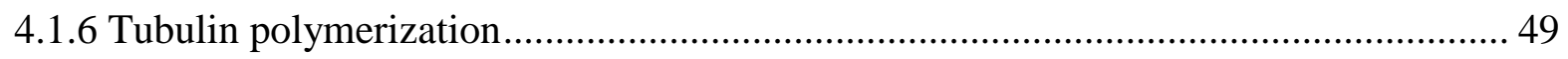

4.1.7 Establishing a xenograft tumor model ....................................................................... 49

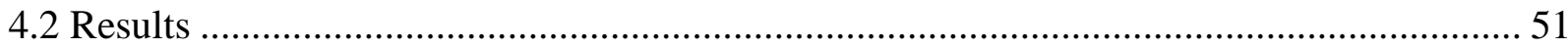

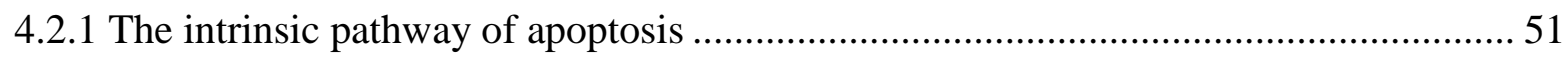

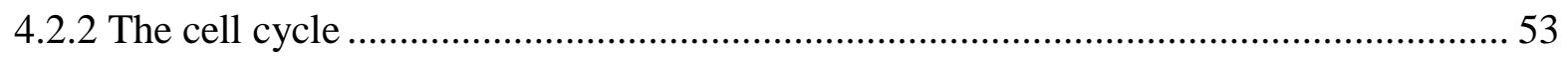

4.2.3 Calcium and the ER stress pathway ……………..................................................... 57

4.2.4 Calpains and calcium .......................................................................................... 59

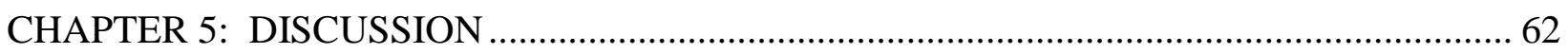

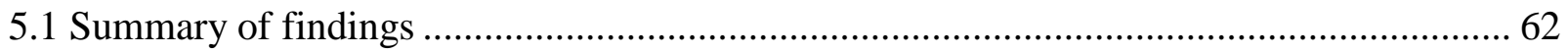

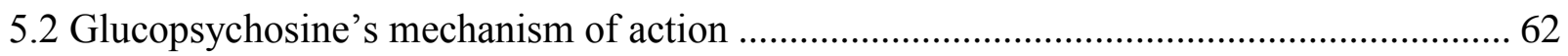

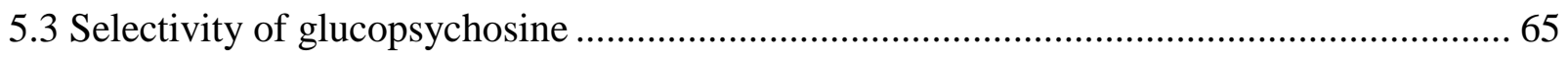

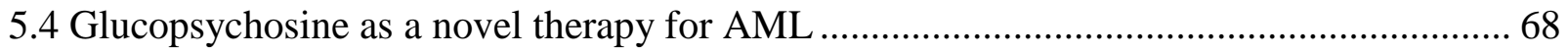

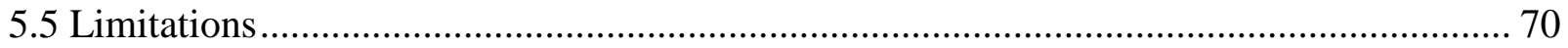

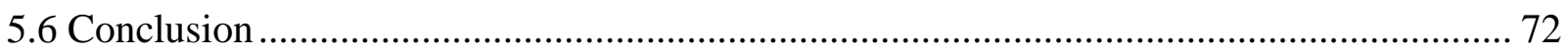




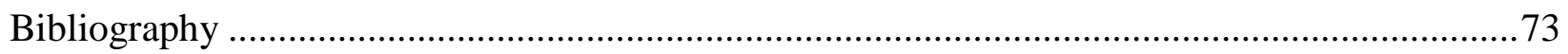

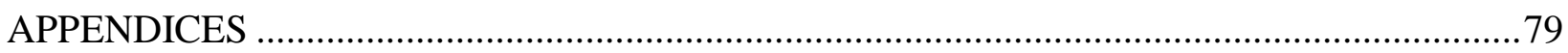

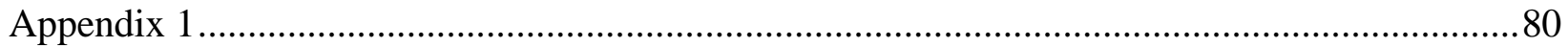

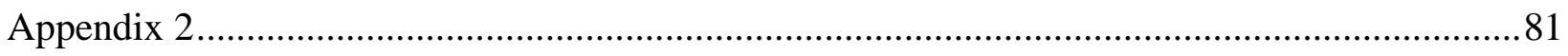

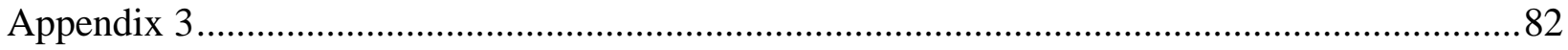

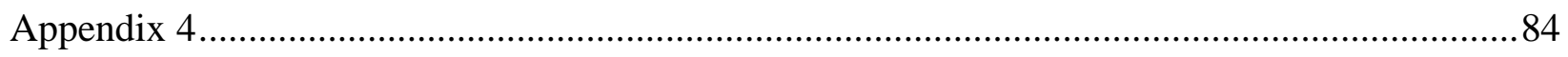

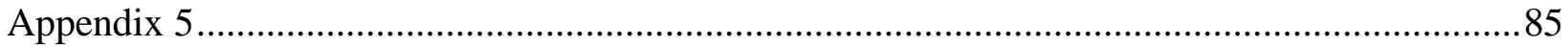




\section{LIST OF FIGURES AND TABLES}

\section{Chapter 1}

Figure 1. Glucosylsphingosine (glucopsychosine) chemical structure.................... 7

Figure 2. Death receptor and intrinsic mitochondrial pathway of apoptosis................. 10

Figure 3. ER stress mediated apoptosis and the various sources of calcium influx............ 12

\section{Chapter 3}

Figure 4. Glucopsychosine is selectively toxic toward AML cells........................ 27

Figure 5. Glucopsychosine induced AML cell apoptosis............................. 29

Figure 6. Glucopsychosine increased cytosolic calcium and activated calpain enzymes........ 32

Figure 7. The extracellular space is the source of glucopsychosine-mediated increases in

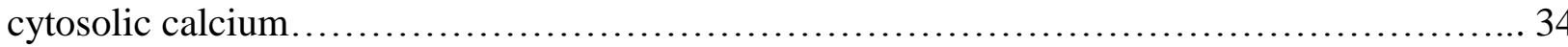

Figure 8. Glucopsychosine delayed tumor growth and reduced tumor weight in leukemia

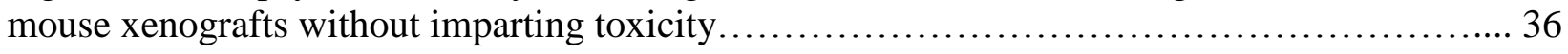

Supplemental figure 1: Glucopsychosine in non-AML cell lines....................... 42

Supplemental figure 2: Glucopsychosine in the presence of inhibitors of intracellular

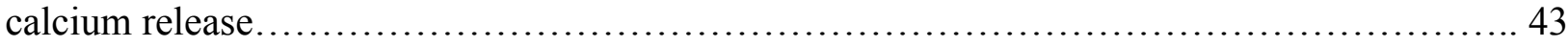

Supplemental figure 3: Hematoxylin and eosin stained tumor sections x200.............. 43

Supplementary Table 1: AML surface markers..................................... 44

\section{Chapter 4}

Table 1. Antibodies. .48 
Figure 9. Assessing the intrinsic mitochondrial pathway of apoptosis.

Figure 10. Cell cycle arrest and tubulin polymerization.............................. 56

Figure 11. Assessing the ER stress pathway of apoptosis...............................58

Figure 12. Basal levels of calpain expression......................................59

Figure 13. Fluo 3-AM cytosolic Ca2+ quantification assay in normal CD34+ sample and

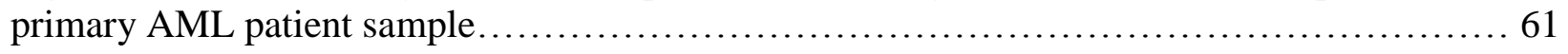

\section{Chapter 5}

Figure 14. Simplified schematic noting the cellular differences between normal hematopoietic cells and AML cells ................................................... 68

\section{Appendices}

Supplementary Table 2. List of under-expressed calcium channels in AML.................. 80

Supplementary Table 3. List of over-expressed calcium channels in AML................... 81

Supplementary Table 4. Calcium Channel Gene Information.......................... 82

MDL28170 inhibits increases in apoptosis ...................................... 84

Eight NOD/SCID mice were injected with human leukemia cell lines and monitored for the

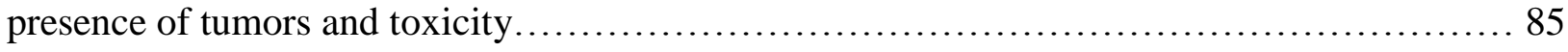




\section{TABLE OF ABBREVIATIONS}

ALL Acute lymphoblastic leukemia

AML Acute myeloid leukemia

APL

Acute promyelocytic leukemia

ANN/PI

Annexin V/Propidium iodide

AIF

Apoptosis inducing factor

CLCAs

Calcium-activated chloride channels

CCNS

Cell cycle non-specific

CCS

Cell cycle specific

Ch.

Chapter

CML

Chronic myeloid leukemia

CRC

Colorectal cancer

CR

Complete Remission

AraC

Cytarabine

DA

Daunorubicin \& Cytarabine

DISC

Death-inducing signalling complex

DMSO

Dimethyl sulfoxide

ER

Endoplasmic reticulum

FADD

FAS-associated death domain

FAB

French-American-British

GLU

Glucopsychosine

G $\beta$ Gase

Glucosylceramide- $\beta$-glucosidase

EC50

Half maximal effective concentration

IC50

Half maximal inhibitory concentration

Jurk

Jurkat

mRNA

Messenger RNA

$\Delta \Psi_{\mathrm{m}}$

Mitochondrial membrane potential

mPTP

Mitochondrial permeability transition pore 


$\begin{array}{ll}\text { MDS } & \text { Myelodysplastic syndrome } \\ \text { NAC } & \text { N-acetyl-cysteine } \\ \text { NHPs } & \text { Natural health products } \\ \text { NOC } & \text { Nocodazole } \\ \text { NOD/SCID } & \text { Nonobese diabetic/severe combined immunodeficiency } \\ \text { OD } & \text { Opitcal density } \\ \text { PS } & \text { Phosphatidylserine } \\ \text { PMCA } & \text { Plasma membrane Ca }{ }^{2+} \text { ATPase } \\ \text { PMCA2 } & \text { Plasmalemmal Ca }{ }^{2+} \text { ATPases } 2 \\ \text { PARP } & \text { Poly(ADP-ribose)ylation polymerase } \\ \text { ROS } & \text { Reactive oxygen species } \\ \text { SERCA } & \text { Sarcoendoplasmic reticular Ca } \text { ATPase }^{2+} \text { AT } \\ \text { SR } & \text { Sarcoplasmic reticulum } \\ \text { tBid } & \text { Truncated-Bid } \\ \text { UPR } & \text { Unfolded protein response } \\ \text { VER } & \text { Verapamil } \\ \text { WHO } & \text { World health organization } \\ & \end{array}$




\section{CHAPTER 1: LITERATURE REVIEW}

\subsection{Acute myeloid leukemia}

Leukemia, a malignancy of the blood, will affect 52,380 new American patients in 2014. Thirty percent of those patients will be further classified as having acute myeloid leukemia (AML). According to the American Cancer Society, the estimated number of deaths in the United States attributable to AML will be 10,460 people [1]. This implies that in 2014,28 people per day will die from AML in the United States alone. Even though the median age is 67 [2] at the time of diagnosis, AML is also prevalent in children. Leukemia is the most common pediatric cancer (34 percent of new cancer cases in children is leukemia, either ALL or AML) [3]. Since AML is a heterogeneous disease, five-year survival rates in children range from 90 percent (in the most favourable prognostic group) to as low as 22 percent [4]. Unfortunately, these statistics only decrease as age increases - older AML patients (>60 years old) having a reported five-year survival rate of less than 10 percent [5]. AML is a devastating disease that indiscriminately occurs in all ages and people groups.

Leukemia is the cancer of haematological processes. Haematopoiesis is the process by which all blood cell-types are formed, starting with a haematopoietic stem cell found in the bone marrow that is capable of differentiating or self-renewing itself. It is able to differentiate into myeloid progenitor cells or lymphoid progenitor cells. In AML, differentiation is arrested at the myeloid progenitor level which leads to the accumulation of immature myeloid cells referred to as "myeloid blasts" [6]. 
The objectives of AML treatment is to induce complete remission (CR) and prevent patient relapse. CR, defined by the National Cancer Institute, is the achievement of specific hematologic parameters (no extramedullary leukemia, neutrophil recovery, and platelet recovery) and less than 5 percent bone marrow myeloid blasts [7]. Cytarabine and daunorubicin have been the standard chemotherapeutics used for the treatment of AML since their discovery in the 1960’s [8, 9]. Slight dosing modifications have improved treatment efficacy of these drugs. However, a large portion of AML patients cannot tolerate these chemotherapeutics, due to their dose limiting toxicities.

\subsubsection{Pathology}

The etiology of AML begins with DNA mutation (i.e., cytogenetic lesions) which includes deletions and translocations in certain chromosomes. The most prevalent genetic deletion in AML is the $\mathrm{t}(15 ; 17)$ translocation which is present in over 90 percent of AML cases [6]. AML can be classified under the French-American-British (FAB) system which divides AML into 8 different groups (M0-M7) via their cytogenetic properties. Recently, the FAB system of classification was updated by the World Health Organization's (WHO) classification system which integrates genetic, immunophenotypic, biological, and clinical features of AML [10]. Irrespective of the classification system used, classifying AML on common disease state phenotype can aide in selecting appropriate treatment. The primary example of this is the $\mathrm{t}(15 ; 17)$ deletion which has been sub-classified as acute promyelocytic leukemia (APL).

The translocation seen in APL results in the formation of a PML/RAR $\alpha$ fusion protein which arrests myeloid cell differentiation by incorrectly localizing PML within the cell [11]. It 
was discovered that all-trans retinoic acid restored cell differentiation by enabling the proper distribution of PML. Now APL is treated with the highest success rate of all AML prognostic groups with expected cure rates of greater than 70 percent [12]. This provides evidence that novel therapies can be developed and catered to specific AML sub-types. However, AML is a heterogeneous disease which in most cases is the result of multiple mutations.

\subsubsection{Diagnosis}

In AML, the normal myeloid cells in the body are replaced with leukemic blasts that deplete the body of their normal blood proportions which results in cytopenia (a reduction in the

number of blood cells). Fatigue, hemorrhaging, and an increased predisposition to infections and fevers are common in AML patients because of decreases in red blood cells, platelets, and white cells respectively [6]. When AML progresses, the leukemic cells in the bone marrow can escape into the blood system and can cause granulocytic sarcomas (isolated leukemic tumors) and hyperleukocytosis $\left(>100,000\right.$ white blood cells per $\mathrm{mm}^{3}$ ).

As a general rule, AML is diagnosed in a patient when their myeloid blasts in bone marrow or blood exceeds 20 percent (according to the WHO criterion) [2]. The number of myeloid leukemia cells can be measured via multicolor flow cytometry by counting cells expressing cell markers unique to myeloid cells such as CD33, CD13, CD64, or CD41. Although there are different prognostic groups, patients with myelodysplastic syndromes (MDS; 11-19 percent white blood cells in bone marrow or blood) [6] may fare better with AML treatment options and AML patients with >20 percent blasts may fare better with MDS treatment 
options. Therefore, multiple parameters such as cytogenetics or immunophenotype must also be considered before making any clinical decisions [2].

\subsubsection{Treatment}

Patients are diagnosed based on cytogenetics, age, karyotype and clinical features of AML (white blood cell count, platelets, and bone marrow blasts) [10]. This ranges from favourable to unfavourable, depending on which classification system one uses (refer to Ch. 1.1.1).

The gold standard of AML treatment has been the combination of cytarabine (AraC, a pyrimidine analogue) with an anthracycline such as daunorubicin. Daunorubicin and AraC (DA) was introduced in 1960's and it was the first instance of inducing CR in an AML patient [8]. Daunorubicin is administered at $45-60 \mathrm{mg} / \mathrm{m}^{2} / \mathrm{d}$ for 3 days and is combined with standard-dose cytarabine at $100-200 \mathrm{mg} / \mathrm{m}^{2}$ over 7 days. This is known as the " $3+7$ induction regimen" and it induces CR in 65 to 75 percent of younger patients ( $<60$ years of age) and 50 percent in older patients ( $>60$ years of age) $[9,13]$. While these numbers are promising, the rate of relapse in the favourable subgroup of AML patients is 30 to 40 percent (and they increase depending on their prognostic group) [6]. The disease free survival of this treatment is 30 percent of patients for long-term ( $>5$-years). Cytarabine is also used at higher doses in the next stages of therapy consolidation, maintenance, and salvage therapy - which focuses on keeping remission and ridding the body of any residual cancer.

Dosing modifications and adding other chemotherapeutics, such as etoposide, have been tested over the years yielding important facts about AML treatment. Studies assessing high-dose 
cytarabine treatment $\left(2-3 \mathrm{~g} / \mathrm{m}^{2}\right)$ show a lack of evidence for better CR rates with an increased intensity of induction therapy. The same is true when studies were done with a second phase of induction therapy [13]. Clinicians try to increase CR of their patients by making dosing modifications, rotating new chemotherapeutics with the $3+7$ regimen, or adding additional rounds of induction chemotherapy. Ultimately, novel therapies are needed to improve disease outcomes for these patients.

\subsection{Nutraceuticals}

The term "nutraceutical” was coined in 1989 by Dr. Stephen DeFelice and the Foundation for Innovation in Medicine as,

"... any substance that may be considered a food or part of a food and that provides medical or health benefits, including the prevention and treatment of disease. Such products may range from isolated nutrients, dietary supplements and diet plans to genetically engineered 'designer' foods, herbal products and processed foods such as cereals, soups and beverages." [14]

Nutraceuticals are a component of a larger family of compounds known as natural health products (NHPs) which accounts for a third of Consumer Health Products Canada member's total sales indicating their prevalence in health care in Canada [15]. As of late, many research initiatives are looking to nutraceuticals as potential cures to a wide array of diseases. This is not a new phenomenon, but one of the oldest forms of drug discovery. The bioactive components of foods have been known to affect many biological processes related to neoplastic growth such as cell differentiation, apoptosis, cell cycle, carcinogen metabolism, inflammatory responses, and DNA repair [16]. 
From 1981-2002, NHPs represented 28 percent of the number of new drugs introduced in addition to the 24 percent of new chemical compounds derived from a natural product pharmacophore [17]. From 2005 to 2007 there were thirteen NHP-derived drugs that were approved and currently there are over a hundred NHP-derived drugs undergoing clinical trials [18]. Because natural products are chemically diverse, previously identified therapeutic NHPs can and should be reassessed for potential efficacy in other diseases. Of the 25,000 nutraceutical compounds, only 500 of these compounds have been assessed in studies for cancer treatment and prevention [16]. Drug repurposing libraries have increased in popularity because of emerging technologies and new methods of high-throughput screening. Therefore, nutraceuticals are a valuable source for drug discovery or repurposing as they are an underrepresented subcategory of NHPs.

\subsubsection{Glucopsychosine}

Glucopsychosine, also known as glucosylsphingosine, is naturally found in milk as a membrane lipid [19]. It is a modified glycosphingolipid which are ubiquitous in all eukaryotic membranes. Glucopsychosine is composed of a glucose sugar attached to a sphingosine at the C1 hydroxyl group (Figure 1) [20]. In the body, glucopsychosine is broken down and metabolised by the enzyme glucosylceramide- $\beta$-glucosidase (G $\beta$ Gase) into psychosine [20, 21]. It has been reported that psychosine accumulation in the central nervous system, as seen in Gaucher disease patients, is due to a decreased amount of G $\beta$ Gase activity. An experiment by Jatana et al. (2002) [21] showed that the IC50 in rat C6 glial cells after 24 hours was $20 \mu \mathrm{M}$. Lloyd-Evans et al. (2003) [22] showed that glucopsychosine may be involved in sensitizing 
ryanodine receptors on the endoplasmic reticulum (ER) membrane to allow the efflux of $\mathrm{Ca}^{2+}$ ions into the cytosol in brain microsomes. There has been no research to date assessing glucopsychosine's toxicity in AML cells.

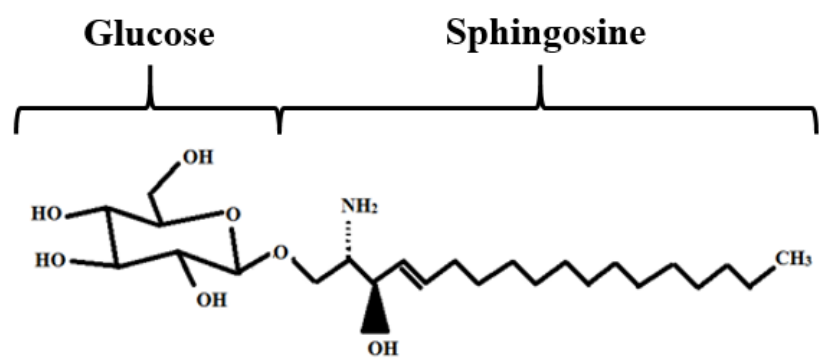

Figure 1. Glucosylsphingosine (glucopsychosine) chemical structure.

Membrane lipids can participate in many complex cell-to-cell signalling events due to the wide diversity of their headgroups and formations. The ceramide/sphingomyelin pathway utilizes lipids as second messengers for regulating apoptosis [23]. The precursor lipids are sphingolipids which are generated in the ER. Sphingolipids are classified by their characteristic eighteen carbon amino-alcohol backbone which can be used as a precursor to all other sphingolipid modifications [24]. Sphingosine (Fig. 1) can be modified to become a pro-apoptotic or an anti-apoptotic second messenger. Phosphorylation of the $\mathrm{C} 1$ hydroxyl group leads to the anti-apoptotic lipid signaller sphingosine-1-phosphate while acylation of sphingosine produces ceramide molecules which are generally pro-apoptotic [25].

\subsection{Programmed cell death}

There are three main cell death pathways. These are apoptosis, autophagy, and necrosis. Autophagy differs from apoptosis and necrosis because it primarily functions as a pro-survival mechanism during cellular stress by recycling cellular components through the merging of 
autophagic vesicles (containing damaged parts) and lysosomes. However, in the presence of prolonged autophagic signalling the cell may use autophagy as a mode of cell death [26, 27]. Necrosis was once thought of as an unregulated form of cell death, but recent studies suggest that necrosis can be genetically regulated [27]. Apoptosis is a genetically regulated process of cell death where cells systematically undergo a series of morphological changes and are consumed by surrounding cells. The term "programmed cell death" refers to any genetically controlled form of cellular termination [26].

\subsubsection{Apoptosis}

More than 50 percent of neoplasms have dysfunctional apoptotic machinery [26]. While uncontrollable apoptosis can lead to degenerative diseases, insufficient apoptosis will lead to uncontrollable proliferation. The tumor suppressor gene TP53 is an oft mutated gene in neoplastic diseases and results in the inactivation of p53. p53 is a sensor of genotoxic stress during DNA damage acts as an apoptotic switch. In the absence of this sensor, but in the presence of DNA damage, cells will continue to function as normal because there is no input from p53 [26]. This will ultimately lead to unregulated cell division of damaged DNA.

Apoptosis can be induced by DNA damage, nutrient starvation, reactive oxygen species production, death-receptor ligand binding, calcium increases, and other cellular stresses. The characteristics of apoptosis are cell shrinkage, chromatin condensation, membrane blebbing, the formation of apoptotic bodies, and the lysis and phagocytosis of apoptotic bodies by surrounding cells [28]. An early marker of apoptosis is the flipping of phosphatidylserine (PS) to the outer leaflet of the plasma membrane. This process is mediated by two enzymes $-\mathrm{Ca}^{2+}$-dependent 
scramblases and ATP-dependent aminophospholipid translocases [29]. Phagocytes recognize PS and target the apoptotic cells for degradation [28].

Caspases are cysteine aspartic proteases which are functionally inactive until cleaved at a specific site. They play key roles in cytoskeletal degradation and nuclear fragmentation. There are fourteen known caspases, but not all are involved at the same time [28]. Depending on the pathway of apoptosis, different caspases can be activated. Caspase- 3 and -7 are known as the executioner caspases because they are involved in the final proteolytic event in many apoptotic pathways. Caspase-3 and -7 can cleave the DNA repair protein, poly(ADP-ribose)ylation polymerase (PARP) [30, 31] at the DEVD (Asp-Glu-Val-Asp) tetrapeptide site rendering PARP unable to repair DNA. The inactivation of PARP allows DNA fragmentation, which is characteristic of all apoptotic pathways.

\subsubsection{Pathways of apoptosis}

The death receptor pathway is initiated via external factors that cause the cell to undergo apoptosis directly. Death receptors situated on the outer leaflet of the plasma membrane commence the apoptotic response when bound by pro-apoptotic ligands. The six known death receptors are CD95, DR2, DR3, DR4, DR5, and TNR1 [32]. The death-inducing signalling complex (DISC) is assembled upon a ligand (from the TNF-superfamily) binding to the death receptor. The FAS-associated death domain (FADD) adaptor protein then recruits caspase-8, which can induce apoptosis through proteolytic cleaving of procaspase- 3 thereby activating it. In addition, there can be crosstalk between the death receptor pathway and the intrinsic pathway 
through caspase-8's ability to cleave Bid (Fig. 2). Truncated-Bid (tBid) is an inhibitor of antiapoptotic proteins found in the mitochondria [26, 32].

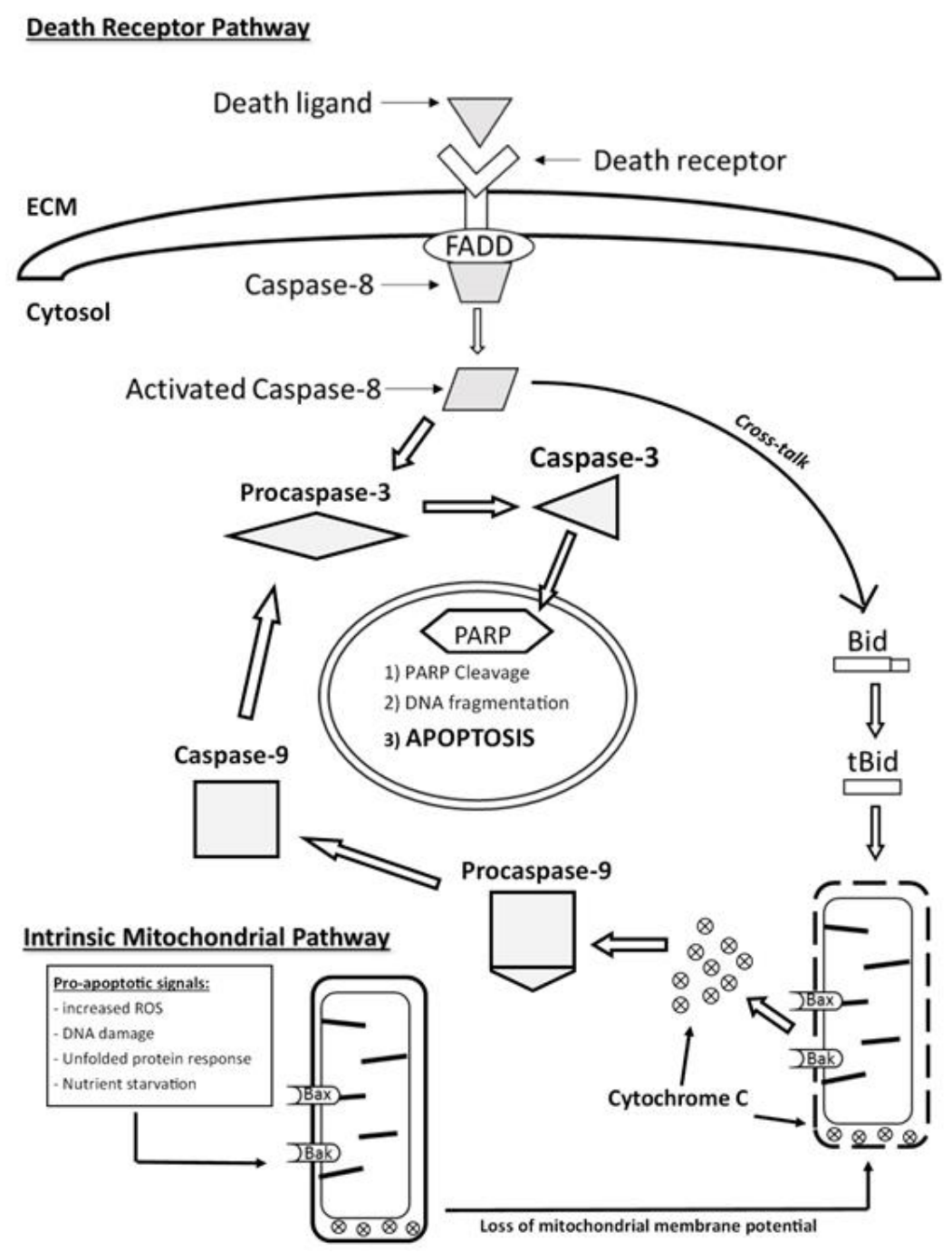

Figure 2. Death receptor and intrinsic mitochondrial pathway of apoptosis. Modified from Hotchkiss et al. Cell death. N Engl J Med. 2009 [33]. The death receptor pathway involves the binding of a death ligand to a death receptor (CD95, DR2, DR3, DR4, DR5, and TNR1) located on the cell membrane. This complex recruits caspase- 8 which can then activate caspase- 3 or cleave Bid (cross-talk with the intrinsic pathway). The intrinsic pathway is initiated by various cellular stresses which causes a loss in mitochondrial membrane integrity which allows cytochrome c (found in the inner mitochondrial membrane) to be released activating the caspase- 9 cascade. Caspase- 3 activation leads to the cleavage of PARP (a DNA repair protein) and the execution of apoptosis. 
The intrinsic pathway is mediated by many mitochondrial related proteins which are either anti-apoptotic or pro-apoptotic. Anti-apoptotic proteins such as Bcl-2 and Bcl- $\mathrm{X}_{\mathrm{L}}$ are in constant flux with pro-apoptotic proteins including (but not limited to) Bid, Bak, Bax, and Puma. Ultimately, the intrinsic pathway of apoptosis leads to the loss of mitochondrial membrane potential $\left(\Delta \Psi_{\mathrm{m}}\right)$ and the release of apoptotic effector proteins from the inner mitochondrial membrane matrix $[26,34]$. Cytochrome $\mathrm{c}$ is one of these inner mitochondrial membrane matrix proteins and, when released, is a part of the apoptosome complex. This complex allows the activation of procaspase- 9 which then results in the proteolytic activation of the executioner caspases and leads to apoptosis [34]. Therefore, regulation of cytochrome c release is Bcl-2 and Bcl- $\mathrm{x}_{\mathrm{L}}$ 's role. The cleavage of Bid to tBid causes the inhibition of $\mathrm{Bcl}-2 / \mathrm{Bcl}-\mathrm{x}_{\mathrm{L}}$ and the activation of Bax and Bak [26].

Less common pathways of apoptosis involve the ER, calcium, and the calpain family of cysteine proteases. The ER is the organelle that folds and post-translationally modifies peptides for further packaging and compartmentalization. When there is an accumulation of unfolded proteins, the unfolded protein response (UPR) occurs in hopes to salvage cells. The UPR causes an up-regulation of GRP78 protein chaperone which shuttles unfolded proteins back into the ER lumen to stimulate protein folding and circumvent apoptosis [35]. However, in the state of prolonged UPR, the cell may undergo apoptosis via the ER stress pathway.

The ER stress pathway involves procaspase- 12 which, in its inactive state, is bound to the cytosolic side of the ER. Procaspase-12 is activated by m-calpains in the cytosol and can go on to initiate the caspase cascade via caspase- 3 and -7 activation. Apart from cleaving PARP, 
caspase-3 also cleaves calpastatin - an endogenous inhibitor of calpains in the cytosol - leading to a positive feedback loop with caspase-3 and calpains [36]. Caspase-12 is also able to activate caspase-9 which is involved in the intrinsic mitochondrial pathway and this presents a cytochrome c independent model of apoptosis [35].

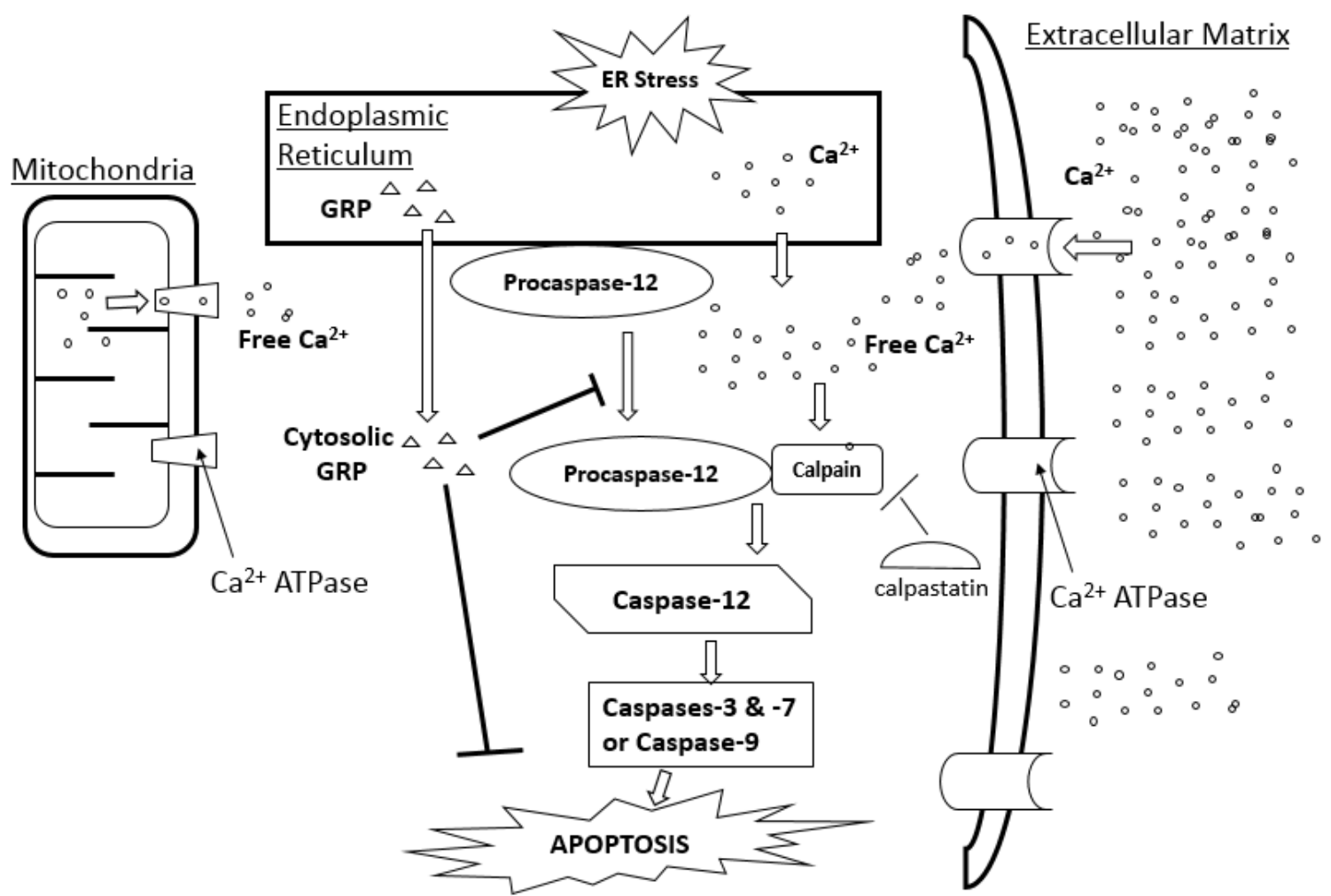

Figure 3. ER stress mediated apoptosis and the various sources of calcium influx. ER stress can be initiated by a depletion of ER calcium stores or large and rapid influx of extracellular calcium into the cytosol. When GRP78 is inefficient in shuttling unfolded proteins back to the ER, pro-caspase-12 translocates from the ER membrane to be activated by active calpain. Under normal conditions calpains are inhibited by calpastatin, but calcium binding releases calpastatin from calpains enabling them to cleave procaspase-12. The caspase-12 cascade can cause apoptosis by activating caspase- 3 and 7 directly or through caspase- 9 . 
The ER stress pathway can also act independently of caspase- 12 by causing the loss of $\Delta \Psi_{\mathrm{m}}$ and the release of cytochrome $\mathrm{c}$ or endonuclease $\mathrm{G}$ [37]. Endonuclease $\mathrm{G}$ is a DNase that can fragment DNA $[34,37]$. While there has been little focus on the ER stress pathway, new studies are showing that it is involved in many cell death related programs. Research into curcumin and its anti-cancer effects in HL60 cells shows that curcumin causes apoptosis via the ER stress pathway [38].

\subsubsection{The calpain cysteine proteases}

The calpains are a family of $\mathrm{Ca}^{2+}$-activated cysteine proteases that are located exclusively intracellularly in all mammalian cells. There are two classes of calpains which are ubiquitously expressed $-\mu$-calpain and $\mathrm{m}$-calpain. These calpains require different concentrations of calcium in order to become active. $\mu$-Calpains require micromolar concentrations $(3-50 \mu \mathrm{M})$ whereas $\mathrm{m}$ calpains need millimolar $(400-800 \mu \mathrm{M})$ concentrations of calcium [39]. Structurally, these

proteins are highly conserved and similar, with $\mu$-calpain being slightly larger than m-calpain. Calpains are heterodimeric proteins consisting of a large domain ( $\sim 80 \mathrm{kDa})$ and a small domain $(\sim 28 \mathrm{kDa})$ [40]. The large subunit is composed of four domains (I, II, III, and IV) and domain I is autolysed prior to activating its proteolytic function. The small subunit is composed of two domains (V and VI) and contains a lethality gene which highlights the importance of these proteases for regulating key processes [41]. These proteases reside predominantly in the cytoplasm, however, multiple studies have confirmed that they are redistributed to subcellular locations during mitosis/meiosis, as they play essential roles in cell cycle progression [41]. 
Calpains are constitutively inhibited by calpastatin to prevent unspecific activation by normal $\mathrm{Ca}^{2+}$ flux [36]. These inhibitors are heat stable and calpain-specific, resistant to many denaturing agents such as urea, SDS, or trichloroacetic acid. One calpastatin molecule (110 kDa) can inhibit four calpain molecules because of its four repeating domains [39]. Calpastatin also requires calcium to inhibit calpains, however, the amount of calcium needed is significantly lower and therefore has a prevailing tendency to keep calpains inhibited. Calcium does not bind to calpastatin, but instead to calpains at a specific site which allows calpastatin to block the autolysis of calpain $[39,40]$. In the presence of excess $\mathrm{Ca}^{2+}$ levels, calpastatin will dissociate and allow calpains to autolyse and become an active protease against various substrates including its own inhibitor, calpastatin [39].

Once activated, calpains can act on a variety of substrates located in the cytosol, nucleus (including PARP), or plasma membrane [39]. Calpains can initiate apoptosis independent of caspase enzymes. This involves release of mitochondrial proteins such as apoptosis inducing factor (AIF) and endonuclease G. AIF becomes truncated by calpains and translocated from the mitochondria to the cytosol and then to the nucleus where it initiates chromatin condensation and DNA fragmentation independent of caspases [42]. However, there is still crosstalk between calpains and caspases [36]. Caspase-3 can cleave calpastatin to free calpains from their inhibitor. Many studies have shown calpains involvement in cell cycle progression [40, 41, 43]. Calpains are essential proteases during S phase and G2/M phase cell cycle checkpoints. Inhibiting calpains causes arrest at multiple points on the cell cycle. In cells arrested at the G1/S phase, addition of GM-CSF (a mitogen) resumed cell cycle progression after 9 hrs in TF-1 cells, 
but it took 18 hours in the presence of a calpain inhibitor, PD 150606 [41]. It is hypothesized that calpains regulate cell cycle by degrading p53, a tumor suppressor protein, which leads to the down-regulation of the Cdk inhibitor, p21 [41]. This has implications in regards to cancer cell morphology because calpains therefore promote oncogenesis within cells. Niapour et al. [44] has shown that AML cells have elevated levels of calpains which could be used by the malignant cells to accelerate cell division in AML.

\subsection{Calcium}

Cellular signalling is mediated through the binding of one compound which causes a chemical or structural change to another compound or protein. Protein kinases, for example, remove the $\gamma$ phosphate (high energy) from an ATP molecule and attach it to the hydroxyl group of a substrate protein residue (e.g., serine, tyrosine, or threonine) which further changes the properties of that protein [45]. Calcium is a very potent cell signalling molecule due to its distinguishing characteristics. As an alkaline earth metal it carries a +2 charge when ionised. This enables it to bind a large array of proteins causing conformational and polarity changes which can elicit a signal [46]. The normal physiological range of cytosolic $\mathrm{Ca}^{2+}$ is $100 \mathrm{nM}$ which is significantly less than the extracellular $\mathrm{Ca}^{2+}$ concentration of $2 \mathrm{mM}[36,46]$. This 20,000 -fold gradient allows for large and rapid cellular signalling. Additionally, cells can finely regulate cytosolic $\mathrm{Ca}^{2+}$ for signalling events that require only transient rises in cytosolic $\mathrm{Ca}^{2+}$.

\subsubsection{Calcium channels}

Increases in cytosolic $\mathrm{Ca}^{2+}$ can occur either by release from intracellular stores or influx from the extracellular space through plasma membrane channels. The main calcium stores are 
mitochondria, the ER, and the sarcoplasmic reticulum (SR) which can be controlled by various second messengers. Calcium itself can act as a second messenger to release more calcium into the cytosol from intracellular stores [47]. Calcium signalling can be split into "on" and "off" reactions. "On" reactions include second-messenger signalling that promote the influx of free calcium into the cytosol. In contrast, "off" reactions refer to the removal of free $\mathrm{Ca}^{2+}$ mediated by intracellular buffers, pumps, and exchangers [47]. The homeostasis of calcium is dependent on the balance of these reactions. Cellular processes controlled by calcium signalling will differ based on the spatial and temporal increases in calcium. For example, sustained and high levels of cytosolic $\mathrm{Ca}^{2+}$ will result in cellular events such as gene transcription and proliferation [48], while transient fluctuations can trigger exocytosis [49]. For apoptosis to be triggered by calcium, sustained increases in calcium or depletion of intracellular stores beyond a threshold is required. Channels and pumps which span the plasma membrane are the main regulators of cytosolic $\mathrm{Ca}^{2+}$.

Calcium ions are not readily diffused across the plasma membrane, but slight increases in membrane permeability could result in large influx because of the calcium-gradient. If the membrane is not compromised, calcium can enter the cell through multiple integral proteins. The types of calcium channels found on the cell surface are voltage-gated, ligand-gated, storeoperated channels, and sodium-calcium exchangers [46, 48]. Voltage gated channels open when the membrane is depolarized below a threshold [50]. When intracellular stores are depleted, store-operated channels on the plasma membrane can open to allow calcium to "refill" the stores [48]. Ligand gated channels can be further divided into receptor operated channels, which are activated by binding of an agonist to an allosteric site, or second-messenger operated channels 
which are activated by a variety of molecules such as inositol phosphates and lipid-derived molecules [48]. Lastly, calcium can enter through sodium-calcium exchangers in certain cases as it is usually used to pump calcium out of the intracellular space [46]. Cells are very sensitive to cytosolic $\mathrm{Ca}^{2+}$ and have multiple intra and extracellular pumps to reduce cytosolic $\mathrm{Ca}^{2+}$ levels. ATPase pumps are sanctioned to continually push $\mathrm{Ca}^{2+}$ ions into the ER or SR via sarcoendoplasmic reticular $\mathrm{Ca}^{2+}$ ATPase (SERCA) pumps or out of the cell through plasma membrane $\mathrm{Ca}^{2+}$ ATPase (PMCA) pumps [46]. Therefore, the cell is able to control and monitor its cellular $\mathrm{Ca}^{2+}$ levels through various channels giving it control of its intracellular $\mathrm{Ca}^{2+}$ levels.

\subsubsection{Calcium and apoptosis}

Calcium plays a key role in early apoptosis. Recall that calcium is involved in the flipping of phospholipids to the outer leaflet of the plasma membrane. An early event in apoptosis is the externalization of PS which signals for phagocytic degradation. While the exact mechanism of $\mathrm{Ca}^{2+}$ in this process is unclear, it is understood that the flipping of PS is $\mathrm{Ca}^{2+}$ dependant but not $\mathrm{Ca}^{2+}$ regulated [36]. It was thought that intracellular $\mathrm{Ca}^{2+}$ levels needed to be in the 25 to $100 \mu \mathrm{M}$ range, but a recent paper by Weiss et al. showed $\mathrm{Ca}^{2+}$-dependent scramblase achievable at an EC50 of as low as $1.2 \mu \mathrm{M}$ [29].

As mentioned previously, calpains are $\mathrm{Ca}^{2+}$-activated cysteine proteases and can lead to apoptosis through multiple apoptotic pathways. Few chemotherapeutics focus on calcium regulation as a mechanism for cancer treatment. Suramin, paclitaxel, and vincristine are of the few chemotherapies reported to illicit a calcium response within the cell. Of the three mentioned, only vincristine has benefits in AML treatment specifically [51]. 


\section{CHAPTER 2: OBJECTIVES AND HYPOTHESIS}

The objectives of this project are:

1. Characterize glucopsychosine's mechanism of action in acute myeloid leukemia cells in vitro and;

2. Determine glucopsychosine's efficacy ex vivo and in vivo using primary patient samples and animal models, respectively.

These objectives fulfilled the original hypothesis that:

Glucopsychosine is selectively cytotoxic to myeloid leukemia cells and increases the levels of intracellular calcium which ultimately leads to apoptosis.

\section{Short term goals:}

Complete the preclinical research and relevant literature review necessary for glucopsychosine to warrant further investigation into clinical use for acute myeloid leukemia. This will be accomplished by performing experiments to understand glucopsychosine's mechanism of action and demonstrate its in vivo efficacy and safety.

\section{Long term goals:}

Upon successful completion of the aforementioned short term goals, the next steps would be to 1) understand the pharmacokinetic properties of glucopsychosine in humans, 2) begin Phase 1 clinical trials. 


\title{
CHAPTER 3: GLUCOPSYCHOSINE INCREASES CYTOSOLIC CALCIUM TO INDUCE CALPAIN-MEDIATED APOPTOSIS OF ACUTE MYELOID LEUKEMIA CELLS
}

\author{
The contents of this chapter were republished with permission from the journal Cancer \\ Letters (348: 29-37, 2014).
}

This is a License Agreement between Leonard Angka ("You") and Elsevier ("Elsevier") provided by Copyright Clearance Center ("CCC"). The license consists of your order details, the terms and conditions provided by Elsevier, and the payment terms and conditions.

License number: 3394380944988

License date: May 22, 2014

Licensed content publisher: Elsevier

Licensed content publication: Cancer Letters

Licensed content title: Glucopsychosine increases cytosolic calcium to induce calpain-mediated apoptosis of acute myeloid leukemia cells

Licensed content author: Leonard Angka, Eric A. Lee, Sarah G. Rota, Thomas Hanlon, Mahadeo

Sukhai, Mark Minden, Elliott M. McMillan, Joe Quadrilatero, Paul A. Spagnuolo.

Licensed content date: 28 June-1 July 2014

Licensed content volume number: 348

Licensed content issue number: $1-2$

Number of pages: 9

Start Page: 29

End Page: 37

Type of Use: reuse in a thesis/dissertation

Portion: full article

Format: both print and electronic

Are you the author of this Elsevier article? Yes

Will you be translating? No

Title of your thesis/dissertation: Glucopsychosine increases cytosolic calcium to induce calpainmediated apoptosis of acute myeloid leukemia cells

Expected completion date: Aug 2014

Estimated size (number of pages): 100

Elsevier VAT number: GB 494627212

Permissions price: 0.00 USD

VAT/Local Sales Tax: 0.00 USD / 0.00 GBP

Total: 0.00 USD 


\subsection{Introduction}

Acute myeloid leukemia (AML) is an aggressive malignant disease characterized by the clonal expansion of myeloid precursors that fail to terminally differentiate (i.e., blasts) [6]. Frontline AML therapy consists of 3 days of daunorubucin $\left(45-90 \mathrm{mg} / \mathrm{m}^{2}\right)$ and 7 days of continuous intravenous infusions of cytarabine $\left(100 \mathrm{mg} / \mathrm{m}^{2}\right)$ and results in complete response rates up to $80 \%$ [52]. However, within 2 years there may be a reoccurrence of disease that is resistant to induction chemotherapy [53]. Although recent advances have improved therapies for other hematological malignancies, AML therapy has remained essentially unchanged for 30 years [54]. Thus, there is a critical need for new, more efficacious AML therapies.

Nutraceuticals are food-derived bioactive compounds with physiological activity and belong to a larger group of molecules known as natural health products. While the role of nutraceuticals in cancer treatments is largely unknown, recent studies have demonstrated that the natural health products kinetin riboside [55], an adenosine derivative from coconut milk, and parthenolide [56], an extract from the medicinal herb feverfew, possess anti-leukemia activity. Given these findings, we hypothesized that nutraceuticals would possess similar anti-leukemia activity. Since nutraceuticals are under-represented in large commercially available libraries, we compiled a unique nutraceutical-specific library consisting of 30 compounds and screened this library against AML cell lines to identify novel anti-leukemia nutraceuticals. From this screen, we identified glucopsychosine (GLU), a lipid derived from bovine milk. 


\subsection{Materials and methods}

\subsubsection{Reagents}

Glucopsychosine was obtained from Matreya, Inc. (Pleasant Gap, PA) and reconstituted in $100 \%$ ethanol. The stock solution $(5 \mathrm{mM})$ was diluted in phosphate buffered saline (PBS), aliquoted and stored at $-20{ }^{\circ} \mathrm{C}$ to prevent excessive freeze thaw cycles. Fluo-3AM (Life Technologies; Grand Island, NY), z-VAD-FMK (Z-VAD; R\&D Systems, Minneapolis, MN), Verapamil, Q-VD-OPh, 8-(N,N-Diethylamino)-octyl-3,4,5-trimethoxybenzoate HCl (TMB-8) and cyclosporin (Sigma Chemical; St. Louis, MO) and MDL28170 (Tocris; Bristol, UK) were purchased and reconstituted according to manufacturer's protocols.

\subsubsection{Cell culture}

Acute myeloid leukemia (OCI-AML2, KG1A, U937) cell lines were cultured in Iscove's Modified Dulbecco's Medium (IMDM; Life Technologies; Grand Island, NY) supplemented with $10 \%$ fetal calf serum (FCS; Hyclone, Logan, UT) and antibiotics (100 units/mL of streptomycin and $100 \mu \mathrm{g} / \mathrm{mL}$ of penicillin; Sigma Chemical). RWPE-1, normal prostate cells were incubated in keratinocyte serum free media (Life Technologies). Cells were incubated in a humidified air atmosphere containing $5 \% \mathrm{CO}_{2}$ at $37^{\circ} \mathrm{C}$.

Primary human AML samples, obtained from Dr. Mark Minden, Princess Margaret Cancer Center, were cultured at $37{ }^{\circ} \mathrm{C}$ in IMDM, 20\% FCS and antibiotics. These cells were isolated from the peripheral blood of consenting AML patients who had at least $80 \%$ malignant cells among the mononuclear cells. Normal bone marrow-derived $\mathrm{CD} 34^{+}$hematopoietic cells were purchased from Stem Cell Technologies (Vancouver, BC). The collection and use of human 
tissue for this study was approved by institutional ethics review boards (University Health Network, Toronto, ON, Canada and University of Waterloo, Waterloo, Ontario).

\subsubsection{Cell growth and viability}

Cell growth and viability was measured using the 3-(4,5-dimethylthiazol-2-yl)-5-(3carboxymethoxyphenyl)-2-(4-sulfophenyl)-2H-tetrazolium inner salt (MTS) reduction assay (Promega, Madison, WI), according to the manufacturer's protocol and as previously described [57, 58]. Cells were seeded in 96-well plates and treated with compound for $72 \mathrm{~h}$. Optical density was measured at $490 \mathrm{~nm}$. Cell viability was also assessed by Annexin V and PI (ANN/PI) staining (Biovision, Mountainview, CA) and flow cytometry, as previously described [58].

\subsubsection{Nutraceutical screen}

Nutraceuticals were obtained from commercial sources (NeaLanders Inc., Frutarom, Matreya and Sequoia Chemical Inc.). The unique nutraceutical library was created and screened similar to previously described methods [57-59]. Briefly, AML cells $\left(1.5 \times 10^{4} /\right.$ well $)$ were seeded in 96-well polystyrene tissue culture plates. After seeding, cells were treated with aliquots (10 $\mu \mathrm{M}$ final concentration) of library compound with a final dimethyl sulfoxide (DMSO) concentration of less than $0.05 \%$. After $72 \mathrm{~h}$, cell growth and viability were measured by the MTS assay.

\subsubsection{Cytosolic calcium measurements}

Cytosolic calcium was measured using fluo-3AM, which is a highly charged fluorescent dye that accumulates in the cytosol and emits green fluorescence following subsequent binding 
of calcium ions, similar to methods described previously [60]. Briefly, a stock solution of $1 \mathrm{mM}$ fluo-3AM was diluted to $5 \mu \mathrm{M}$ in fluo-3AM loading buffer (10 mM 4-(2-hydroxyethyl)-1piperazineethanesulfonic acid (HEPES), $137 \mathrm{mM} \mathrm{NaCl}, 5 \mathrm{nM} \mathrm{KCl}, 1 \mathrm{mM} \mathrm{Na} 2 \mathrm{HPO}_{4}, 5 \mathrm{mM}$ glucose, and $0.5 \mathrm{mM} \mathrm{MgCl} 2$ (pH 7.4)). Treated cells (with glucopsychosine or vehicle control) were incubated with fluo-3AM for $30 \mathrm{~min}$ at $37^{\circ} \mathrm{C}$ with gentle agitation. After incubation, cells were washed twice in a calcium estimation buffer (fluo-3AM loading buffer and $1 \mathrm{mM} \mathrm{CaCl}$ ) to remove and inactivate any extracellular fluo-3AM. Cells were then incubated with propidium iodide (PI) for $15 \mathrm{~min}$ at room temperature. The shift in green fluorescence was measured by flow cytometry (Guava 8HT; EMD Millipore, Billerica, MA). Cytosolic calcium was quantified by taking the mean fluorescence values of live gated cells and normalizing them to the zero control.

\subsubsection{Western blotting}

Whole cell lysates were prepared from treated cells, heated for $5 \mathrm{~min}$ at $95^{\circ} \mathrm{C}$, and subjected to gel electrophoresis on $7.5 \%$ SDS-polyacrylamide gels at $150 \mathrm{~V}$ for $85 \mathrm{~min}$. The samples were then transferred at $25 \mathrm{~V}$ for $45 \mathrm{~min}$ to a PVDF membrane and blocked with $5 \%$ milk in Tris-buffered saline-tween (TBS-T) for $1 \mathrm{~h}$. The membrane was incubated with the primary antibody, PARP-1 or calpain antibody (1:1000; Santa Cruz Biotechnologies), overnight at $4{ }^{\circ} \mathrm{C}$. Membranes were then washed and incubated with the appropriate secondary antibody (1:10000) for $1 \mathrm{~h}$ at room temperature. Enhanced chemiluminescence (ECL) was used to detect proteins according to the manufacturer's instructions (GE Healthcare; Baie d'Urfe, Quebec) and luminescence was captured after 5 min using the Kodak Image Station 4000MM Pro and 
analyzed with a Kodak Molecular Imaging Software Version 5.0.1.27. All membranes were stained with Ponceau S and imaged to ensure equal loading, as described by Dam et al. [61].

\subsubsection{Calpain activation assay}

The Calpain-Glo Protease Assay (Promega, Madison, WI) was used to measure calpain activity through luminescence. A proluminescent calpain substrate was added to treated cells in white-walled, 96-well plates and measured at 10 min intervals according to manufacturer's instructions. The experiment was performed in triplicate with the mean luminescence value and standard deviation shown for each sample treatment.

\subsubsection{Xenograft animal model}

NOD/SCID ( $N=24$, Jackson Laboratory, Bar Harbor, ME) mice were injected subcutaneously in the left flank with OCI-AML2 leukemia cells $\left(2.5 \times 10^{6}\right)$. Mice were then randomly assigned to receive glucopsychosine $(20$ or $40 \mathrm{mg} / \mathrm{kg} / \mathrm{every}$ other day; in $0.9 \% \mathrm{NaCl}$ and $0.01 \%$ tween-80) or vehicle control $(0.9 \% \mathrm{NaCl}$ and $0.01 \%$ tween-80) intraperitoneally. Tumor volumes (tumor length $\times$ width $^{2} \times 0.5236$ ) were monitored every other day using a caliper. At the end of the experiment (18d), mice were sacrificed by sodium pentobarbital injection and cardiac puncture, blood collected and tumors excised and weighed. Blood was sent to the Animal Health Laboratory, University of Guelph for blood biochemistry analysis. All animal studies were carried out according to the regulations of the Canadian Council on Animal Care and with the approval of the University of Waterloo, Animal Care Committee. 


\subsubsection{Interrogation of publically available databases}

The expression profile of the set of known calcium channel genes was assessed in publicly available datasets of AML patients compared to normal hematopoietic cells [62]. Mean fold-change was computed for the AML vs. normal comparison, and statistical significance (>1.25-fold; $p<0.001)$ was assessed by ANOVA to derive the set of differentially expressed calcium channel genes.

\subsubsection{Statistical analysis}

Unless otherwise stated, the results are presented as mean $\pm \mathrm{SD}$. Data were analyzed using GraphPad Prism 4.0 (GraphPad Software, USA). $p \leqslant 0.05$ was accepted as being statistically significant.

\subsection{Results}

\subsubsection{A nutraceutical screen for novel anti-cancer compounds identifies glucopsychosine.}

To identify nutraceuticals with anti-cancer activity we compiled a unique library consisting of 30 nutraceuticals with previously uncharacterized anti-cancer activity from commercially available sources. The library was screened against the AML cell lines, OCIAML2 and KG1A, and the "normal" prostate cell line RWPE using the MTS assay following a $72 \mathrm{~h}$ incubation period. The compound which imparted the greatest reduction in viability in both AML cell lines without affecting normal cell viability was glucopsychosine (Fig. 4A and B). Compound 4 (toosendanin) demonstrated toxicity in all cell lines, including the control cell line, 
and was therefore not analyzed further and compound 21 is currently being evaluated in our laboratory. Glucopsychosine's activity was validated by generating dose response curves on a panel of available AML $(\mathrm{n}=3)$ cell lines using the MTS assay following a $72 \mathrm{~h}$ incubation period. It reduced the viability in a dose dependent manner in all AML lines tested (Fig. 4C, left panel; see Supplementary Table 1 for confirmation of AML surface markers). Cell lines of breast, colon and cervical cancer origin were also tested and showed varying degrees of sensitivity to glucopsychosine; ALL, CML and myeloma cells were not sensitive and AML cells were consistently the most sensitive (Supplementary Fig. 1). Glucopsychosine's cytotoxicity was confirmed using the Annexin/PI assay following $72 \mathrm{~h}$ of incubation (IC50: $4.2 \pm 0.5 \mu \mathrm{M}$; Fig. 4C, right panel).

Given the cytotoxicity of glucopsychosine in AML cell lines, we tested its activity in primary AML patient samples and in normal hematopoietic cells using the ANN/PI assay. Glucopsychosine reduced the viability of primary AML patient samples $(n=3)$ but had no effect on the viability of normal hematopoietic cells $(n=3)$ (Fig. 4D). Together, these results demonstrate glucopsychosine's selective toxicity toward AML cells. 
a
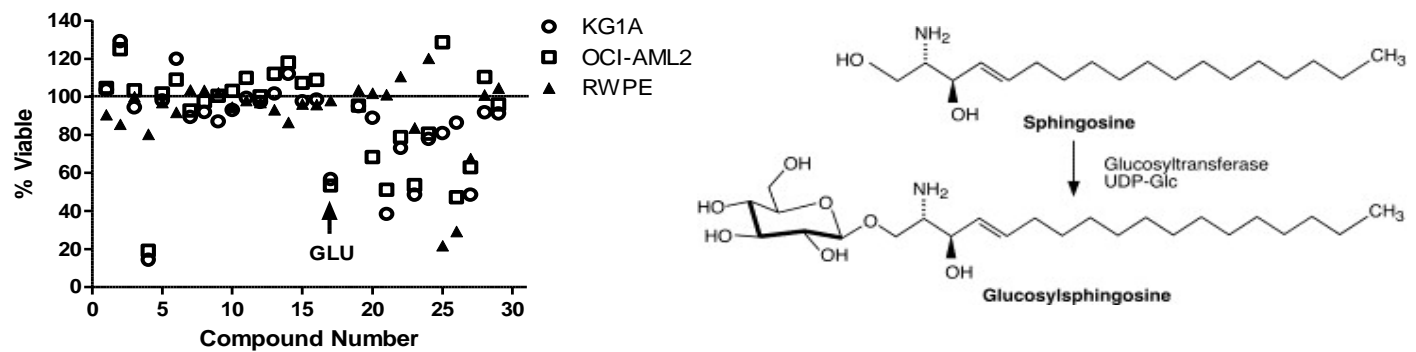

C
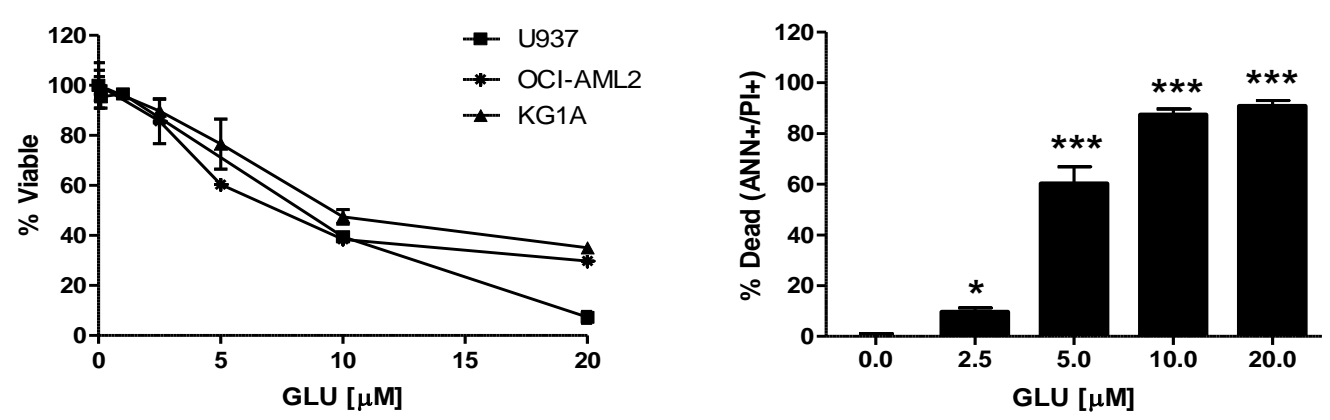

d
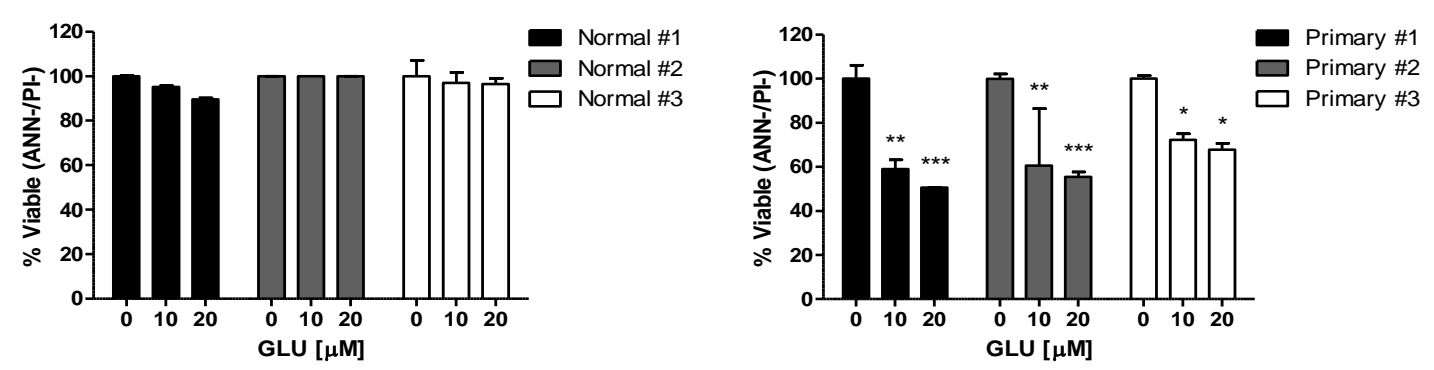

Figure 4. Glucopsychosine is selectively toxic toward AML cells. (A) A screen of our nutraceutical library determined that glucopsychosine reduced viability of 2 AML cell lines without affecting the viability of RWPE, a "normal" prostate cell line. Compounds were incubated with nutraceuticals for $72 \mathrm{~h}$ and cell growth and viability were measured by the MTS assay. (B) Glucopsychosine's structure from Schueler et al. [20] (C) (Left panel) AML cell lines were treated with increasing concentrations of glucopsychosine for $72 \mathrm{~h}$ and cell growth and viability were measured by the MTS assay. Data are the mean percentage of viable cells \pm SD from three experiments. Representative figure is shown. (Right panel) Glucopsychosine's cytotoxicity was confirmed by the Annexin V (ANN)/Propidium Iodide (PI) assay following $72 \mathrm{~h}$ of incubation in OCI-AML2 cells. Data are the mean percentage of dead cells (i.e., $\left.\mathrm{ANN}^{+} / \mathrm{PI}^{+}\right) \pm \mathrm{SD}$ from representative experiments. (D) Normal CD34 ${ }^{+}$bone marrow cells (left panel) and primary AML samples (right panel) were treated with increasing concentrations of glucopsychosine for $24 \mathrm{~h}$ and viability was measured by the ANN/PI assay. ${ }^{*} p<0.05 ;{ }^{* * *} p<0.005 ;{ }^{* * *} p<0.0001$. 


\subsubsection{Glucopsychosine induces caspase-independent apoptosis}

Time course analysis using the ANN/PI assay demonstrated that glucopsychosineinduced apoptosis (i.e., $\mathrm{ANN}^{+} / \mathrm{PI}^{-}$), which was initiated after $12 \mathrm{~h}$ of treatment with $10 \mu \mathrm{M}$ glucopsychosine (Fig. 5A, left panel). This apoptotic response was consistent with observations that glucopsychosine caused cleavage of poly (ADP) ribose polymerase (PARP) protein, a common downstream target of active cysteine proteases (e.g., calpain and caspase-3) [63] (Fig. $5 \mathrm{~A}$, right panel).

Caspase-3 is a cysteine protease actively involved in apoptosis. To evaluate caspase enzyme involvement in glucopsychosine-mediated apoptosis, we blocked caspase activity with the pan-caspase inhibitor Z-VAD. However, treatment with $50 \mu \mathrm{M} Z$ Z-VAD did not affect glucopsychosine's activity (Fig. 5B, left panel). Interestingly, high Z-VAD concentrations (i.e., $100 \mu \mathrm{M})$ attenuated glucopsychosine's activity (Fig. 5B, right panel); however, high concentrations have been associated with reduced activity of other non-caspase enzymes, including calpain [42]. We therefore tested glucopsychosine's activity in the presence of Q-VD$\mathrm{OPh}$, a specific caspase-3 inhibitor. Cell death was not affected following Q-VD-OPh treatment suggesting glucopsychosine-induced apoptosis was not dependent on caspase-3 (Fig. 5C, left panel). 


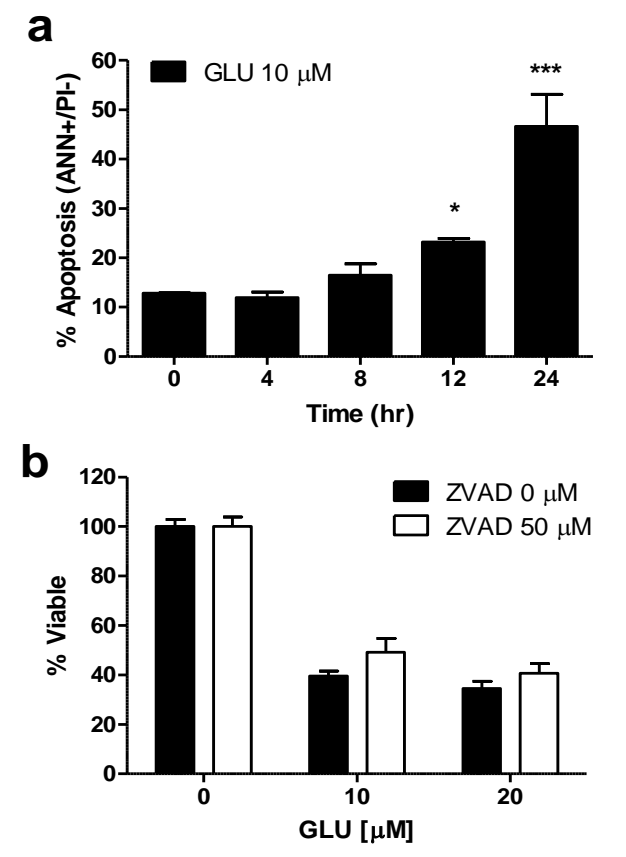

\section{PARP}
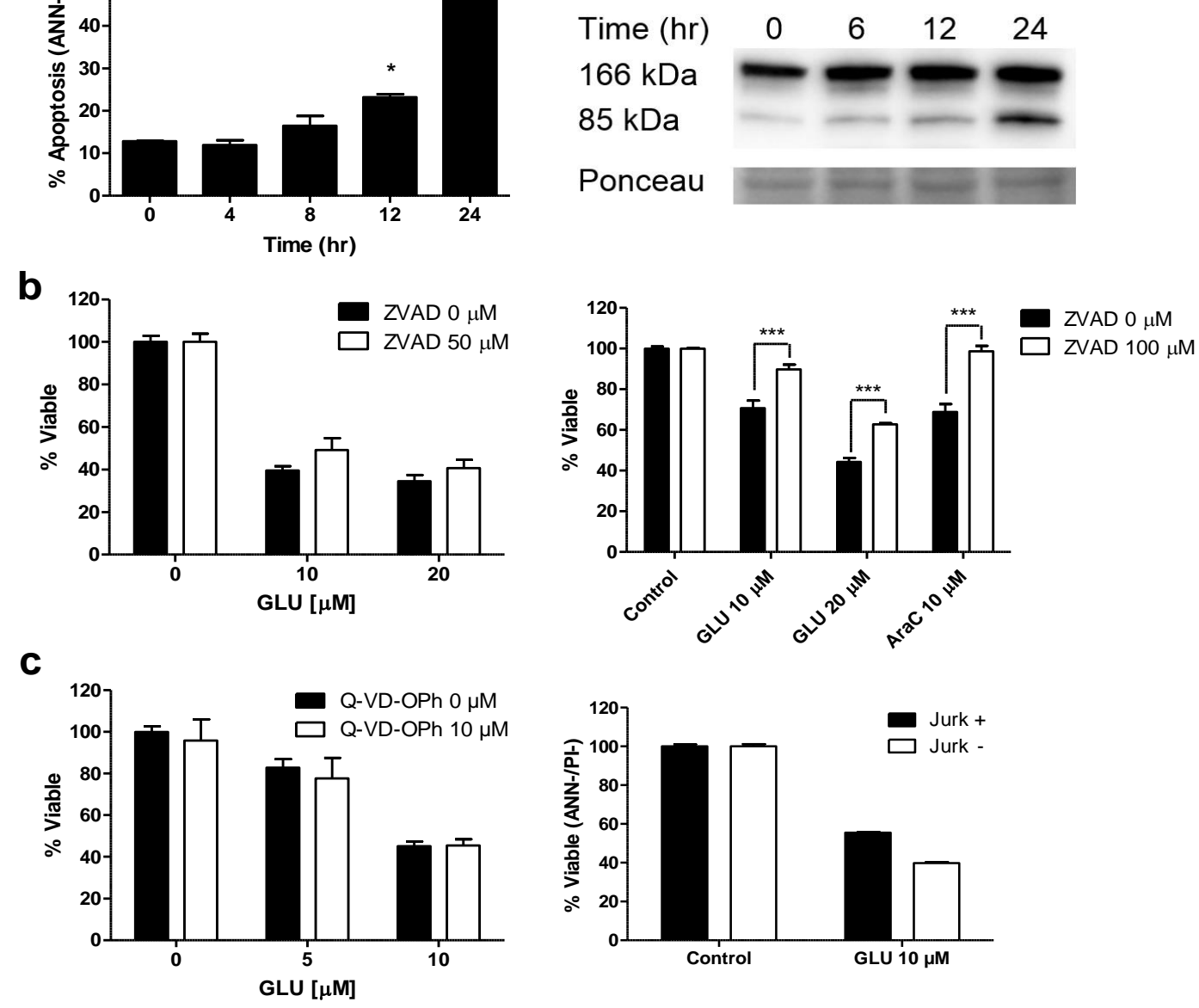

Figure 5. Glucopsychosine induced AML cell apoptosis. (A) (Left panel) Time course analysis shows that glucopsychosine $(10 \mu \mathrm{M})$ induced apoptosis $\left(\mathrm{ANN}^{+} / \mathrm{PI}^{-}\right)$at $12-24 \mathrm{~h}$. (Right panel) Glucopsychosine or control treated cells were incubated for $24 \mathrm{~h}$ and cleavage of PARP, a nuclear protein participating in DNA repair that is degraded during apoptosis by cysteine proteases (i.e., calpain or caspase 3), was measured by Western blotting. Representative blot is shown. (B) AML cells were treated with increasing concentrations of glucopsychosine in the presence or absence of the pancaspase inhibitor Z-VAD (50 $\mu \mathrm{M}$, left panel; $100 \mu \mathrm{M}$, right panel). Cytarabine was used as a positive control and viability was measured by the MTS assay. (C) (Left panel) AML cells were treated with increasing concentrations of glucopsychosine in the presence or absence of the caspase-3 specific inhibitor Q-VD-OPh for $24 \mathrm{~h}$ and cell viability was measured by the ANN/PI assay. (Right panel) Jurkat T cells with (Jurk+) or without functional mitochondria (Jurk-) were incubated with $10 \mu \mathrm{M}$ glucopsychosine for $24 \mathrm{~h}$ and cell viability was measured by the ANN/PI assay. Unless otherwise stated, data are presented as the mean or fold increase compared to control \pm SD from representative experiments. ${ }^{*} p<0.05 ;{ }^{* * *} p<0.0001$. 
To exclude mitochondrial involvement, we tested glucopsychosine in Jurkat T leukemia cells lacking functional mitochondria, which were generated, as previously described [64, 65] by sequential passaging of live cells in media containing $50 \mathrm{ng} / \mathrm{ml}$ of ethidium bromide, $100 \mathrm{mg} / \mathrm{ml}$ sodium pyruvate and $50 \mu \mathrm{g} / \mathrm{ml}$ uridine. Since these cells typically are resistant to apoptosis inducing agents [66], we hypothesized that if mitochondria were involved in glucopsychosinemediated apoptosis, glucopsychosine-induced death would be abolished in cells lacking functional mitochondria. However, as shown in Fig. 5C (right panel), cells without functional mitochondria are equally sensitive to glucopsychosine $(10 \mu \mathrm{M})$. Together, these results show that glucopsychosine induces caspase-independent apoptosis.

\subsubsection{Extracellular calcium channels are significantly under-expressed in AML over} normal cells

A previous study showed that glucopsychosine-mediated death was a result of changes in cytosolic calcium [22]. To probe whether changes in cytosolic calcium could be related to glucopsychosine's AML cell selectivity, we interrogated publicly available gene expression profiling datasets [62] for changes in expression of surface calcium channel subunits in AML patient samples compared to normal hematopoietic cells. From this analysis, we determined that 36 different calcium channel genes were significantly under-expressed $(p<0.001$, minimum fold-change of 1.25) in at least one subtype of AML (M0-M4); only 3 of these would be expected to be altered during myeloid differentiation (Supplementary Table 2). Conversely, 28 calcium channel genes were significantly over-expressed in AML $(p<0.001$, minimum foldchange of 1.25); 11 of these were expected to be over-expressed during myeloid differentiation 
(Supplementary Table 3). Thus, there is evidence for preferential under-expression of calcium channel genes in AML (33 significantly under-expressed genes, compared to 17 significantly over-expressed; ratio of nearly 2:1). Together, these results suggest that calcium channels are significantly down-regulated in AML cells.

\subsubsection{Glucopsychosine increases intracellular calcium to induce calpain-mediated} apoptosis

Given our finding that calcium surface channels are significantly dysregulated in AML, we next assessed whether glucopsychosine's AML activity was related to changes in cytosolic calcium levels using the fluorescent dye fluo-3AM. A 2-3-fold increase in cytosolic calcium (i.e., shift in fluorescent intensity) was observed in glucopsychosine treated cells between 4 and $8 \mathrm{~h}$ of incubation (i.e., prior to the onset of apoptosis) (Fig. 6A, left and right panels).

Since increases in cytosolic calcium can induce apoptosis through activation of the calcium-dependent cysteine protease calpain, we next assessed whether glucopsychosine activated calpain enzymes. AML cells were incubated with $10 \mu \mathrm{M}$ glucopsychosine for increasing durations and calpain activation was determined using a commercially available luminescent calpain activation assay. Consistent with the observed increases in intracellular calcium, calpain activity was significantly increased compared to vehicle control between 6 and $8 \mathrm{~h}$ of incubation (Fig. 6B, left panel: ${ }^{*} p<0.05$ ). Protein levels of active calpain in glucopsychosine treated leukemia cells were also detected using Western blot analysis (Fig. 6B, middle panel). To confirm the importance of calpain in glucopsychosine-mediated cell death, AML cells were co-incubated with the calpain inhibitor MDL28170. Treatment with the calpain 
inhibitor abolished glucopsychosine-mediated AML cell death (Fig. 6B, right panel, ${ }^{*} p<0.001$ )

and apoptosis (Appendix 4). These results demonstrate that active calpain is functionally important for glucopsychosine's toxicity.

a
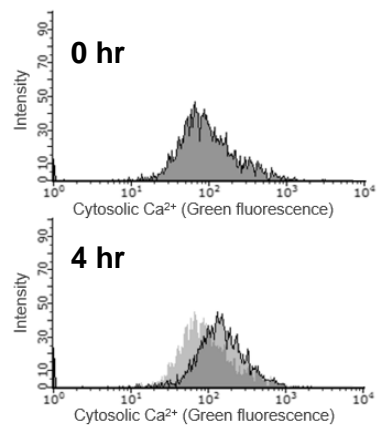

b

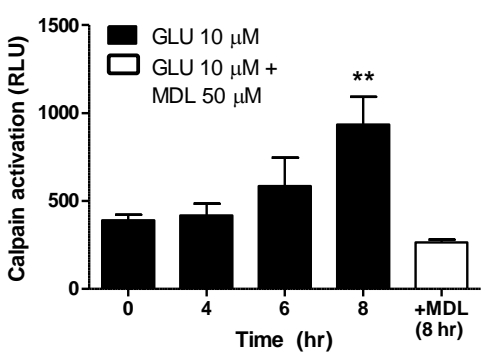

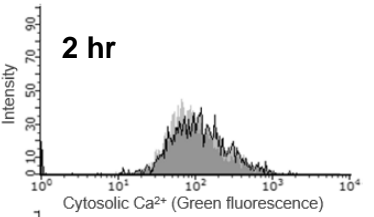

$8 \mathrm{hr}$

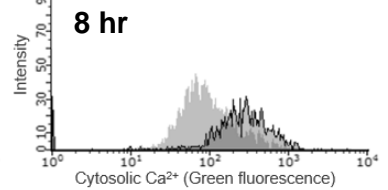

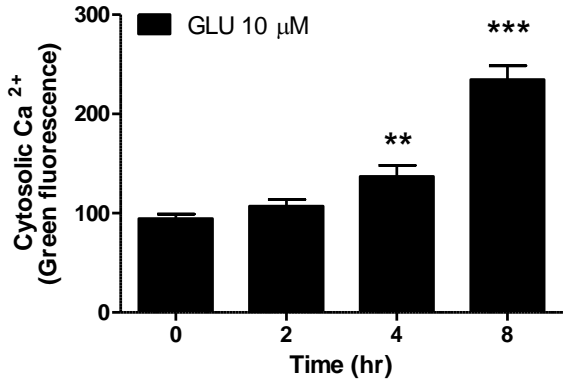

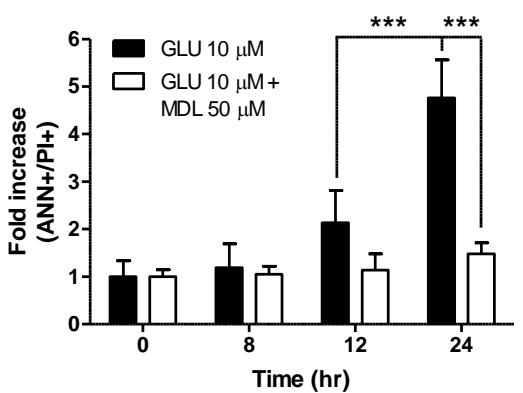

Figure 6. Glucopsychosine increased cytosolic calcium and activated calpain enzymes. (A) (Left panel) AML cells incubated with $10 \mu \mathrm{M}$ glucopsychosine or vehicle control for increasing duration showed increases in cytosolic calcium, as measured by the intracellular calcium selective, fluorescent dye fluo-3AM and flow cytometry. Cytosolic calcium was determined by quantifying the shift in green fluorescence compared to control. Representative histograms are shown. (Right panel) Graphical representation demonstrating the cytosolic calcium increase. (B) (Left panel) Calpain activity was measured in control or glucopsychosine treated AML cells using a commercially available kit as outlined in the Methods. Cells were also co-incubated with a calpain inhibitor MDL28170 (MDL). (Middle panel) Protein levels of active calpain (MW $=60 \mathrm{kDa}$ ) were also measured in these cells by Western blotting. Representative blots are shown. (Right panel) Glucopsychosine was co-incubated with MDL for increasing duration and cell death was measured by the ANN/PI assay. Unless otherwise stated, data are presented as the mean or fold increase compared to control $\pm \mathrm{SD}$ from representative experiments. $p<0.05 ;{ }^{* * *} p<0.005 ;{ }^{* * *} p<0.0001$. 


\subsubsection{Glucopsychosine-induced apoptosis is mediated by extracellular calcium and not}

intracellular stores

Calcium can enter the cytosol from the extracellular matrix via surface calcium channels or through intracellular calcium stores such as the mitochondria or endoplasmic reticulum [36, 67]. To determine the source of glucopsychosine-mediated increases in cytosolic calcium, we first co-incubated leukemia cells with verapamil, cyclosporin A, or TMB-8, which block increases in cytosolic calcium mediated by L-type plasma membrane channels, mitochondria or endoplasmic reticulum, respectively [68-70]. Only verapamil abrogated glucopsychosine-induced increases in cytosolic calcium and apoptosis, suggesting that the source of calcium in glucopsychosine-mediated AML cell death is from the extracellular space (Fig. 7A, left and right panel; and Supplementary Fig. 2). Moreover, our results demonstrating glucopsychosine's activity is unchanged in cells lacking mitochondria further exclude mitochondrial involvement in glucopsychosine-mediated death (Fig. 7C, right panel). To confirm that the extracellular space was the source of glucopsychosine-mediated increases in cytosolic calcium, glucopsychosine's ability to induce death was assessed in calcium-free media. Since basal levels of death increased when our AML cells were incubated in calcium-free media, we performed these experiments using shorter incubation times at higher glucopsychosine concentrations (i.e., $20 \mu \mathrm{M}, 1 \mathrm{~h}$ ). Here, AML cells were suspended in PBS, in the absence and presence of high glucopsychosine concentrations, and cell death was evaluated after $1 \mathrm{~h}$ by the Annexin/PI assay. Glucopsychosine's activity was abolished in calcium-free media (Fig. 7B, left). Moreover, no increases in cytosolic calcium were observed following treatment in calcium-free media (Fig. 7B, 
right panel). Together, these results indicate that the source of glucopsychosine-mediated increases in cytosolic calcium is from the extracellular space.

a
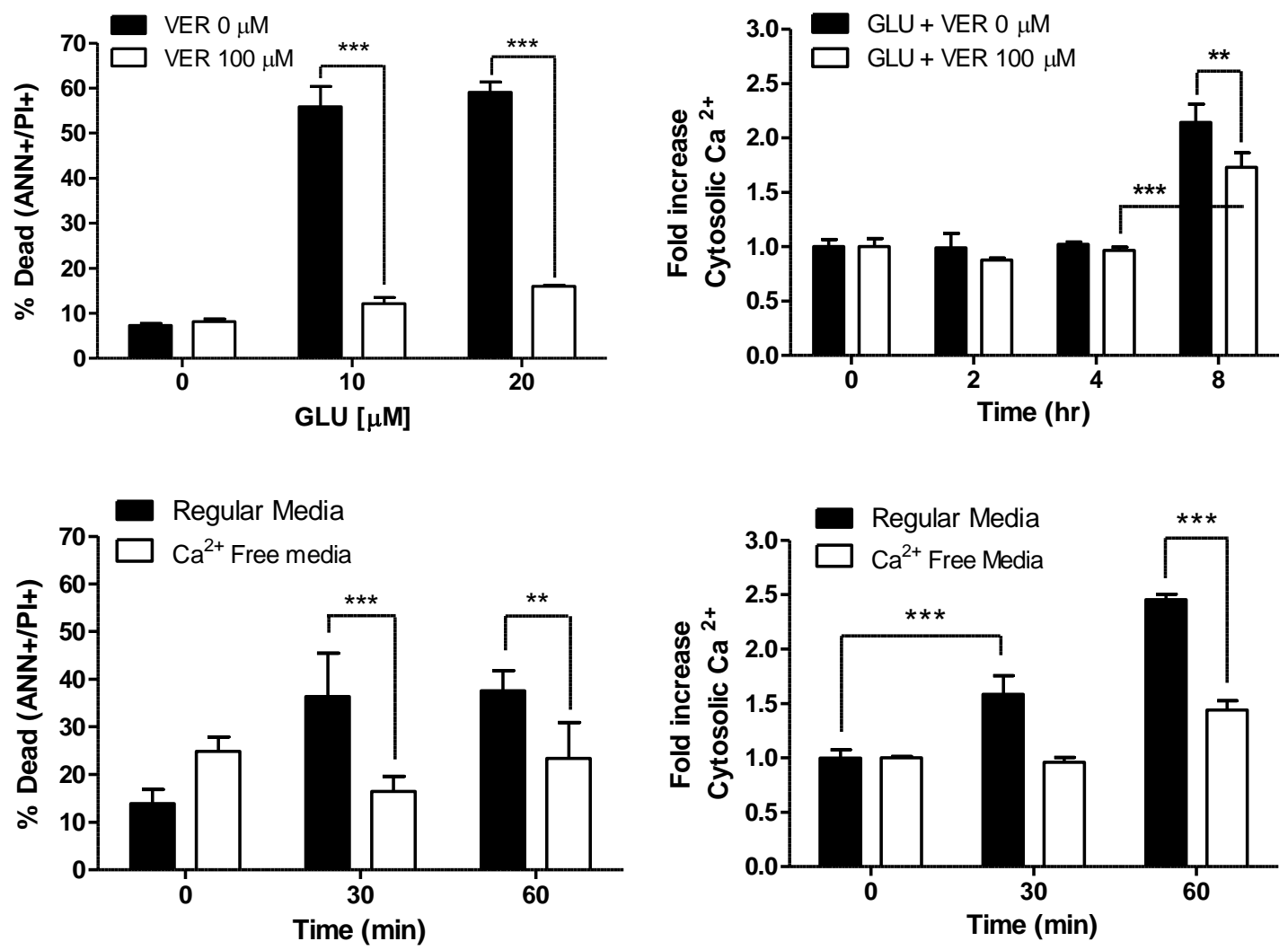

Figure 7. The extracellular space is the source of glucopsychosine-mediated increases in cytosolic calcium. (A) (Left panel) AML cells were incubated with increasing concentrations of glucopsychosine for $24 \mathrm{~h}$ in the absence or presence of verapamil (VER). Cell death was measured using the ANN/PI assay. (Right panel) Cytosolic calcium was measured in AML cells treated with glucopsychosine $(10 \mu \mathrm{M})$ in the absence or presence of verapamil as described in the Methods section using the fluorescence indicator, fluo-3AM. (B) (Left panel) AML cells were cultured in regular or calcium-free media with $20 \mu \mathrm{M}$ glucopsychosine for increasing duration. Cell death was measured by the ANN/PI assay. (Right panel) Increases in cytosolic calcium were measured in AML cells treated with $20 \mu \mathrm{M}$ glucopsychosine in normal or calcium free media as described in the Methods section using the fluorescence indicator, fluo-3AM. Unless otherwise stated, data are presented as the mean or fold increase compared to control \pm SD from representative experiments. ${ }^{* *} p<0.005 ;{ }^{* * *} p<0.0001$. 


\subsubsection{Glucopsychosine delays tumor growth and reduces tumor weights in leukemia}

mouse xenografts

Given glucopsychosine's in vitro activity, we next tested its activity in vivo. Here, OCIAML2 cells were subcutaneously injected into the left flank of NOD/SCID mice. Mice were then intraperitoneally treated every other day with 20 or $40 \mathrm{mg}$ of glucopsychosine $/ \mathrm{kg}$ body weight or a PBS vehicle control. Compared to control treated mice, both concentrations of glucopsychosine delayed tumor growth (Fig. 8A; left panel) and reduced tumor weights upon sacrifice (Fig. 8A; right panel). In addition, analysis of hematoxylin and eosin stained tissue sections demonstrated decreased cellular density in tumors of animals treated with glucopsychosine indicating cell death in the tumor following drug treatment (Supplemental Fig. 3).

To assess glucopsychosine's toxicology, blood was collected upon sacrifice and analyzed for levels of alkaline phosphatase or creatine kinase, markers of kidney and liver function, respectively [71]. There were no differences in blood biochemistry makers following glucopsychosine treatment (Fig. 8B). In addition, mouse body weights were unchanged between control and glucopsychosine treated mice throughout the duration of the experiment (Fig. 8B). Finally, complete blood count analysis showed no differences in red blood cell counts or hemoglobin concentrations between glucopsychosine and control treated mice (Fig. 8B). Taken together, these results show that glucopsychosine imparts anti-tumor activity without toxicity. 

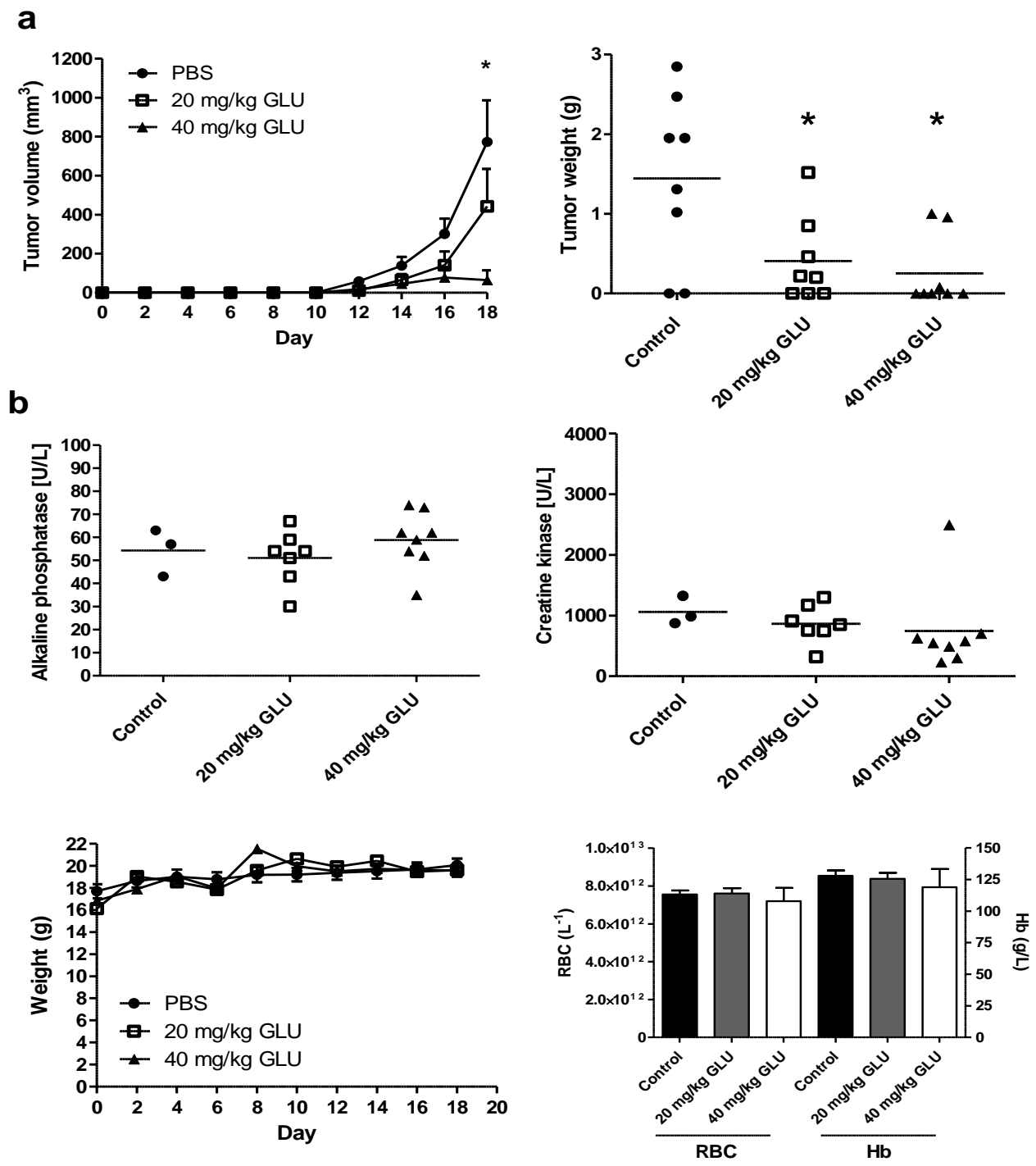

Figure 8. Glucopsychosine delayed tumor growth and reduced tumor weight in leukemia mouse xenografts without imparting toxicity. NOD/SCID mice were subcutaneously injected with OCI-AML2 cells ( $n=24 ; 8$ /group) and following implantation were treated intraperitoneally with 20 or $40 \mathrm{mg} / \mathrm{kg}$ glucopsychosine or a PBS control every other day for 18 days. Tumor volume and body weights were measured every other day. At the termination of the experiment, mice were sacrificed, blood was collected and tumors were excised and weighed. (A) Glucopsychosine significantly delayed tumor growth (left panel, ${ }^{*} p<0.05,0$ vs. $40 \mathrm{mg} / \mathrm{kg}$ ) and reduced tumor weights (right panel; ${ }^{*} p<0.05$ ). (B) Glucopsychosine treated mice had no changes in serum levels of alkaline phosphatase or creatine kinase, which are markers of kidney and liver damage, respectively, or changes in body weight, red blood cell counts or hemoglobin concentrations compared to control treated animals. 


\subsection{Discussion}

A screen of a nutraceutical specific library identified glucopsychosine as a novel agent with activity against AML. We determined that AML cells display dysregulated expression of calcium surface channels and that glucopsychosine increased cytosolic calcium, the source of which was the extracellular space, to induce calpain-mediated apoptosis. Our work with mouse xenograft models further demonstrated that glucopsychosine imparts anti-leukemia activity without toxicity.

Glucopsychosine was selectively toxic toward AML over normal cells and imparted in vivo anti-tumor activity without toxicity. The exact mechanism of this specificity is unknown; however, we hypothesize it is related to several features of AML cells. First, interrogation of publically available AML gene expression databases indicated that surface receptors regulating cytosolic calcium levels are significantly under-expressed in AML cells compared to normal cells. This observed pattern of reduced surface calcium channel expression is similar to other disease states such as atrial fibrillation [72], colonic inflammation [73] and cerebral ischemia [74]. Although the physiological consequence of this under-expression in AML cells is not known, reduced calcium channel expression was associated with delayed neuronal death following tissue hypoxia [74]. It is therefore possible that AML cells under-express extracellular calcium channels to increase survival, as this would prevent increases in cytosolic calcium that would otherwise result in activation of apoptotic cell death. In support of this hypothesis, ER calcium concentrations are reduced in AML compared to normal cells [75]. This suggests that AML cells tightly control their stored intracellular calcium levels to limit increases in cytosolic 
calcium. Therefore, a likely component of glucopsychosine's selectively is related to its ability to increase cytosolic calcium via calcium surface channels; however, future studies are needed to confirm which extracellular channel(s) (i.e., voltage or ligand dependent) are specifically involved in glucopsychosine's activity.

A second feature of AML cells that would render them sensitive to glucopsychosine is the recent observation that calpain levels are significantly elevated while calpastatin, a calpain inhibitor, is significantly reduced in AML cells compared to normal hematopoietic cells [44]. Calpain enzymes are activated by increases in cytosolic calcium and, similar to caspase enzymes, are cysteine proteases that induce apoptosis by degrading cellular substrates [40]. In AML cells with high basal calpain levels and reduced calpastatin, additional activation of these enzymes could overcome a threshold and induce apoptosis. This is seen in other disease states characterized by elevated basal caspase 3 levels (i.e., Breast cancer, Parkinson's disease and Celiac disease) where the application of a death stimulus results in caspase-dependent cell death [76-78]. We therefore propose a similar mechanism whereby glucopsychosine's mechanism of AML selectivity is also related to its ability to further activate calpain enzymes resulting in apoptotic cell death.

In our study, increased levels of cytosolic calcium and extracellular calcium were functionally important for glucopsychosine-induced AML cell apoptosis. The increase in cytosolic calcium occurred $4-8 \mathrm{~h}$ following glucopsychosine treatment, which is consistent with other studies reporting slower increases in cytosolic calcium when the calcium originates from the extracellular space $[79,80]$. Increased cytosolic calcium resulted in calpain activation. 
Blocking calpain activation abolished glucopsychosine-mediated apoptosis highlighting the functional importance of calpain in glucopsychosine-induced AML cell death. Calpain activation can result in caspase-3-dependent or independent apoptosis. Calpain-mediated, caspase-3dependent apoptosis requires mitochondrial proteins [36]. However, since death occurred in cells lacking mitochondria and in the presence of caspase inhibitors, our results suggest that glucopsychosine-induced AML apoptosis is calpain-mediated and caspase-independent. This mode of death may be particularly important to a subset of AML patients, as it was recently shown that calpain levels in AML cells may be an important prognostic indicator. Niapour et al. (2012) showed that patients samples with elevated cellular calpain levels had no response to PD150606 (a calpain inhibitor) whereas patient samples with low calpain levels were associated with improved complete response rates [44]. Thus, application of a stimulus to increase calpain in AML cells with already elevated calpain would be a novel approach at inducing a response in these patients, which do not respond to conventional therapy. This represents a novel area in AML therapeutics, as no current clinical AML drug activates this pathway.

Glucopsychosine or glucosylsphingosine is a glycosylated sphingosine (Fig. 4B). It can be synthesized chemically or derived from the milk fat globule membrane and is found in bovine milk at concentrations of $0.067 \mathrm{~g} / \mathrm{L}(0.15 \mu \mathrm{M})$ [81]. Since glucopsychosine concentrations needed to impart anti-leukemia activity would not be achievable following milk or dairy product consumption, glucopsychosine would need to be administered as a nutraceutical, likely in intravenous form. Future studies are needed to assess glucopsychosine's pharmacokinetics following oral dosing. Nutraceuticals are bioactive compounds isolated from food, concentrated 
and sold in pill or liquid form and are a subset of a larger family of compounds known as natural health products. There are an estimated 25000 different nutraceutical compounds, with only a relative few having reported anti-cancer treatment properties [16]. Here, we report for the first time, that the milk-derived glucopsychosine is a novel nutraceutical with activity against AML. There is little existing human pharmacokinetic or safety data on glucopsychosine. Although several in vitro studies report toxicity following exogenous administration to rat hepatocytes and erythrocytes [82] and human and mouse neurons in culture [20, 21], there are limited human or in vivo animal studies reporting glucopsychosine pharmacokinetics or toxicology. Our results show that at double the glucopsychosine concentrations needed to reduce leukemia tumor growth (i.e., $40 \mathrm{mg} / \mathrm{kg}$ ), there were no effects on mouse body weight; or on serum levels of alkaline phosphatase and creatine kinase, which are markers of kidney and liver damage, respectively [71]; or changes in red blood cell counts or hemoglobin levels. However, a limitation to our in vivo work is that a tumor regression model was not used. Thus, future studies would be needed to address whether glucopsychosine is able to regress an already established tumor. Nonetheless, our data in primary samples show that glucopsychosine is selectively toxic toward AML patient cells while not affecting normal cell viability. Together, these results suggest a potentially wide therapeutic window for glucopsychosine. Interestingly, plasma glucopsychosine levels are significantly elevated in patients with Gaucher's Disease [83]. This is a lysosomal storage disorder caused by a deficiency in the enzyme glucocerebrosidase that results in cellular accumulation of glucosylceramide, the deacetylated precursor of glucopsychosine [84]. The lipid filled cells, mostly macrophages, accumulate in liver, spleen and bone marrow resulting in 
hepatosplenomegaly, pancytopenia and bone pain as well as causing possible neurological symptoms such as convulsions and muscle twitches [85]. The physiological consequence of plasma glucopsychosine levels is unknown; however, the aforementioned study showed no correlation between plasma concentrations and disease severity even though plasma glucopsychosine levels were 200-fold greater in Gaucher patients than normal controls [83]. The lack of association between plasma levels and toxicity suggests that plasma glucopsychosine does not impart toxicity. Nonetheless, given the limited human data, future studies are needed to carefully assess glucopsychosine's pharmacokinetics and safety.

In summary, a screen of a unique, in-house nutraceutical library identified

glucopsychosine, a bovine milk-derived lipid, as a novel compound capable of inducing calpainmediated AML cell apoptosis. Surface calcium channels are significantly under-expressed in AML cells and the extracellular space was the source of glucopsychosine-mediated increases in cytosolic calcium. This provides a unique mechanism of selectivity by which glucopsychosine induces AML cell apoptosis. Future studies are needed to determine which of the surface calcium channels may be affected by glucopsychosine and clinical studies are needed to evaluate glucopsychosine's safety.

\subsection{Authorship}

Contribution: LA and PAS performed experiments, analyzed data and wrote the manuscript. EAL, SGR, TH, EM and MS performed experiments and analyzed data, and MM and JQ analyzed data. Conflict-of-interest disclosure: The authors declare no conflict of interest. 
Correspondence: Paul A. Spagnuolo, School of Pharmacy, University of Waterloo, Kitchener, Ontario, N2G1C5. Email: paul.spagnuolo@uwaterloo.ca

\subsection{Conflict of Interest}

The authors declare no conflict of interest.

\subsection{Acknowledgements}

This study was supported by grants to PAS by the University of Waterloo, Canadian Foundation for Innovation and Ontario Research Fund.

\subsection{Supplemental Figures}

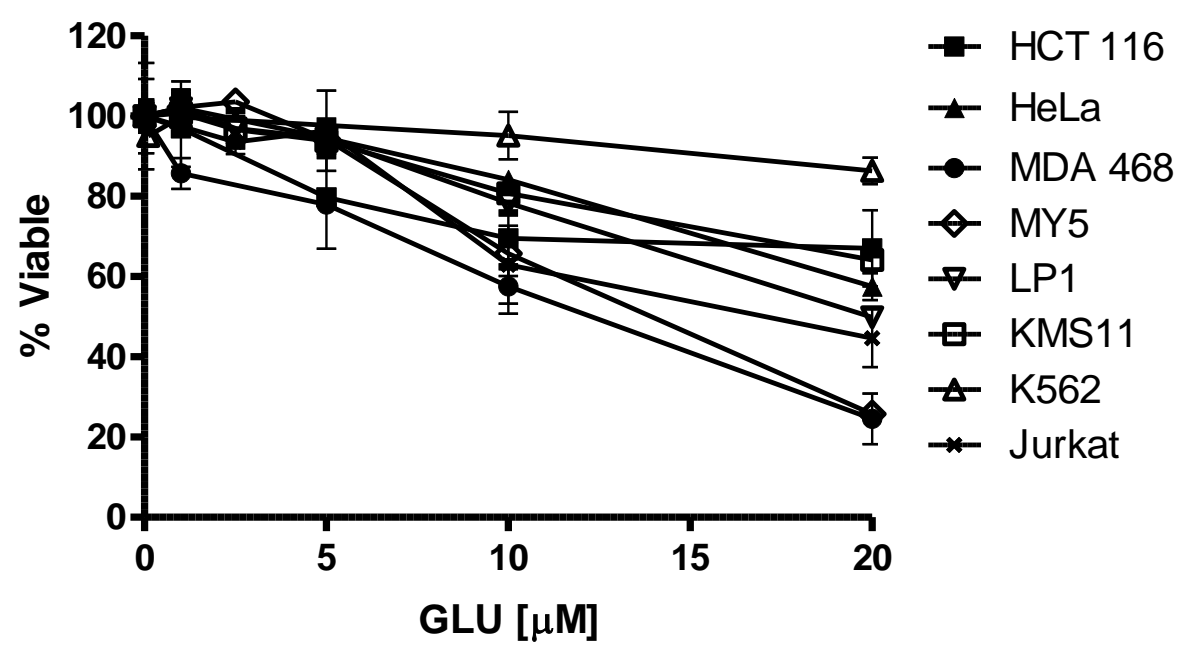

Supplemental figure 1: Glucopsychosine in non-AML cell lines. A panel of solid tumor (HCT116, HeLa, MDA468), myeloma (MY5, LP1, KMS11), ALL (Jurkat), and CML (K562) cell lines were treated with increasing concentrations of glucopsychosine for 72 hours and cell growth and viability were measured by the MTS assay. Data are the mean percentage of viability cells \pm SD from representative experiments. 

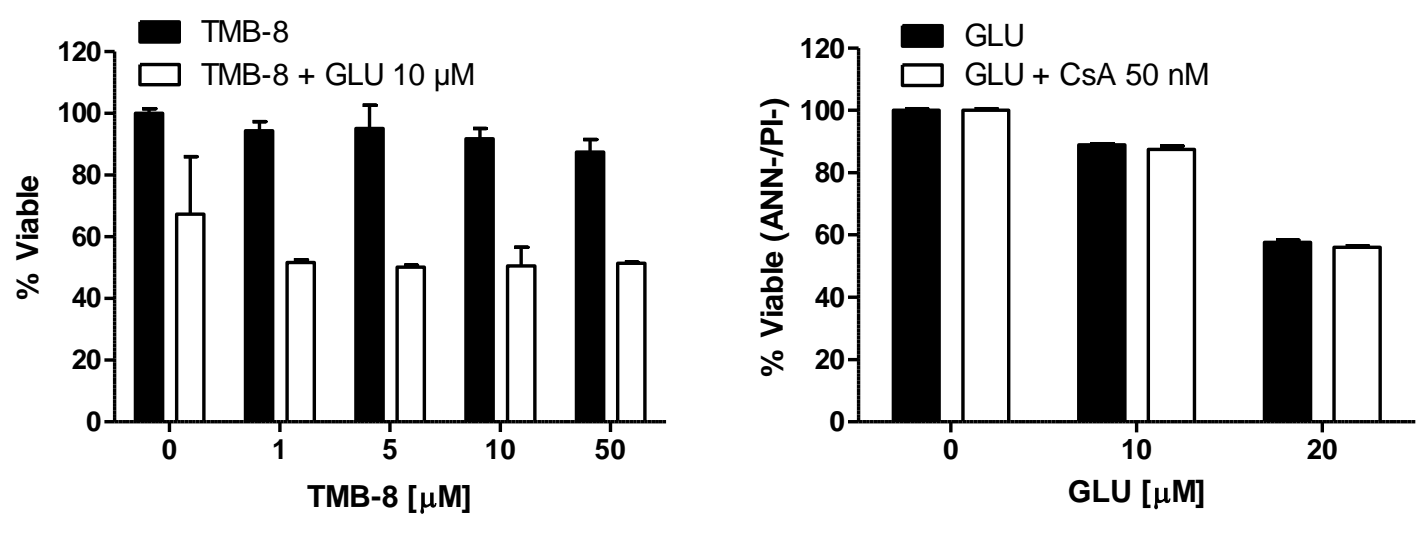

Supplemental figure 2: Glucopsychosine in the presence of inhibitors of intracellular calcium release. AML cells were incubated with $10 \mu \mathrm{M}$ glucopsychosine for 24 hours in the absence or presence of TMB- 8 or cyclosporine. Viability was measured by the ANN/PI assay.
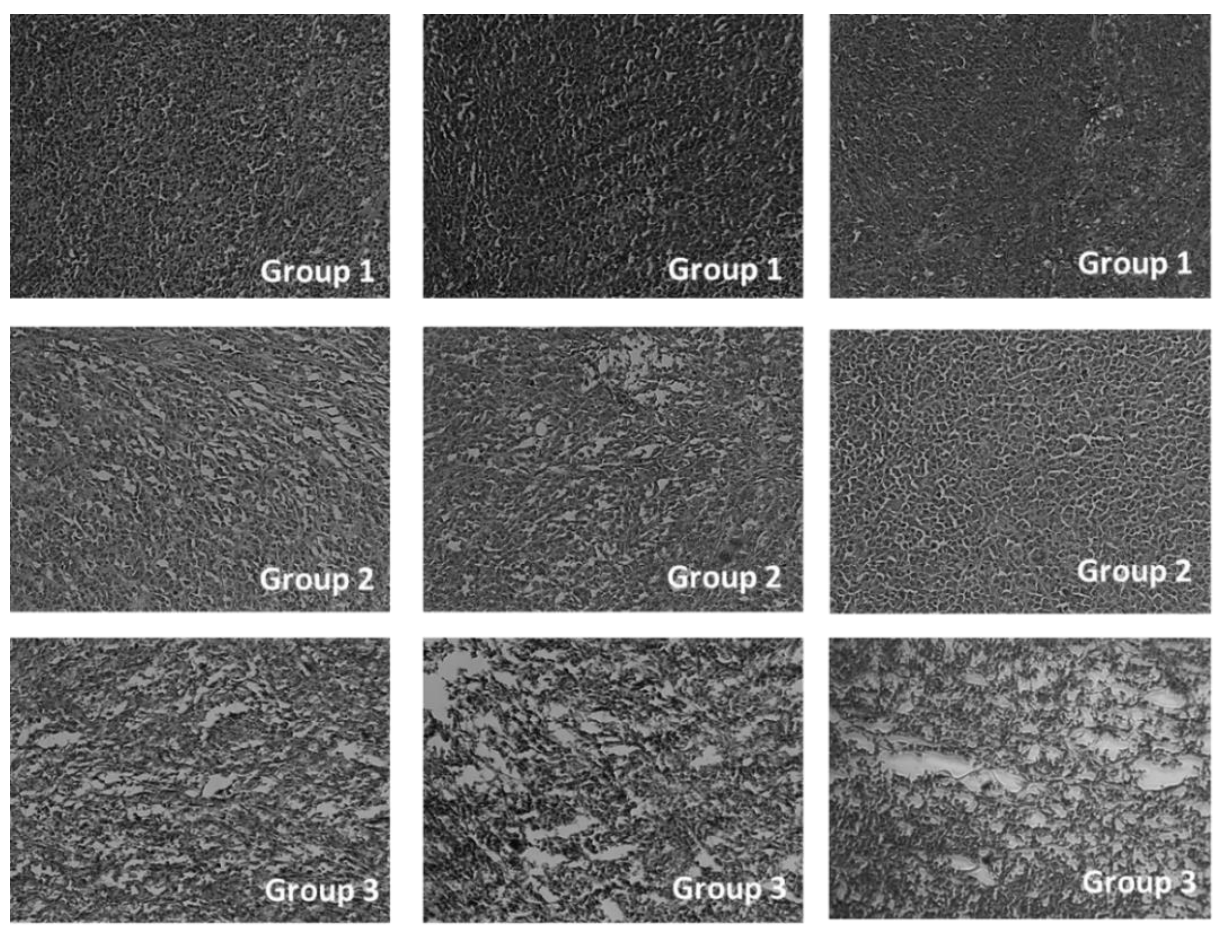

Supplemental figure 3: Hematoxylin and eosin stained tumor sections x200. Tumors from each treatment group were sectioned and stained with hematoxylin and eosin. Three representative images from each treatment group are presented at x 200 magnification (Group 1 - PBS; Group 2 - $20 \mathrm{mg} / \mathrm{kg} \mathrm{GLU}$; Group 3 - $40 \mathrm{mg} / \mathrm{kg}$ GLU). 
Supplementary Table 1: AML surface markers. The myeloid markers $\left(\mathrm{CD} 123^{+}\right.$and $\mathrm{CD} 3^{+} / \mathrm{CD} 19^{-}$) were tested to confirm the nature of our cell lines.

\begin{tabular}{|ccc|}
\hline Cell line & \% $\mathbf{C D 3 3}^{+} / \mathbf{1 9}^{-}$ & $\mathbf{\% C D 1 2 3}^{+}$ \\
\hline AML2 & 85.2 & 75.8 \\
\hline KG1a & 91.2 & 79.5 \\
\hline U937 & 85.8 & 79.2 \\
\hline
\end{tabular}




\section{CHAPTER 4: EXPERIMENTAL RATIONALE}

The purpose of this chapter is to provide rationale for the experiments used in this thesis. The following expanded methods are in addition to those listed in Chapter 3.

\subsection{Materials and methods}

\subsubsection{MTS cell viability assay}

The MTS cell viability assay measures the ability of viable cells to metabolize NADPHdependent cellular oxidoreductase enzymes which produces a formazan product that is purple. The amount of formazan formed will give an indication of the number of metabolizing cells when absorbance is read and compared to control wells. In these experiments, $95 \mu \mathrm{L}$ of cells per well are seeded in 96 well plates at a concentration at which when ready to read (eg. 24 or 72 hours later) the amount of cells per well will be at $90 \%$ confluency. $5 \mu \mathrm{L}$ of drugs or vehicle control are added to each well and incubated. $20 \mu \mathrm{L}$ of 3-(4,5-dimethylthiazol-2-yl)-5-(3carboxymethoxyphenyl)-2-(4-sulfophenyl)-2H-tetrazolium inner salt (MTS) reduction assay (Promega, Madison, WI) is added directly to the 96 well plate and incubated at $37^{\circ} \mathrm{C}$ for $2-3$ hours at which then the optical density is read at 490nm.

\subsubsection{Flow cytometry and Annexin V/propidium iodide (PI) viability assay}

Flow cytometry assays were performed on the Guava easyCyte 8HT Bench top Flow Cytometer (Millipore, Billerica, MA) and GuavaSoft 2.2.3 (Millipore) flow cytometry software. All assays were performed in 96 well plates with appropriate unstained and single-stain controls to set basal thresholds and compensate for multi-stain bleeding. Annexin V/propidium iodide 
(ANN/PI) staining was used to determine cell viability $\left(\mathrm{ANN}^{-} / \mathrm{PI}^{-}\right)$, early apoptosis $\left(\mathrm{ANN}^{+} / \mathrm{PI}^{-}\right)$, and cell death $\left(\mathrm{ANN}^{+} / \mathrm{PI}^{+}\right)$. A mastermix solution was made combining $250 \mu \mathrm{L}$ of Annexin $\mathrm{V}$ Binding Buffer (BD Pharmingen), $1 \mu \mathrm{L}$ of $150 \mu \mathrm{g} / \mathrm{mL}$ Annexin V (Biovision) and $2.5 \mu \mathrm{L}$ of 250 $\mu \mathrm{g} / \mathrm{mL}$ PI (Biovision) per sample. Treated cells were spun down and resuspended in $250 \mu \mathrm{L}$ of mastermix solution and incubated for 20 minutes at room temperature in the dark prior to collection and analysis via flow cytometry.

\subsubsection{Caspase 3/7 assay}

Apo-ONE® Homogeneous Caspase-3/7 (Promega) was purchased and performed according to manufacturer's protocol. $50 \mu \mathrm{L}$ of Apo-ONE homogenous caspase-3/7 reagent was added to $50 \mu \mathrm{L}$ of blank, control (Doxorubicin treated cells, Sigma-Aldrich) or glucopsychosine treated cells and mixed at 300-500 rpm for 30 seconds in white-walled 96 well plates. Samples were incubated for 1 hour in the dark at room temperature. Fluorescence was measured at an excitation wavelength range of $499 \mathrm{~nm}$ and an emission wavelength of $521 \mathrm{~nm}$.

\subsubsection{Western blotting}

Whole-cell lysate preparation

Treated cells were collected and incubated with chilled RIPA buffer (Sigma-Aldrich) supplemented with protease inhibitors (Sigma-Aldrich) in a 2:1 ratio. Cells were vortexed continuously for 20 minutes or until lysed. Protein was collected by centrifuging lysed cells at 13,200 RPM for 20 minutes at $4^{\circ} \mathrm{C}$ and collecting the supernatant. 


\section{BCA protein assay and sample preparation}

The BCA protein assay was used to measure total protein content. Bovine serum albumin (BSA; Sigma-Aldrich) diluted in distilled water generated a standard curve and was used to determine total protein content of each sample of lysate. Prior to taking absorbance readings, $200 \mu \mathrm{L}$ of bicinchoninic acid (BCA) working agent was added to each sample (50 parts BCA:1 part copper II sulfate; Sigma-Aldrich) and incubated for 30 minutes at $37^{\circ} \mathrm{C}$. OD was then measured at $527 \mathrm{~nm}$ using a spectrophotometer and values were plotted on against the standard curve. Values from the BCA protein assay were used to prepare samples containing $30-50 \mu \mathrm{g}$ total protein, with $1 / 6$ sample buffer $(240 \mathrm{mM}$ Tris- $\mathrm{HCl}$ at $\mathrm{pH} 6.8,6 \% \mathrm{w} / \mathrm{v} \mathrm{SDS}, 30 \% \mathrm{v} / \mathrm{v}$ sucrose, $0.02 \% \mathrm{w} / \mathrm{v}$ bromophenol blue, and $50 \mathrm{mM}$ DTT) volume and lysis buffer to a total volume of $30 \mu \mathrm{l}$. Prior to well loading, samples were heated at $95^{\circ} \mathrm{C}$ for 5 minutes and spun for 3 seconds to collect protein sample.

\section{SDS-PAGE and immunodetection of target proteins}

Sodium dodecyl sulfate polyacrylamide gel electrophoresis (SDS-PAGE) was used to separate proteins based on size. Samples were loaded into $10 \%-15 \%$ polyacrylamide gels and separated using a Mini Trans-Blot Cell (Bio-Rad, Hercules, CA) in electrophoresis buffer (25 $\mathrm{mM}$ Tris base, $190 \mathrm{mM}$ glycine, $3.5 \mathrm{mM}$ sodium dodecyl sulfate) at $150 \mathrm{~V}$ for 1 hour. The proteins are then transferred onto a PVDF membrane (Bio-Rad) in transfer buffer (25 mM Tris base, $190 \mathrm{mM}$ glycine, 20\% v/v methanol) using a Trans-Blot semi-dry transfer cell at $25 \mathrm{~V}$ for $45 \min$. 
PVDF membranes were then blocked with 5\% BSA in Tris-buffered saline (20 mM Tris base, $150 \mathrm{mM} \mathrm{NaCl}$, pH 7.6) plus $0.1 \%$ Tween (TBS-T) for 1 hour or overnight at $4{ }^{\circ} \mathrm{C}$. Blocking solution was discarded and primary antibodies (Table 1) were incubated with the membranes for 1 hour or overnight at $4{ }^{\circ} \mathrm{C}$. Membranes are washed and incubated with corresponding secondary antibody for 1 hour at room temperature. Enhanced chemiluminescence (ECL) was used to detect proteins according to the manufacturer's instructions (GE Healthcare; Baie d'Urfe, Quebec) and luminescence was captured after 5 min using the Kodak Image Station 4000MM Pro and analyzed with a Kodak Molecular Imaging Software Version 5.0.1.27. All membranes were stained with Ponceau S and imaged to ensure equal loading, as described by Dam et al. [61].

\section{Table 1. Antibodies}

\begin{tabular}{|l|l|l|l|l|}
\hline Antibody & Isotype & MW (kDa) & Concentration & Manufacturer \\
\hline Calpain & Mouse & 60 & $1: 1000$ & Santa Cruz Biotechnology \\
\hline Caspase 12 & Rat & 50,40 & $1: 200$ & Santa Cruz Biotechnology \\
\hline Cytochrome C & Rabbit & 14 & $1: 1000$ & Cell signaling technology \\
\hline GRP78 & Goat & 78 & $1: 400$ & Santa Cruz Biotechnology \\
\hline PARP & Rabbit & 89,116 & $1: 1500$ & Cell signaling technology \\
\hline
\end{tabular}

\subsubsection{Cell cycle analysis}

Prior to cell cycle analysis, cells were treated with 1, 5, or $10 \mu \mathrm{M}$ glucopsychosine (Matreya), 0.01 or $1 \mu \mathrm{M}$ nocodazole (Sigma-Aldrich), or 0.2\% DMSO (Sigma-Aldrich) and incubated for $24 \mathrm{hrs}$. Afterwards, $0.5 \times 10^{6} \mathrm{KG} 1 \mathrm{a}$ cells were collected and washed with ice cold PBS (Sigma-Aldrich) and fixed with $200 \mu \mathrm{L}$ of $100 \%$ ethanol for $1 \mathrm{hr}$ at $-20^{\circ} \mathrm{C}$. The fixed cells were thawed and washed in ice cold PBS and then diluted to a concentration of $1 \times 10^{5}$ cells $/ \mathrm{ml}$ in 
ice cold PBS. Each sample was then incubated for 30 minutes at $37^{\circ} \mathrm{C}$ with DNase-free RNase A (Sigma-Aldrich) at a final concentration of $5 \mu \mathrm{g} / \mathrm{ml}$. Lastly, PI was added at a final concentration of $50 \mu \mathrm{g} / \mathrm{ml}$ and incubated for 15 minutes at room temperature in the dark. The samples were analyzed with the Guava Cell Cycle Software Module.

\subsubsection{Tubulin polymerization}

Purified bovine tubulin (1.8 mg/mL; Cytoskeleton) was added to ice-cold polymerization buffer (PEM: 80mM PIPES, 0.5mM EGTA, 2mM MgCl2, 10\% glycerol, and 1mM GTP) and centrifuged for 5 minutes at $4^{\circ} \mathrm{C}$ at top speed in a microcentrifuge to collect the supernatant. $5 \mu \mathrm{L}$ of controls (PBS, Paclitaxel, nocodazole; Sigma-Aldrich) or glucopsychosine, were plated in 96well plates and $95 \mu \mathrm{L}$ of supernatant (containing tubulin) was added. Immediately after the addition of tubulin, the plate was placed in the spectrophotometer, which was maintained at $37^{\circ} \mathrm{C}$, and the absorbance measured every 2.5 minutes for 1 hour at $340 \mathrm{~nm}$.

\subsubsection{Establishing a xenograft tumor model}

As a prerequisite to performing our in vivo studies with glucopsychosine, we investigated which human myeloid leukemia cell lines were able to induce xenograft tumors in non-obese diabetic severely combined immunocompromised (NOD/SCID) mice (Appendix 5). The cells lines tested were KG1a, TEX, OCI-AML2, and U937. Eight NOD/SCID mice were split into two groups of four and marked by ear notching. On day 1, Group 1 mice were injected subcutaneously above the left hind leg with $1 \times 10^{6} \mathrm{KG} 1 \mathrm{a}$ cells. Group 2 mice were injected in 
the same fashion, but with TEX cells, $1 \times 10^{6}$ and $0.5 \times 10^{6}$. The mice were monitored three times a week for the presence of xenograft tumors which should be present 10-17 days post injection.

By day 23, tumors were still not present in any of our mice so we performed another set of injections. Two mice from Group 1 received an increased number of KG1a cells injected $\left(10 \times 10^{6}\right.$ cells $)$ and the remaining two mice received $1 \times 10^{6}$ cells. On day 30 , Group 2 mice received two alternate cell lines (U937 and OCI-AML2) in place of the TEX cell line. U937 and OCI-AML2 cells were injected above the right and left hind leg respectively at $10 \times 10^{6}$ and $5 \times 10^{6}$ cells. By day 37, OCI-AML2 tumors were present.

Tumor lengths and widths were measured with an electronic caliper and tumor volumes were calculated with the equation: width ${ }^{2} \times \frac{\text { length }}{2}$. Measurements at day 39 showed excessive tumor growth past our designated endpoint $\left(1000 \mathrm{~mm}^{3}\right)$ and the $10 \times 10^{6}$ OCI-AML2 mice were sacrificed immediately via cardiac puncture. Mice 6 and 7 (OCI-AML2 at $5 \times 10^{6}$ cells) showed a slower tumor growth progression and reached end point at day 50 and day 44 respectively. Finally, Group 1 NOD/SCID mice injected with KG1a started to grow tumors at day 44, twentyone days after the second round of injections. All mice were sacrificed via cardiac puncture and tumors were harvested. OCI-AML2 cells injected at $5 \times 10^{6}$ cells per mouse was sufficient to grow tumors. All animal studies were carried out according to the regulations of the Canadian Council on Animal Care and with the approval of the University of Waterloo, Animal Care Committee. 


\subsection{Results}

The initial screen (Fig. 4A) was performed by Dr. Spagnuolo at the University of Waterloo, School of Pharmacy. Glucopsychosine was selected because it fulfilled the criteria explained in Ch. 3.3.1. Eric Lee further assessed glucopsychosine's ability to reduce cell viability in multiple cell lines with the MTS assay and Annexin V/PI cell viability assay. The dose response curve (Ch. 3.8 Supp. Fig. 1) exhibited glucopsychosine's ability to inhibit cell growth of multiple cancerous cell lines (HCT116, HeLa, MDA468, MY5, LP1, KMS11, Jurkat, and K562).

\subsubsection{The intrinsic pathway of apoptosis}

The intrinsic pathway of apoptosis involves the loss of mitochondrial membrane potential which releases executioner proteins of apoptosis [26]. The generation of reactive oxygen species (ROS) can initiate this apoptotic pathway. Antioxidants such as N-acetyl-cysteine (NAC) can be used to neutralize the effects of ROS, thereby protecting the cells [86]. To investigate this pathway, AML cells were incubated with glucopsychosine or glucopsychosine + NAC and cell viability was measured by the MTS assay (Fig. 9A).

The results from this experiment showed that co-treatment with NAC abrogated cell death in KG1a cells suggesting that NAC could be protecting the cells from ROS cytotoxicity. As shown in Ch. 1.3.2 Figure 2, increases in ROS can lead to loss of mitochondrial membrane potential, which leads to the release of cytochrome $\mathrm{c}$ and the eventual downstream activation of caspase 3 [33]. Caspase 3 targets many cellular substrates directly resulting in cell apoptosis. To determine if executioner caspases were activated to induce glucopsychosine-mediated apoptosis, 
a caspase 3/7 activation assay was done by Eric Lee (Fig. 9B). The results from this experiment showed an insignificant increase in caspase 3/7 activation in cells treated with glucopsychosine (ANOVA $(\mathrm{F}(3,4)=5.897, \mathrm{p}>0.05, \mathrm{r}=0.8156)$. This experiment marked the end of the preliminary data collected prior to my taking over of the project.

The next experiment we did was to look for cytochrome c release from the mitochondria. Western blots showed no increases in cytochrome c protein levels with increased glucopsychosine exposure (Fig. 9C). If the mitochondrial pathway was being activated by glucopsychosine, cytochrome c levels should have increased with glucopsychosine exposure. To confirm that the mitochondria was not an integral part of glucopsychosine-mediated cell death, a Jurkat cell line lacking functional mitochondria was used as described in Ch. 3.3.2 Fig. 5C. This cell line was still sensitive to glucopsychosine treatment which confirmed that mitochondria were not an essential part of glucopsychosine-mediated cell death.

Finally, through literature review of the MTS assay, we found that this assay should not be used when assessing anti-oxidizing agents because they are prone to give false positive results $[87,88]$. Given this experimental limitation, it is likely that NAC gave a false positive result and did not block glucopsychosine-cell death. Thus, ROS is likely not functionally important in glucopsychosine-mediated death. 


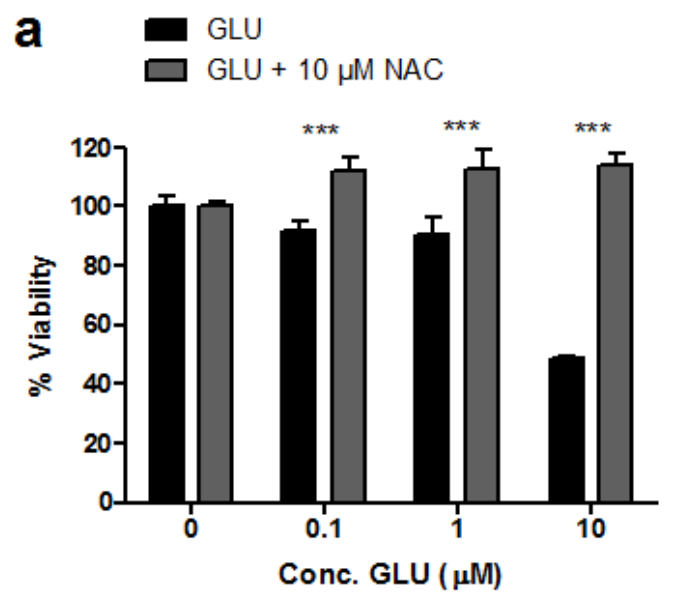

b

C

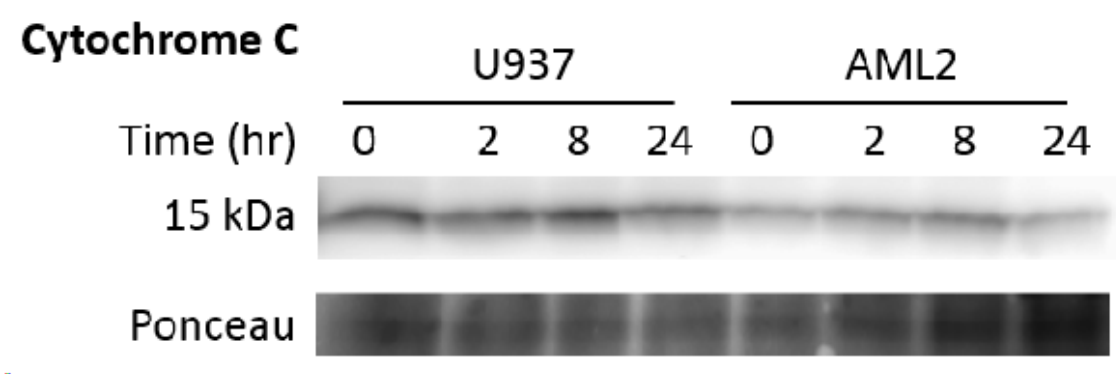

Figure 9. Assessing the intrinsic mitochondrial pathway of apoptosis. (A) N-acetyl-cysteine and the MTS assay. KG1a cells were incubated with increasing concentrations of glucopsychosine and cell viability was assessed via the MTS assay to determine if incubation with NAC would abrogate cell death. (B) Caspase 3/7 activation assay with glucopsychosine for $24 \mathrm{hr}$. Caspase 3 and 7 substrates were introduced into the cells with a luminescent probe that produces a signal when cleaved by caspase 3 or 7 . The relative intensity was recorded and compared. Doxorubicin was used as a positive control and glucopsychosine at $0 \mu \mathrm{M}$ was a negative control. (C) Western blot of cytochrome c protein in U937 and OCI-AML2 cell lines. Cytochrome C (15 kDa) was Western blotted for in two different AML cell lines treated with $10 \mu \mathrm{M}$ glucopsychosine at $0,2,8$, and 24 hours. Ponceau staining was used to quantify equal loading of samples. ${ }^{* * * *} p<0.0001$

\subsubsection{The cell cycle}

A defining attribute of cancerous cells is their ability to overcome cell cycle signal checkpoints and continuously divide [89]. Indeed, many anti-cancer drugs inhibit the cell cycle 
at specific stages. These agents can target DNA directly, DNA regulatory machinery, DNA synthetic proteins, or cell cycle machinery such as microtubules to cause cell cycle arrest [90, 91]. Anti-cancer drugs are generally classified based on which phase of the cell cycle they act on. Broadly, these cytotoxic agents can be cell cycle specific (CCS) or cell cycle non-specific (CCNS). CCS drugs are selective to cells that have high turnover rates (such as blood cells) because these cells cycle through phases more frequently than non-dividing cells (such as neuronal cells). To investigate if glucopsychosine affected the cell cycle, we performed a cell cycle analysis in KG1a cells incubated with glucopsychosine at increasing concentrations. Nocodazole was used as a positive control because it interferes with microtubule polymerization and arrests cells in the G2/M phase (Fig. 10A) [92]. The results from this experiment showed that cell cycle was being arrested during the G2/M phase when treated with $10 \mu \mathrm{M}$ glucopsychosine for $24 \mathrm{hrs}$. This result was similar to the nocodazole control, therefore, microtubule polymerization was assessed next.

Tubulin is an essential cytoskeletal protein that polymerizes to form microtubules that are important for structural and functional purposes [93]. Tubulin activity is dependent on its dynamic characteristics where it dimerizes and polymerizes to perform its function, which includes participation in cell division (mitotic spindle), cell movement and transportation [93]. Drugs can alter polymerization of microtubules by either stabilizing polymerization or favouring depolymerization of tubulin subunits. Paclitaxel promotes tubulin polymerization by stabilizing the microtubule polymer and preventing disassembly of the lagging end [94]. This is cytotoxic to cells because cells cannot form proper spindle fibres which will inhibit mitosis. In contrast, 
nocodazole alters tubulin polymerization by destabilizing microtubules and favouring disassembly of tubulin subunits which has similar devastating effects [92].

In this experiment, nocodazole was used as a positive control for depolymerization and paclitaxel was used as a positive control for increased polymerization. An untreated sample was used to represent normal tubulin polymerization. Purified tubulin was kept on ice until ready to be plated on 96 well plates in which the drugs were previous loaded and absorbance readings were taken every 2.5 minutes. As tubulin polymerizes, OD340 $\mathrm{nm}$ readings also increase until reaching a saturation point. The samples were treated with glucopsychosine at 50 or $100 \mu \mathrm{M}$ to ensure a response ensued (Fig. 10B).

The results from the experiment showed no significant increase or decrease in the rate of tubulin polymerization with glucopsychosine treatment. We concluded from this that tubulin targeting was not glucopsychosine's mechanism of action. 
a
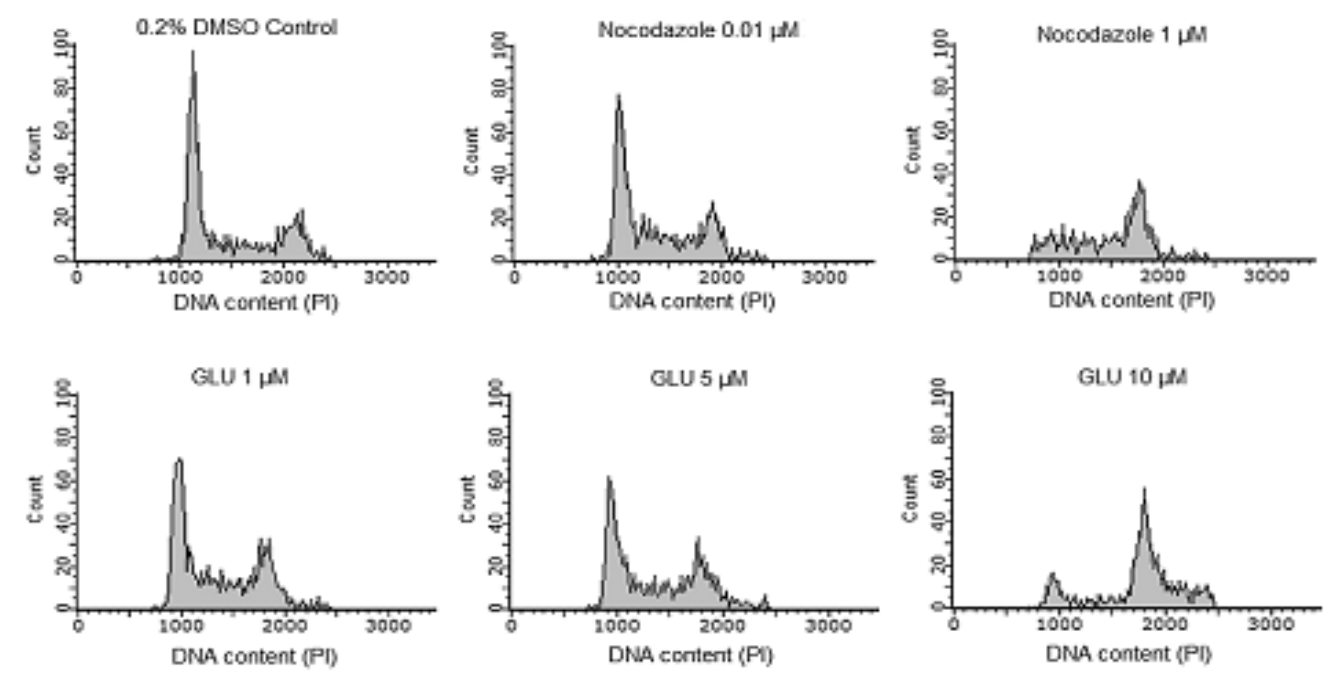

b

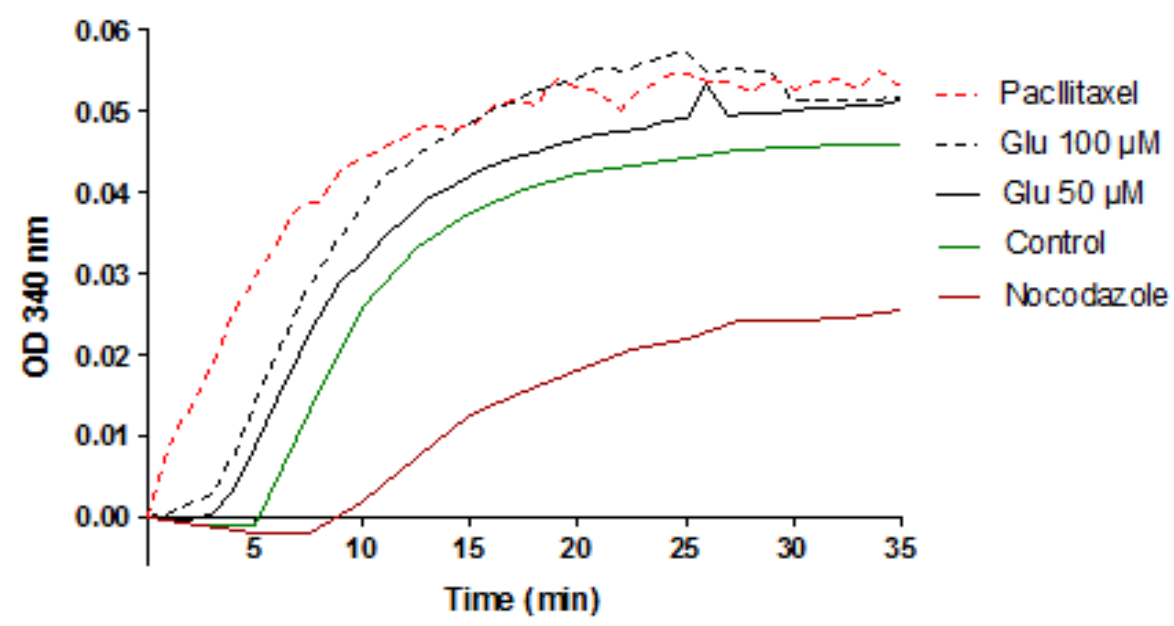

Figure 10. Cell cycle arrest and tubulin polymerization. (A) Cell cycle analysis of KG1a cells treated with glucopsychosine. KG1a cells were treated with glucopsychosine at 1,5 , and $10 \mu \mathrm{M}$ for $24 \mathrm{hrs}$. The cells were fixed and stained with PI according to literature protocol. DNA content was assessed via flow cytometry using the Guava Soft Cell Cycle Analysis software. 0.2\% DMSO was used as a negative control and nocodazole was used as a positive control. Each peak represents the number of cells found with that amount of DNA (1X, 1X to 2X, or 2X). (B) Tubulin polymerization experiment. Polymerization rates were assessed with the tubulin polymerization protocol and compared against a depolymerizer (nocodazole) and a promoter of polymerization (paclitaxel). Purified tubulin was incubate with glucopsychosine at 50 and $100 \mu \mathrm{M}$ and OD340 $\mathrm{nm}$ readings were taken every 2.5 minutes until polymerization saturation occurred. 


\subsubsection{Calcium and the ER stress pathway}

Previous literature on glucopsychosine demonstrated that glucopsychosine increases intracellular calcium in rat brain microsomes [22]. Therefore, we looked at intracellular calcium increases with the fluo-3 AM assay as explained in Ch. 3.2.5 and Ch. 3.3.4 in AML cell lines. We confirmed that glucopsychosine increased intracellular calcium levels within AML cell lines. Initially we hypothesized that glucopsychosine was increasing intracellular calcium levels and activating the ER stress response (refer to Ch. 1.3.2 Fig. 3). We tested protein levels of GRP78, a chaperone protein which is released as a precursor to the UPR to prevent the cells from committing to the ER stress pathway of apoptosis $[37,95]$. The ER is a center for protein folding and when there is insufficient protein folding, cytosolic GRP78 will shuttle unfolded proteins back into the ER to refold them [95]. We treated OCI-AML2 and U937 cells with $10 \mu \mathrm{M}$ glucopsychosine for increasing time points and looked for changes in GRP78 protein expression (Fig. 11A).

The results of multiple Western blots showed no increase in GRP78 protein expression. However, to confirm that the ER stress pathway was not involved we probed for caspase-12 activation. Caspase- 12 is normally bound to the ER as pro-caspase- 12 until it becomes unbound and cleaved by calpains during ER stress [95]. Active caspase-12 can then initiate the caspase cascade and lead to apoptosis [38]. Our Western blots showed very slight increases in active caspase-12 (Fig. 11B) in OCI-AML2 cells but not U937. 
a

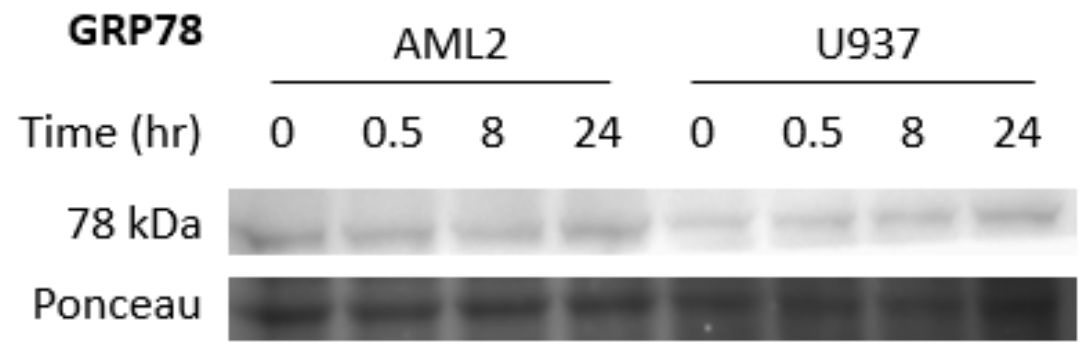

b

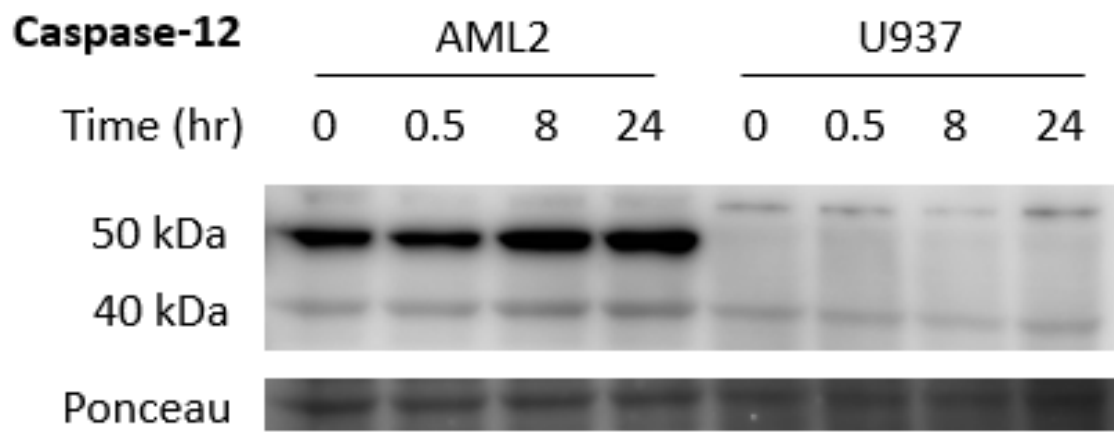

Figure 11. Assessing the ER stress pathway of apoptosis. (A) GRP78 Western blot. OCI-AML2 and U937 cells were treated with glucopsychosine at $10 \mu \mathrm{M}$ for $0,0.5,8$, and $24 \mathrm{hrs}$ and whole cell lysates were Western blotted for GRP78 protein $(78 \mathrm{kDa})$ according to standard Western blot protocol. (B) Caspase-12 Western blot showing uncleaved (50 kDa) and cleaved (40 kDa) caspase12. OCI-AML2 cells were incubated with $10 \mu \mathrm{M}$ glucopsychosine at $0,0.5,8$, and $24 \mathrm{hrs}$ and changes in caspase-12 was observed.

Because the activation of caspase-12 was modest and there was no increase in cytosolic GRP78, we excluded ER stress as the main pathway of glucopsychosine-mediated cell death. At this point, we decided to test for caspase inhibitors, specifically Z-VAD and Q-VD-OPh (Fig. 5B and C). The results from these experiments showed that in the presence of pan-caspase (Z-VAD) or caspase-3 specific (Q-VD-OPh) inhibitors, glucopsychosine was still cytotoxic to AML cells. 
Since caspases were not essential to the mechanism of glucopsychosine, we assessed alternative proteases capable of initiating caspase-independent apoptosis.

\subsubsection{Calpains and calcium}

We purchased a commercially available calpain activation assay to assess calpain activity (refer to Ch. 3.2.7 and Fig. 6B, left panel). The results from these assays, summarized in Ch. 3.3.4, demonstrate a significant $(p<0.005)$ increase in active calpain. In addition, calpain protein expression was assessed by Western blotting (Fig. 6B, middle panel). Similar to the activation assay, there was an increase in active calpain, as determined by Western blot analysis. Moreover, when we inhibited calpain with MDL28170 we prevented calpain activation and abrogated cell death (Fig. 6B, right panel). Finally, it has been shown that AML cells have upregulated levels of calpain [44]. To determine if calpain levels were a predictor of glucopsychosine's ability to induce death, we tested calpain protein levels in multiple glucopsychosine sensitive cell lines and compared them to cells lines that were less sensitive to glucopsychosine treatment by Western blot analysis (Fig. 12).

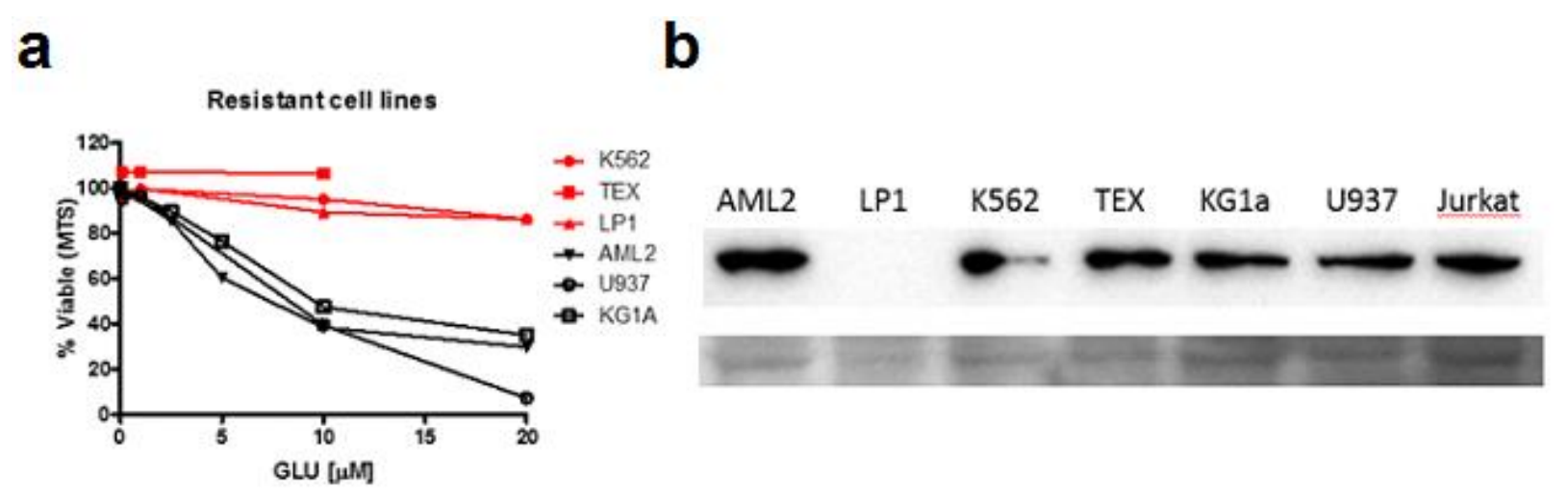

Figure 12. Basal levels of calpain expression. (A) Dose-response curve of glucopsychosine in multiple cell lines. (B) Western blot of basal calpain expression across multiple cell lines. 
There was no correlation between calpain expression and glucopsychosine sensitivity among the cell lines assayed. While the LP1 (myeloma cell line), K562 (CML), and TEX (AML stem cell initiating line) were insensitive to glucopsychosine (Fig. 12A, left panel), only LP1 followed our hypothesis that less sensitive cell lines would have reduced calpain expression.

The last set of experiments aimed to identify the source of the intracellular calcium increases. In addition to the calcium experiments discussed in Ch. 3.3.5., we used the calcium quantification assay in a primary AML patient sample and normal CD34+ sample that we had in excess (Figure 13). After treating these samples with glucopsychosine at $0,5,10$, and $20 \mu \mathrm{M}$ for $8 \mathrm{~h}$, we have shown that in our normal CD34+ cells, cytosolic $\mathrm{Ca}^{2+}$ levels did not increase. Therefore glucopsychosine is not increasing calcium in normal hematopoietic cells. However, when primary AML samples were exposed to glucopsychosine under the same conditions, there was an insignificant increase in calcium (ANOVA $(\mathrm{F}(3,4)=5.355, \mathrm{p}>0.05, \mathrm{r}=0.6676)$ with 5 $\mu \mathrm{M}$ glucopsychosine. These results strengthen our hypothesis that increasing cytosolic calcium plays a key role in glucopsychosine's mechanism of action and selectivity. 
a

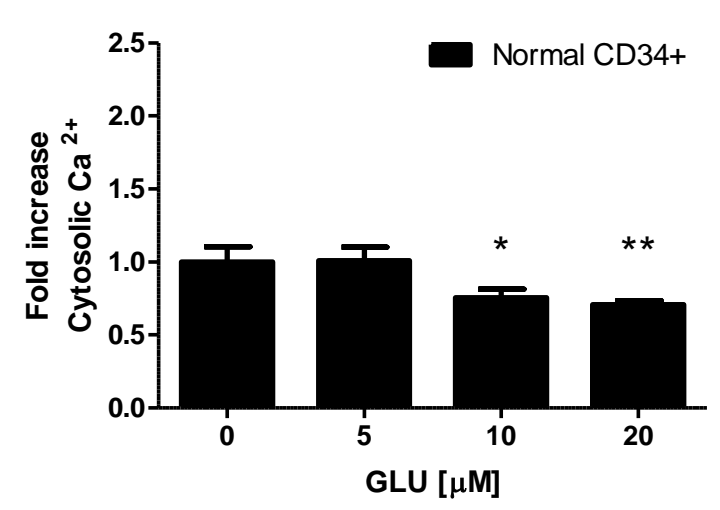

b

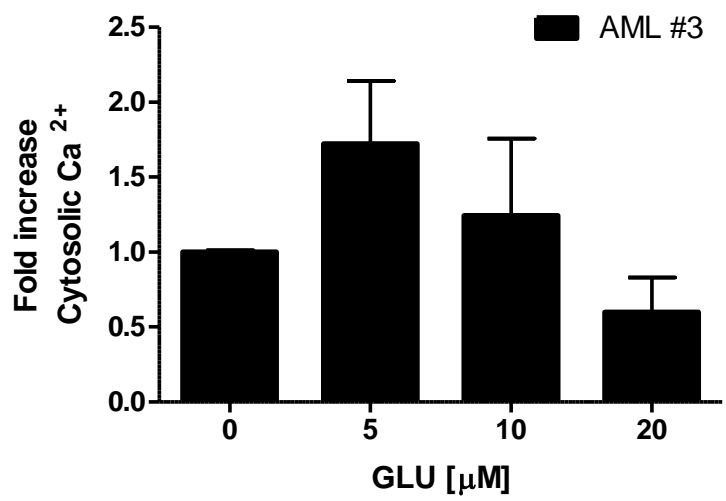

Figure 13. Fluo 3-AM cytosolic Ca2+ quantification assay in normal CD34+ sample and primary AML patient sample. Cells were subjected to increasing concentrations of GLU $(0,5$, $10,20 \mu \mathrm{M}$ ) for $8 \mathrm{~h}$ and cytosolic $\mathrm{Ca} 2+$ levels were quantified via flow cytometry and fluo-3AM/PI staining. (A) Normal CD34+ and (B) primary AML patient sample \#3 cells. 


\section{CHAPTER 5: DISCUSSION}

\subsection{Summary of findings}

This project investigated the anti-cancer treatment properties of glucopsychosine, a nutraceutical derived from bovine milk. We accomplished this by assessing glucopsychosine's in vitro and in vivo effects in AML cells and mouse models. In addition, we identified a unique characteristic of AML cells through interrogation of available mRNA databases of calcium surface channel expression, which showed that they were significantly down-regulated in AML cells compared to normal myeloid cells. Coupling this information with the recent discovery that AML cells have basally increased calpain levels with an associated down-regulation of the calpain inhibitor, calpastatin, gives a plausible hypothesis for glucopsychosine's preferential selectivity for AML cells (discussed below).

\subsection{Glucopsychosine's mechanism of action}

From our study, we showed that glucopsychosine was cytotoxic to multiple AML cell lines, primary AML patient samples, and was able to reduce the size of tumors in NOD/SCID mice. In contrast, glucopsychosine was not cytotoxic to non-AML cell lines (RWPE and CD44+ normal hematopoietic cells) and was not toxic in mice according to the physiological markers tested (i.e., weight loss, red blood cell counts, hemoglobin levels or serum markers of kidney and liver damage). Through mechanistic studies, glucopsychosine increased cytosolic calcium levels leading to the cytotoxic activation of calpain proteases. Extracellular calcium was functionally important for glucopsychosine-mediated cell death. Cell viability assays in calcium-free media 
or in combination with surface calcium inhibitors neutralized glucopsychosine's cytotoxicity in AML cells (Fig. 7). We hypothesize that glucopsychosine is able to modulate the ability of plasma membrane calcium channels to allow the influx of extracellular calcium.

It is well established that cells tightly maintain the levels of intracellular calcium $[46,67]$. Because all cells require a controlled intracellular environment, the plasma membrane is integral in maintaining homeostasis. The plasma membrane is a dynamic structure which can passively or actively allow the diffusion of solutes and ions through channels and pumps. Extracellular pumps are a common target for therapies across multiple diseases [96, 97]. Lidocaine, a local anesthetic that blocks voltage-gated sodium channels (Nav1), is administered for the treatment of neuropathic pain [96]. Nicotine is an example of an agonist for the nicotinic acetylcholine receptor (nAChR) subtypes, mimicking the effects of acetylcholine binding [97].

Although we did not identify the specific surface calcium channel that was modulated by glucopsychosine, we were able to prevent glucopsychosine induced cell death by concomitantly treating AML cells with verapamil, an L-type calcium channel inhibitor (Fig. 7A, left panel). However, calcium influx was not completely blocked by verapamil (Fig. 7A, right panel). Thus, L-type calcium channels are not glucopsychosine's only target and it is possible that glucopsychosine may be acting on multiple surface channels simultaneously. Future studies could focus on systematically knocking down each channel to identify which channel(s) are involved in glucopsychosine mediated cell death. Regardless of the specific channel(s) being modulated, extracellular calcium was shown to be essential to glucopsychosine's mechanism of 
action because removing calcium from the media effectively blocked cell death and reduced increases in intracellular $\mathrm{Ca}^{2+}$ levels (Fig. 7B).

The influx of calcium into the cells triggered a pathway of apoptosis mediated by calpains. Glucopsychosine treatment increased calpain activation and protein levels. This was functionally important as cell death was abrogated when co-incubated with MDL28170, a calpain inhibitor [98](Fig. 6B). Our experimental results show that calpains are the main executioner proteases; however, we are not discrediting the parallel pathways that can also be at work simultaneously. Once activated, caspases and calpain have many overlapping protein targets including pro-caspase-3 and -7, structural proteins (eg. actin), and DNA repair proteins (eg. PARP) [36, 99]. Calpains are less specific in their substrate candidates and have been reported to inactivate a number of caspases by proteolytic cleavage [100]. Caspases have also been implicated in the cleavage of calpastatin from calpains thereby activating them [99].

The role of caspases in glucopsychosine cytotoxicity has never been reported prior to this study. A related study by Sueyoshi et al. (2001) [101] investigated the caspase-independent cell death pathway of lysosphingolipids in neuronal cells. They reported that Neuro2a cells exposed to lysosphingolipids increased caspase-3 activity and laddered DNA. The DNA fragmentation was caspase-3-independent because total inhibition of caspase-3 with Z-VAD did not prevent DNA laddering. Interestingly, they commented that glucopsychosine could be mechanistically similar, but this was not deliberated further or experimentally tested [101]. When we assessed caspase activation in glucopsychosine treated AML cells we saw insignificant increases in caspase 3/7 activation (Fig. 9B). However, Q-VD-OPh (a caspase 3/7 inhibitor) did not affect 
glucopsychosine cytotoxicity. We also showed that the intrinsic mitochondrial pathway was not induced by glucopsychosine because Jurkat cells lacking functional mitochondrion were as susceptible as normal Jurkat cells to glucopsychosine (Fig. 5C, right panel). Treatment with cyclosporin A (Ch. 3.8 Supp. Fig. 2), an mPTP inhibitor [102], did not prevent cell death and there was no increase in cytochrome $\mathrm{c}$ (an inner mitochondrial membrane protein) in response to glucopsychosine treatment (Fig. 9C).

In our experiments, when Z-VAD (a pan-caspase inhibitor) was used at $100 \mu \mathrm{M}$ in the presence of glucopsychosine, cells were slightly protected from cytotoxicity (Fig. 5B, right panel). However, Z-VAD at concentrations of $100 \mu \mathrm{M}$ or greater have been reported to cause unspecific inhibition of calpains and other proteases [42]. Although not formally tested, this provides a rationale for the observed protective effects of high $\mathrm{Z}-\mathrm{VAD}$ concentrations. Alternatively, Z-VAD could be preventing caspases from inactivating calpastatin, thereby preventing calpain activation [103]. Therefore, since only MDL28170 (a calpain protease inhibitor) was able to abrogate cell death, we conclude that calpains and not caspases are functionally important for glucopsychosine-induced death.

\subsection{Selectivity of glucopsychosine}

An effective chemotherapeutic must show selectivity towards malignant cells. Here we showed that glucopsychosine was selective towards cancerous cells and was most sensitive in leukemia cells. Glucopsychosine did not reduce the cell viability of the CD34+ normal hematopoietic population of cells at concentrations up to $20 \mu \mathrm{M}$ over 24 hours (with Annexin V/PI). When we assessed glucopsychosine in primary AML patient samples, a trend appeared 
that showed cell cytotoxicity plateauing at higher concentrations. It is possible that glucopsychosine is saturating its target calcium channel(s) at higher concentrations and therefore increases in glucopsychosine will not lead to increases in calcium influx. This hypothesis is strengthened by the fact that surface calcium channel expression is down-regulated in AML patients which suggests that saturation can occur more readily.

In this study, in collaboration with Dr. Mahadeo Sukhai from the Princess Margaret Cancer Centre, we determined that the expression of surface calcium channels across AML patients from various AML subtypes (M0-M4) were significantly under-expressed compared to normal hematopoietic cells (CD34+, polymorphonuclear leukocytes, and promyelocytes) (Supplementary Tables 2 and 3). There is still debate whether down-regulation of calcium channels confers a pro-survival or pro-death phenotype during the differentiation of cancer cells. Yang et al. (2013) [104] performed a similar expression database screen looking at levels of calcium-activated chloride channels (CLCAs) in colorectal cancer (CRC) patients and normal colonic mucosa. They found that in CRC patients, CLCAs were significantly under expressed which was functionally important for blocked differentiation and increased proliferation [104]. We believe that AML cells are under-expressing their surface calcium channels for similar reasons - to evade calcium triggered cell death and growth arrest.

It is common for cells to have altered physiological morphology in diseased states as seen in atrial fibrillation [72], colonic inflammation [73] and cerebral ischemia [74]. In the same way, cancerous cells take on an altered physiological morphology. For example, PMCA2 (Plasmalemmal $\mathrm{Ca}^{2+}$ ATPases 2) is over-expressed in breast cancer and plays a role in conferring 
resistance to apoptotic signals [67, 105]. Baggott et al. (2012) [105] showed that targeting and disrupting the function of PMCA2 promoted apoptosis and paclitaxel-induced death in breast cancer cells. Therefore, we believe that glucopsychosine counters the pro-survival mechanism conferred by the under expressed surface calcium channels in AML cells.

The second factor that may contribute to glucopsychosine's selectivity relates to calpain and calpastatin levels in AML cells compared to normal cells. Calpain activity has been reported in numerous pathological states to be increased. Niapour et al. (2012) [44] showed that calpain activity is highly elevated in the CD34+/CD38- populations of AML subtypes. The elevated levels of calpains conferred a pro-survival mechanism because treatment with PD150606 (a calpain inhibitor) induced apoptosis [44]. Their study also showed that calpain levels were significantly lower in CD34+ cells of complete remission patients compared to those patients who had no response to treatment. Therefore, calpain can be used as a potential prognostic factor for determining treatment options in AML therapy. In combination with this finding, calpastatin levels were inversely related to calpain levels in AML cells [44]. This relationship amplifies the potential effectiveness of activating calpains in AML (Fig. 14). Thus we propose that AML cells down-regulate their plasma calcium channels to prevent increases in cytosolic calcium from nonspecifically activating calpains past a point where they initiate cell death. Glucopsychosine exploits this and selectively increases calcium in AML cells. This implies that increased calpains render AML cells more sensitive to glucopsychosine. Although, we were unsuccessful in our crude attempt (i.e., Western blotting) to correlate calpain levels and cell line glucopsychosine sensitivity, future studies would be needed to use more precise measures of calpain content. 

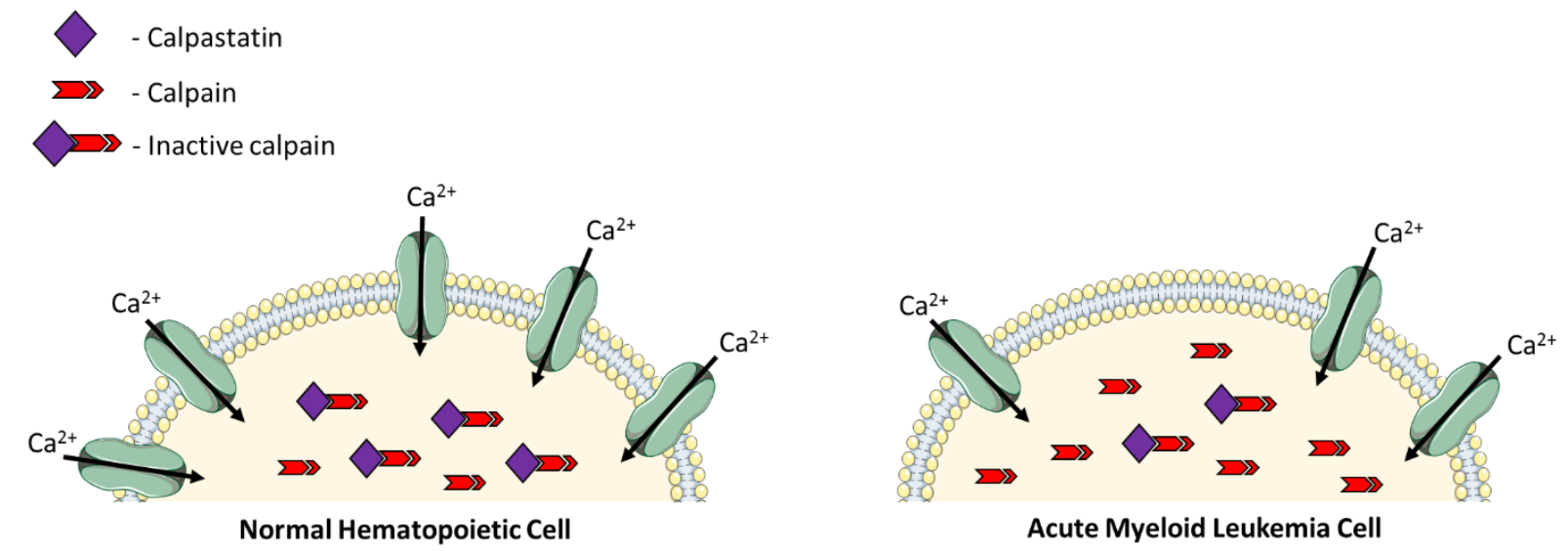

Figure 14. Simplified schematic noting the cellular differences between normal hematopoietic cells and AML cells. Normal cells have normal levels of surface calcium channels and calpastatin which prevent calpains from being activated by normal calcium flux. AML cells have reduced surface calcium channels and increased unbound calpain which confer pro-survival mechanisms.

\subsection{Glucopsychosine as a novel therapy for AML}

A major goal of this research was to perform pre-clinical studies to assess glucopsychosine for its potential as a novel anti-AML agent. Currently glucopsychosine is not being marketed as a nutraceutical or a chemotherapeutic, but this research shows that glucopsychosine can have therapeutic effects. Furthermore, the characterization of the different cell and molecular properties of AML cells, with regard to their calcium channel expression, are alone an important contribution to the field. In this section we discuss the implications of glucopsychosine for the treatment of AML.

The first consideration is the mode of glucopsychosine administration. Glucopsychosine is a sphingolipid that can be synthesized chemically. It is naturally found at low concentrations in milk $(0.067 \mathrm{~g} / \mathrm{L}$ or $0.15 \mu \mathrm{M})$ [81], thus in order to reach therapeutic levels, glucopsychosine 
must be concentrated and administered as a nutraceutical. According to Lipinski's rule of five [106], glucopsychosine would not be suitable as an oral formulation due to its 6 H-bond donors, large polar surface area $\left(145.63 \AA^{2}\right)$, and 18 rotatable bonds ${ }^{1}$ and would therefore be administered via intravenous route. There is limited literature on pharmacokinetic properties of glucopsychosine in humans or murine models. However, studies have shown that glucopsychosine levels are greatly elevated in the brain of type 2 and 3 Gauchers disease patients [83]. In type 1 Gauchers disease, which is the form of the lysosomal storage disorder that does not include the central nervous system, plasma levels of glucopsychosine was on average more than 200-fold greater than in healthy subjects. Although glucopsychosine was present at such high concentrations in the plasma of Gauchers disease patients, there was no significant correlation to disease pathology [83]. Therefore, while glucopsychosine treatment may increase plasma concentrations in humans, there is no documented correlation with disease pathology. Furthermore, our in vivo study showed that glucopsychosine administered at twice the concentration needed to reduce tumour growth (i.e., $40 \mathrm{mg} / \mathrm{kg}$ ) had no signs of toxicity in mice. Nonetheless, future studies would be needed to determine acceptable therapeutic doses for rotating glucopsychosine into standard regimens.

Calcium channels are key targets in cardiac pharmacology and calcium channel blockers are usually employed to prevent tachycardias [107]. Because the sinoatrial and atrio-ventricular nodes are very concentrated in calcium channels, calcium increases are very prevalent in these regions and causes the increased conduction through the AV node. In addition, calcium

\footnotetext{
${ }^{1}$ Values were calculated with JChem computational software.
} 
channels are present in smooth muscles lining blood vessels [108]. Patients with a history of hypertension have increased intracellular calcium levels and may be on hypertension medication such as the calcium channel blockers nifedipine, amlodipine, diltiazem, or verapamil [109]. Therefore, simultaneous use of these calcium channel blockers could interfere with glucopsychosine's mechanism of action in AML cells, as seen in vitro with verapamil (Fig. 7A). Future human studies would need special consideration for patients with a history of heart disease and/or on prescription medication for blocking of calcium channels.

\subsection{Limitations}

As mentioned in Chapter 5.3, the initial screen used RWPE a prostate cell line which may have different growth kinetics and features compared to AML cells or normal hematopoietic cells. Alternatively, non-cancerous lymphocytes, monocytes, granulocytes, or bone marrow cells would have been better suited to assess the selectivity of the validated compounds. However, RWPE cells did serve as a "normal" epithelial cell line, and the use of "normal lines" is common in literature $[59,76]$. In addition, the use of primary CD34+ normal hematopoietic cells rectified this limitation. Another possible limitation of this screen was the number of cell lines used to test and validate. The US National Cancer Institute use a special drug screen when looking for anticancer drugs which involves the use of 60 different cell lines from 9 different tumor types [110]. Our lab does not have access to this number of cell lines and initially the NCI employed these precondition in hopes to limit the use of xenograft mouse models unnecessarily [110]. Therefore, we did not feel the need to expand our validation screen to a larger number of cell 
lines since we were able to show glucopsychosine's therapeutic effect in xenograft mouse models.

The second limitation to this study would be the use of a tumor xenograft model. The xenograft model is an established model that has been used countlessly in AML and cancer research $[111,112]$. However, there are advantages and disadvantages when using xenograft tumors. The main disadvantage with xenograft tumor models for AML is that it does not reflect the pathophysiology of AML. AML is a cancer of the blood and does not naturally form a solid tumor mass. However, when assessed in xenograft mouse models, the AML cells are able to congregate into a mass. The advantage of this model is the ability to visualize and measure tumor response to glucopsychosine treatment [113]. In addition, this is the standard model by which pre-clinical assessment is performed, and although limited in predicting clinical success, it is a very useful tool for physiological assessment [113]. The safety and toxicity data collected from this experiment is not diminished by the limitations of the xenograft model.

The last experiment which posed limitations to this study was the calcium-free media experiment looking at the importance of extracellular calcium to glucopsychosine-mediate cell death. Due to the importance of extracellular calcium for normal cellular function, suspending AML cells in calcium free media caused toxicity at 24 hours. In order to adjust for this we used glucopsychosine at higher concentrations $(20 \mu \mathrm{M})$ and shorter time points $(0,30,60$ minutes $)$. Therefore it is uncertain whether or not the cells were behaving the same as they would normally behave in regular media. We also noticed that when performing the Annexin PI cell viability assay we saw that in calcium free media the cells did not have an ANN+/PI- fraction which 
designates early apoptosis. However, this is likely due to phophatidylserine's dependence on calcium to flip to the outer leaflet of the plasma membrane to be bound by annexin [114]. Therefore, although we saw that cell death was inhibited, we were not able to assess whether early apoptosis was also being inhibited by the calcium-free media.

\subsection{Conclusion}

The conclusions made from this thesis have opened up many more avenues of potential study. Glucopsychosine has a mechanism of action that is unique to current AML therapy calpain-mediated cell death. Future studies will need to clarify the exact pathway of glucopsychosine induced cell death (which calcium channels are being targeted and what cellular substrate is calpain targeting) and investigate its pharmacokinetic properties in mouse and human models. Cancer therapy is constantly changing with new therapies and dosing regimens continuously fine-tuning the current state of treatment. This study was aimed at accomplishing this in acute myeloid leukemia, a disease that is far from cured. The results, insights, and experimental reasoning used in this project can all be used to realize this goal. 


\section{Bibliography}

1. American Cancer Society, Estimated Number of New Cancer Cases and Deaths by Sex, US, 2014, 2014, American Cancer Society, Inc., Surveillance Research.

2. Estey, E.H., Acute myeloid leukemia: 2012 update on diagnosis, risk stratification, and management. Am J Hematol, 2012. 87(1): p. 89-99.

3. Canadian Cancer Statistics 2013. 2013.

4. Puumala, S.E., et al., Epidemiology of childhood acute myeloid leukemia. Pediatr Blood Cancer, 2013. 60(5): p. 728-33.

5. Howlader N, N.A., Krapcho M, Neyman N, Aminou R, Altekruse SF, Kosary CL, Ruhl J, Tatalovich Z, Cho H, Mariotto A, Eisner MP, Lewis DR, Chen HS, Feuer EJ, Cronin KA, SEER Cancer Statistics Review, 1975-2009, 2012, National Cancer Institute: Bethesda, MD.

6. Lowenberg, B., J.R. Downing, and A. Burnett, Acute myeloid leukemia. N Engl J Med, 1999. 341(14): p. 1051-62.

7. de Greef, G.E., et al., Criteria for defining a complete remission in acute myeloid leukaemia revisited. An analysis of patients treated in HOVON-SAKK co-operative group studies. $\mathrm{Br} \mathrm{J}$ Haematol, 2005. 128(2): p. 184-91.

8. Derolf, A.R., et al., Improved patient survival for acute myeloid leukemia: a population-based study of 9729 patients diagnosed in Sweden between 1973 and 2005. Blood, 2009. 113(16): p. 3666-72.

9. Reese, N.D. and G.J. Schiller, High-Dose Cytarabine (HD araC) in the Treatment of Leukemias: a Review. Curr Hematol Malig Rep, 2013. 8(2): p. 141-8.

10. Walter, R.B., et al., Significance of FAB subclassification of "acute myeloid leukemia, NOS" in the 2008 WHO classification: analysis of 5848 newly diagnosed patients. Blood, 2013. 121(13): p. 2424-31.

11. Daniel, M.T., et al., PML protein expression in hematopoietic and acute promyelocytic leukemia cells. Blood, 1993. 82(6): p. 1858-67.

12. Tallman, M.S., et al., Acute promyelocytic leukemia: evolving therapeutic strategies. Blood, 2002. 99(3): p. 759-67.

13. Robak, T. and A. Wierzbowska, Current and emerging therapies for acute myeloid leukemia. Clin Ther, 2009. 31 Pt 2: p. 2349-70.

14. DeFelice, S.L., Nutraceuticals: Opportunities in an Emerging Market, in Scrip Mag1992. p. 1415.

15. Harrington, G., Natural Health Products - Substantiating the Claims. Canadian Pharmacists Journal, 2010. 143.

16. Milner, J.A., Nutrition and cancer: essential elements for a roadmap. Cancer Lett, 2008. 269(2): p. 189-98.

17. Harvey, A.L., Natural products as a screening resource. Curr Opin Chem Biol, 2007. 11(5): p. 480-4.

18. Harvey, A.L., Natural products in drug discovery. Drug Discov Today, 2008. 13(19-20): p. 894901.

19. Morrison, W.R., Polar lipids in bovine milk. I. Long-chain bases in sphingomyelin. Biochim Biophys Acta, 1969. 176(3): p. 537-46. 
20. Schueler, U.H., et al., Toxicity of glucosylsphingosine (glucopsychosine) to cultured neuronal cells: a model system for assessing neuronal damage in Gaucher disease type 2 and 3. Neurobiology of Disease, 2003. 14(3): p. 595-601.

21. Jatana, M., S. Giri, and A.K. Singh, Apoptotic positive cells in Krabbe brain and induction of apoptosis in rat C6 glial cells by psychosine. Neurosci Lett, 2002. 330(2): p. 183-7.

22. Lloyd-Evans, E., et al., Glucosylceramide and glucosylsphingosine modulate calcium mobilization from brain microsomes via different mechanisms. J Biol Chem, 2003. 278(26): p. 23594-9.

23. Kolesnick, R., The therapeutic potential of modulating the ceramide/sphingomyelin pathway. $\mathrm{J}$ Clin Invest, 2002. 110(1): p. 3-8.

24. Gault, C.R., L.M. Obeid, and Y.A. Hannun, An overview of sphingolipid metabolism: from synthesis to breakdown. Adv Exp Med Biol, 2010. 688: p. 1-23.

25. Kartal Yandim, M., E. Apohan, and Y. Baran, Therapeutic potential of targeting ceramide/glucosylceramide pathway in cancer. Cancer Chemother Pharmacol, 2013. 71(1): p. 1320.

26. Hotchkiss, R.S., et al., Cell death. N Engl J Med, 2009. 361(16): p. 1570-83.

27. Surova, O. and B. Zhivotovsky, Various modes of cell death induced by DNA damage. Oncogene, 2012.

28. Elmore, S., Apoptosis: a review of programmed cell death. Toxicol Pathol, 2007. 35(4): p. 495516.

29. Weiss, E., D.C. Rees, and J.S. Gibson, Role of calcium in phosphatidylserine externalisation in red blood cells from sickle cell patients. Anemia, 2011. 2011: p. 379894.

30. A. Hamid Boulares, A.G.Y., Vessela Ivanova, Bogdan A. Stoica, Geping Wang, and a.M.S. Sudha Iyer, Role of Poly(ADP-ribose) Polymerase (PARP) Cleavage in Apoptosis. The Journal of Biological Chemistry, 1999. 274(33): p. 22932-22940.

31. Los, M., et al., Activation and caspase-mediated inhibition of PARP: a molecular switch between fibroblast necrosis and apoptosis in death receptor signaling. Mol Biol Cell, 2002. 13(3): p. 97888.

32. Kantari, C. and H. Walczak, Caspase-8 and bid: caught in the act between death receptors and mitochondria. Biochim Biophys Acta, 2011. 1813(4): p. 558-63.

33. Hotchkiss, R.S., Pathways of Cellular Apoptosis, C. Death, Editor 2009, The New England Journal of Medicine: The New England Journal of Medicine.

34. van Loo, G., et al., The role of mitochondrial factors in apoptosis: a Russian roulette with more than one bullet. Cell Death Differ, 2002. 9(10): p. 1031-42.

35. Momoi, T., Caspases involved in ER stress-mediated cell death. J Chem Neuroanat, 2004. 28(12): p. 101-5.

36. Orrenius, S., B. Zhivotovsky, and P. Nicotera, Regulation of cell death: the calcium-apoptosis link. Nat Rev Mol Cell Biol, 2003. 4(7): p. 552-65.

37. Dolai, S., et al., Endoplasmic reticulum stress-induced apoptosis in Leishmania through Ca2+dependent and caspase-independent mechanism. J Biol Chem, 2011. 286(15): p. 13638-46.

38. Pae, H.O., et al., Curcumin induces pro-apoptotic endoplasmic reticulum stress in human leukemia HL-60 cells. Biochem Biophys Res Commun, 2007. 353(4): p. 1040-5.

39. Momeni, H.R., Role of calpain in apoptosis. Cell J, 2011. 13(2): p. 65-72.

40. Goll, D.E., et al., The calpain system. Physiol Rev, 2003. 83(3): p. 731-801.

41. Janossy, J., et al., Calpain as a multi-site regulator of cell cycle. Biochem Pharmacol, 2004. 67(8): p. 1513-21. 
42. Artus, C., et al., CD44 ligation induces caspase-independent cell death via a novel calpain/AIF pathway in human erythroleukemia cells. Oncogene, 2006. 25(42): p. 5741-51.

43. Santella, L., et al., Calcium, protease action, and the regulation of the cell cycle. Cell Calcium, 1998. 23(2-3): p. 123-30.

44. Niapour, M., et al., Elevated calpain activity in acute myelogenous leukemia correlates with decreased calpastatin expression. Blood Cancer J, 2012. 2(1): p. e51.

45. Weinberg, R.A., The biology of cancer. 2007, New York: Garland Science.

46. Clapham, D.E., Calcium signaling. Cell, 2007. 131(6): p. 1047-58.

47. Berridge, M.J., M.D. Bootman, and H.L. Roderick, Calcium signalling: dynamics, homeostasis and remodelling. Nat Rev Mol Cell Biol, 2003. 4(7): p. 517-29.

48. Parekh, A.B. and J.W. Putney, Jr., Store-operated calcium channels. Physiol Rev, 2005. 85(2): p. 757-810.

49. Leon-Pinzon, C., et al., Exocytosis of serotonin from the neuronal soma is sustained by a serotonin and calcium-dependent feedback loop. Front Cell Neurosci, 2014. 8: p. 169.

50. Turner, R.W., D. Anderson, and G.W. Zamponi, Signaling complexes of voltage-gated calcium channels. Channels (Austin), 2011. 5(5): p. 440-8.

51. Jaggi, A.S. and N. Singh, Mechanisms in cancer-chemotherapeutic drugs-induced peripheral neuropathy. Toxicology, 2012. 291(1-3): p. 1-9.

52. Burnett, A., M. Wetzler, and B. Lowenberg, Therapeutic advances in acute myeloid leukemia. $\mathrm{J}$ Clin Oncol, 2011. 29(5): p. 487-94.

53. Shipley, J.L. and J.N. Butera, Acute myelogenous leukemia. Exp Hematol, 2009. 37(6): p. 649-58.

54. Khan, I., J.K. Altman, and J.D. Licht, New strategies in acute myeloid leukemia: redefining prognostic markers to guide therapy. Clin Cancer Res, 2012. 18(19): p. 5163-71.

55. McDermott, S.P., et al., A small molecule screening strategy with validation on human leukemia stem cells uncovers the therapeutic efficacy of kinetin riboside. Blood, 2012. 119(5): p. 1200-7.

56. Guzman, M.L., et al., The sesquiterpene lactone parthenolide induces apoptosis of human acute myelogenous leukemia stem and progenitor cells. Blood, 2005. 105(11): p. 4163-9.

57. Spagnuolo, P.A., et al., The antihelmintic flubendazole inhibits microtubule function through a mechanism distinct from Vinca alkaloids and displays preclinical activity in leukemia and myeloma. Blood, 2010. 115(23): p. 4824-33.

58. Spagnuolo, P.A., et al., Inhibition of intracellular dipeptidyl peptidases 8 and 9 enhances parthenolide's anti-leukemic activity. Leukemia, 2013. 27(6): p. 1236-44.

59. Skrtic, M., et al., Inhibition of mitochondrial translation as a therapeutic strategy for human acute myeloid leukemia. Cancer Cell, 2011. 20(5): p. 674-88.

60. Revankar, C.M., S.H. Advani, and N.R. Naik, Altered Ca2+ homeostasis in polymorphonuclear leukocytes from chronic myeloid leukaemia patients. Mol Cancer, 2006. 5: p. 65.

61. Dam, A.D., A.S. Mitchell, and J. Quadrilatero, Induction of mitochondrial biogenesis protects against caspase-dependent and caspase-independent apoptosis in L6 myoblasts. Biochim Biophys Acta, 2013. 1833(12): p. 3426-35.

62. Payton, J.E., et al., High throughput digital quantification of mRNA abundance in primary human acute myeloid leukemia samples. J Clin Invest, 2009. 119(6): p. 1714-26.

63. Chaitanya, G.V., A.J. Steven, and P.P. Babu, PARP-1 cleavage fragments: signatures of celldeath proteases in neurodegeneration. Cell Commun Signal, 2010. 8: p. 31.

64. Hashiguchi, K. and Q.M. Zhang-Akiyama, Establishment of human cell lines lacking mitochondrial DNA. Methods Mol Biol, 2009. 554: p. 383-91. 
65. Gamen, S., et al., mtDNA-depleted U937 cells are sensitive to TNF and Fas-mediated cytotoxicity. FEBS Lett, 1995. 376(1-2): p. 15-8.

66. Ferraresi, R., et al., Resistance of mtDNA-depleted cells to apoptosis. Cytometry A, 2008. 73(6): p. 528-37.

67. Monteith, G.R., et al., Calcium and cancer: targeting Ca2+ transport. Nat Rev Cancer, 2007. 7(7): p. 519-30.

68. Garattini, E., et al., ST1926, a novel and orally active retinoid-related molecule inducing apoptosis in myeloid leukemia cells: modulation of intracellular calcium homeostasis. Blood, 2004. 103(1): p. 194-207.

69. Siau, C. and G.J. Bennett, Dysregulation of cellular calcium homeostasis in chemotherapy-evoked painful peripheral neuropathy. Anesth Analg, 2006. 102(5): p. 1485-90.

70. Monette, R., et al., Interaction between Calcium Ions and Bacillus thuringiensis Toxin Activity against Sf9 Cells (Spodoptera frugiperda, Lepidoptera). Appl Environ Microbiol, 1997. 63(2): p. 440-7.

71. Sukhai, M.A., et al., Lysosomal disruption preferentially targets acute myeloid leukemia cells and progenitors. J Clin Invest, 2013. 123(1): p. 315-28.

72. Lai, L.P., et al., Down-regulation of L-type calcium channel and sarcoplasmic reticular Ca(2+)ATPase $m R N A$ in human atrial fibrillation without significant change in the mRNA of ryanodine receptor, calsequestrin and phospholamban: an insight into the mechanism of atrial electrical remodeling. J Am Coll Cardiol, 1999. 33(5): p. 1231-7.

73. Liu, X., et al., Down-regulation of L-type calcium channels in inflamed circular smooth muscle cells of the canine colon. Gastroenterology, 2001. 120(2): p. 480-9.

74. Li, X.M., et al., Contribution of downregulation of L-type calcium currents to delayed neuronal death in rat hippocampus after global cerebral ischemia and reperfusion. J Neurosci, 2007. 27(19): p. 5249-59.

75. Soboloff, J., et al., Sensitivity of myeloid leukemia cells to calcium influx blockade: application to bone marrow purging. Exp Hematol, 2002. 30(10): p. 1219-26.

76. O'Donovan, N., et al., Caspase 3 in breast cancer. Clin Cancer Res, 2003. 9(2): p. 738-42.

77. Hartmann, A., et al., Caspase-3: A vulnerability factor and final effector in apoptotic death of dopaminergic neurons in Parkinson's disease. Proc Natl Acad Sci U S A, 2000. 97(6): p. 287580.

78. Shalimar, D.M., et al., Mechanism of villous atrophy in celiac disease: role of apoptosis and epithelial regeneration. Arch Pathol Lab Med, 2013. 137(9): p. 1262-9.

79. Jeong, J.C., et al., Silibinin induces apoptosis via calpain-dependent AIF nuclear translocation in U87MG human glioma cell death. J Exp Clin Cancer Res, 2011. 30: p. 44.

80. Yanamandra, N., et al., Tipifarnib-induced apoptosis in acute myeloid leukemia and multiple myeloma cells depends on Ca2+ influx through plasma membrane Ca2+ channels. J Pharmacol Exp Ther, 2011. 337(3): p. 636-43.

81. Jensen, R.G., The composition of bovine milk lipids: January 1995 to December 2000. J Dairy Sci, 2002. 85(2): p. 295-350.

82. Igisu, H., et al., Inhibition of cytochrome c oxidase and hemolysis caused by lysosphingolipids. Lipids, 1988. 23(4): p. 345-8.

83. Dekker, N., et al., Elevated plasma glucosylsphingosine in Gaucher disease: relation to phenotype, storage cell markers, and therapeutic response. Blood, 2011. 118(16): p. e118-27.

84. Beutler, E., Gaucher disease: new molecular approaches to diagnosis and treatment. Science, 1992. 256(5058): p. 794-9. 
85. Zimran, A., et al., Gaucher disease. Clinical, laboratory, radiologic, and genetic features of 53 patients. Medicine (Baltimore), 1992. 71(6): p. 337-53.

86. Zafarullah, M., et al., Molecular mechanisms of N-acetylcysteine actions. Cell Mol Life Sci, 2003. 60(1): p. 6-20.

87. Bruggisser, R., et al., Interference of plant extracts, phytoestrogens and antioxidants with the MTT tetrazolium assay. Planta Med, 2002. 68(5): p. 445-8.

88. Natarajan, M., et al., Antioxidant compounds interfere with the 3. Cancer Detect Prev, 2000. 24(5): p. 405-14.

89. Hanahan, D. and Robert A. Weinberg, Hallmarks of Cancer: The Next Generation. Cell, 2011. 144(5): p. 646-674.

90. Jordheim, L.P., et al., Advances in the development of nucleoside and nucleotide analogues for cancer and viral diseases. Nat Rev Drug Discov, 2013. 12(6): p. 447-64.

91. American Cancer Society. Different types of chemotherapy drugs. Chemotherapy Principles 2013 February 7, 2013 July 22, 2014]; Available from:

http://www.cancer.org/treatment/treatmentsandsideeffects/treatmenttypes/chemotherapy/chemoth erapyprinciplesanin-depthdiscussionofthetechniquesanditsroleintreatment/chemotherapyprinciples-types-of-chemo-drugs.

92. Kitagawa, K. and Y. Niikura, Caspase-independent mitotic death (CIMD). Cell Cycle, 2008. 7(8): p. 1001-5.

93. Parker, A.L., M. Kavallaris, and J.A. McCarroll, Microtubules and their role in cellular stress in cancer. Front Oncol, 2014. 4: p. 153.

94. Ahmed, A.A., et al., Modulating microtubule stability enhances the cytotoxic response of cancer cells to Paclitaxel. Cancer Res, 2011. 71(17): p. 5806-17.

95. Martinez, J.A., et al., Calpain and caspase processing of caspase-12 contribute to the ER stressinduced cell death pathway in differentiated PC12 cells. Apoptosis, 2010. 15(12): p. 1480-93.

96. Kaczorowski, G.J., et al., Ion channels as drug targets: the next GPCRs. J Gen Physiol, 2008. 131(5): p. 399-405.

97. Williams, D.K., J. Wang, and R.L. Papke, Positive allosteric modulators as an approach to nicotinic acetylcholine receptor-targeted therapeutics: advantages and limitations. Biochem Pharmacol, 2011. 82(8): p. 915-30.

98. Smith, M.A. and R.G. Schnellmann, Calpains, mitochondria, and apoptosis. Cardiovasc Res, 2012. 96(1): p. 32-7.

99. Chaitanya, G.V. and P.P. Babu, Differential PARP cleavage: an indication of heterogeneous forms of cell death and involvement of multiple proteases in the infarct of focal cerebral ischemia in rat. Cell Mol Neurobiol, 2009. 29(4): p. 563-73.

100. Chua, B.T., K. Guo, and P. Li, Direct cleavage by the calcium-activated protease calpain can lead to inactivation of caspases. J Biol Chem, 2000. 275(7): p. 5131-5.

101. Sueyoshi, N., T. Maehara, and M. Ito, Apoptosis of Neuro2a cells induced by lysosphingolipids with naturally occurring stereochemical configurations. J Lipid Res, 2001. 42(8): p. 1197-202.

102. Deniaud, A., et al., Endoplasmic reticulum stress induces calcium-dependent permeability transition, mitochondrial outer membrane permeabilization and apoptosis. Oncogene, 2008. 27(3): p. 285-99.

103. Rami, A., et al., mu-Calpain activation, DNA fragmentation, and synergistic effects of caspase and calpain inhibitors in protecting hippocampal neurons from ischemic damage. Brain Res, 2000. 866(1-2): p. 299-312. 
104. Yang, B., et al., The transition from proliferation to differentiation in colorectal cancer is regulated by the calcium activated chloride channel A1. PLoS One, 2013. 8(4): p. e60861.

105. Baggott, R.R., et al., Disruption of the interaction between PMCA2 and calcineurin triggers apoptosis and enhances paclitaxel-induced cytotoxicity in breast cancer cells. Carcinogenesis, 2012. 33(12): p. 2362-8.

106. Keller, T.H., A. Pichota, and Z. Yin, A practical view of 'druggability'. Curr Opin Chem Biol, 2006. 10(4): p. 357-61.

107. Elliott, W.J. and C.V. Ram, Calcium channel blockers. J Clin Hypertens (Greenwich), 2011. 13(9): p. 687-9.

108. Billaud, M., et al., Regulation of cellular communication by signaling microdomains in the blood vessel wall. Pharmacol Rev, 2014. 66(2): p. 513-69.

109. Hazari, M.A., et al., Serum calcium level in hypertension. N Am J Med Sci, 2012. 4(11): p. 56972.

110. Shoemaker, R.H., The NCI60 human tumour cell line anticancer drug screen. Nat Rev Cancer, 2006. 6(10): p. 813-23.

111. Sawyers, C.L., et al., Propagation of human blastic myeloid leukemias in the SCID mouse. Blood, 1992. 79(8): p. 2089-98.

112. Richmond, A. and Y. Su, Mouse xenograft models vs GEM models for human cancer therapeutics. Dis Model Mech, 2008. 1(2-3): p. 78-82.

113. Frese, K.K. and D.A. Tuveson, Maximizing mouse cancer models. Nat Rev Cancer, 2007. 7(9): p. 645-58.

114. Bratton, D.L., et al., Appearance of phosphatidylserine on apoptotic cells requires calciummediated nonspecific flip-flop and is enhanced by loss of the aminophospholipid translocase. $\mathrm{J}$ Biol Chem, 1997. 272(42): p. 26159-65. 


\section{APPENDICES}




\section{Appendix 1}

Supplementary Table 2. List of under-expressed calcium channels in AML. Interrogation of publically available data sets revealed a list of 33 genes that are significantly under-expressed $(>1.25$ fold; $p<0.001)$ in AML cells compared to normal cells.

\begin{tabular}{|c|c|c|c|c|c|c|c|c|c|c|c|c|c|c|c|c|c|c|c|c|c|c|c|c|c|c|c|c|c|c|c|c|c|}
\hline \multicolumn{2}{|c|}{ Gene Symbol } & \multirow{2}{*}{$\begin{array}{c}\frac{3}{3} \\
\text { J } \\
\text { 焉 } \\
0.02\end{array}$} & \multirow{2}{*}{ 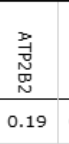 } & \multirow{2}{*}{$\begin{array}{c}\frac{3}{3} \\
\stackrel{N}{N} \\
0.05\end{array}$} & \multirow{2}{*}{$\begin{array}{c}\frac{8}{8} \\
\sum_{n}^{n} \\
\text { 总 } \\
0.01\end{array}$} & \multirow{2}{*}{ 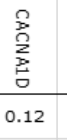 } & \multirow{2}{*}{ 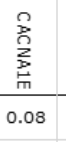 } & \multirow{2}{*}{ 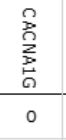 } & \multirow{2}{*}{ 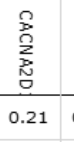 } & \multirow{2}{*}{ 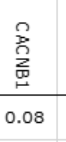 } & \multirow{2}{*}{ 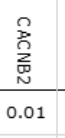 } & \multirow{2}{*}{ 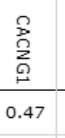 } & \multirow{2}{*}{ 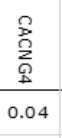 } & \multirow{2}{*}{ 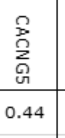 } & \multirow{2}{*}{ 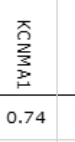 } & \multirow{2}{*}{ 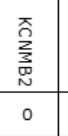 } & \multirow{2}{*}{\begin{tabular}{c|c}
$\frac{\text { 劲 }}{\mathrm{N}}$ \\
0.01
\end{tabular}} & \multirow{2}{*}{ 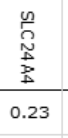 } & \multirow{2}{*}{\begin{tabular}{c|c}
$\frac{n}{n}$ \\
$N$ \\
$\tilde{N}$ \\
离 \\
\\
0.17
\end{tabular}} & \multirow{2}{*}{ 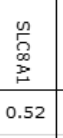 } & 荷 & 꽁 & 곰 & 긍 & 젱 & 叧 & $\frac{7}{3}$ & 弚 & 㐒 & $\frac{70}{\frac{7}{3}}$ & $\frac{\pi}{4}$ & 구 & , \\
\hline & alue & & & & & & & & & & & & & & & & & & & & 0.35 & 14 & 02 & & .39 & 0.01 & 0.03 & 2 & 0.3 & .3 & 48 & 2 & 49 \\
\hline & Ratic & c & 0.84 & 0.8 & 77 & 0.89 & 4 & 0.73 & 0.87 & 1.21 & 0.64 & 94 & 88 & 0.94 & 96 & 0.71 & 0.5 & 7 & 38 & .29 & 8 & 33 & 57 & 73 & 0.89 & 74 & 6 & .3 & 89 & \begin{tabular}{|l|}
0.87 \\
\end{tabular} & 95 & 15 & 0.92 \\
\hline & inge & 6 & 19 . & 25 & 31. & 13. & 9 & -1.36 & 15 & 1.21 & 57 & 07 & -1.14 & 27 & 4 & -1.41 & -1.99 & 1. & 14 & 1.29 & 1.8 & 21 & 5 & 37. & $-1.13-$ & -1.34. & - & .3 & 12 & 15 & 06 & 15 & -1.0 \\
\hline & tion & on & down & down & wn & down & wn & down & down & up & wn & down & down & down & down & down & down & up & wn & up & up & vn & n & wn & down $d$ & 10 & do & up & wn & down & own & up & ow \\
\hline & value & & 04 & 07 & 0 & 0.12 & & 0 & 19 & 32 & & 07 & 11 & 0.18 & & 0 & 0.09 & & 15 & \begin{tabular}{|l|}
0.58 \\
\end{tabular} & 23 & 0.07 & & 0 & 0.7 & & 0.02 & 0.07 & .23 & 0.3 & 19 & .21 & 28 \\
\hline & Ratio & & 79 & 84 & 22 & & & 4 & 88 & & & 86 & 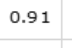 & 0.91 & 86 & 0.72 & 0.67 & 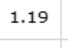 & 89 & .83 & 2 & 0.82 & 4 & 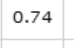 & 0. & 0.76 & 0.77 & 37 & 39 & $\mid 0.89$ & 0.92 & 1.13 & $0.8 \leqq$ \\
\hline & ange & & -1.26 & 19 & 38 . & -1.11 & 26 & -1.35 & 14 & 1.1 & 67. & 16 & -1.09 & .1 & 16 & -1.4 & .49 & 1.19 & 13 & -1.2 & 1.92 & 22 & -1.84 & -1.36 & -1.05 & -1.32 & 29 & 37 & 12 - & -1.13 & $\mid-1.09$ & 13 & -1.1 \\
\hline & & in & down & down & down & down & wn & down & down & up & vn & down & down & down & down & down & $\mathrm{wn}$ & & wn & down & & wn & down & down & down & wn & own & & wn & down & swn & p & low \\
\hline & & & & & & & & 0 & & & & & & & & & & & & & 0.27 & & & & & 0.03 & & & 43 & 0.69 & 0 & the & 0.38 \\
\hline & & & & & & & & & & & & & & & & & & & & & & & & & & & & & & & & & 0.91 \\
\hline & & & & & & & & & & & & & & & & & & & & & & & & & & & & & & & & & 1.4 \\
\hline & & & & & & & & & & & & & & & & & & & & & & & & & & & & & & & & & \\
\hline & & & & & & & & & & & & & & & & & & & & & & & & & & & & & & & & & \\
\hline & & & & & & & & & & & & & & & & & & & & & & & & & & & & & & & & & \\
\hline & nange | & 3 & -1.8 & -4.93 & 36 . & 37. & 57 & -1.51 & -1.59 & -1.3 & 21 & -1.26 & -1.26 & -1.72 & 4 & -1.82 & -3.79 & -3.37 & 44 . & -2.51 & -31.5 & -1.44 & -1.63 & 52. & -1.71 & $-1.28-$ & -1.65 & -3.74 & $57-$ & $\mid-4.94$ & 1 & $4^{4}$ & 1.3 \\
\hline & stion & down & down & down & wn & down & wn & down & down & vn & down & wn & down & down & nn & down & wn & down & down & an 5 & wn & down & down & wn & down $\mathrm{C}$ & wn $d$ & wn & vn & wn 0 & down & $\mathrm{wn}$ & own & dow \\
\hline & alue & & 13 & & & 8 & & c & & & & & 0.01 & 0.12 & & & 87 & & 1 & 34 & 58 & & & & 0.37 & 0.03 & 0.04 & 02 & .2 & - & .58 & .33 & .54 \\
\hline & Ratio & & & & & c & & 72 & - & & -5 & 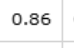 & 0.85 & | & & ${ }^{4}$ & 0.66 & 3.66 & 0.01 & 1.99 & 1.35 & 0.83 & 0.48 & 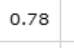 & 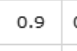 & 0.81 & 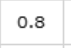 & & \begin{tabular}{c|c}
0.88 & 0 \\
\end{tabular} & 0.85 & 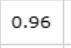 & 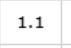 & .94 \\
\hline & ing & - & - & ${ }^{4}$ & $-1-2$ & 5 & -1.2 & . & 3 & 19 & 5 & 6. & - & $2^{2}$ & $5^{-}$ & 4. & 1 & 3. & 3 & 1.99 & 1.35 & $2-1-1$ & -2.09 & 28. & $1-$ & 4 - $^{-}$ & -1.25 & .5 & 3 & 7 & -1.04 & 1.1 & -1.0 \\
\hline & 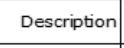 & Ler & . & down & in & down ${ }^{d}$ & nn & 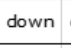 & down & & n & vn & n & in 0 & 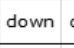 & $n^{n}$ & n' & 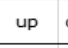 & vn & & up & vn & vn & un & down $\mathrm{C}^{\mathrm{s}}$ & un 0 & down & IP & wn d & down & down & up & down \\
\hline & prave & 0.19 & 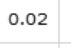 & & & & 0.01 & 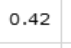 & 0.01 & & 4 & 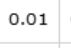 & 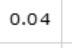 & & & 0.02 & & & & & 0.02 & 0.33 & 0.26 & 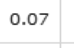 & & & & & & & & & 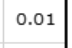 \\
\hline & $\mathrm{Nach}_{1}$ & 1.58 & 1.39 & 2.01 & 0.98 & 1.46 & 年 & 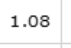 & 1.42 & & 0.01 & 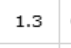 & 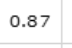 & 1.19 & & 1.33 & 1 & 3.55 & +1 & 9 & 4.00 & 1.14 & 0.75 & 1.21 & 1.0 & 1.05 & ${ }^{4}$ & 1.05 & ${ }^{9}$ & 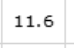 & 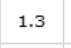 & 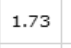 & 1.44 \\
\hline & and & 1.58 & 1.39 & - & $\begin{array}{l}-1.02 \\
\end{array}$ & - & 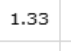 & 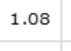 & 2.7 & 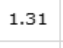 & 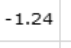 & 沓 & 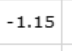 & 1.19 & & 1.33 & & & 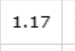 & 4.39 & 1 & & -1.33 & 1.21 & & 2.00 & ${ }^{4}$ & 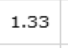 & 9 & 0 & 1.3 & 73 & 1.44 \\
\hline & 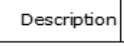 & 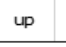 & 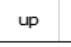 & 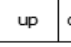 & - & & & & 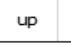 & & - & & - & 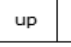 & & & & & & & & & 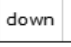 & & & up & 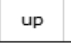 & & & & up & & 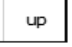 \\
\hline
\end{tabular}




\section{Appendix 2}

Supplementary Table 3. List of over-expressed calcium channels in AML. Interrogation of publically available data sets revealed a list of 17 genes that are significantly over-expressed (>1.25 fold; $\mathrm{p}<0.001)$ in AML cells compared to normal cells.

\begin{tabular}{|c|c|c|c|c|c|c|c|c|c|c|c|c|c|c|c|c|c|}
\hline \multicolumn{2}{|c|}{ Gene Symbol } & \multirow{2}{*}{ 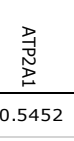 } & \multirow{2}{*}{$\begin{array}{c}\frac{\text { 胥 }}{\stackrel{N}{N}} \\
0.3086\end{array}$} & \multirow{2}{*}{ 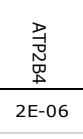 } & \multirow{2}{*}{ 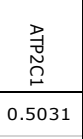 } & \multirow{2}{*}{$\frac{\underbrace{\text { 勇 }}_{0.6217}}{\text { 总 }}$} & \multirow{2}{*}{ 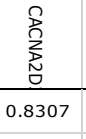 } & \multirow{2}{*}{ 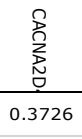 } & \multirow{2}{*}{$\frac{\text { 曾 }}{0.9586}$} & \multirow{2}{*}{$\frac{\sum_{x}^{D}}{0.171}$} & \multirow{2}{*}{ 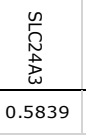 } & \multirow{2}{*}{ 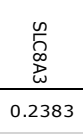 } & \multirow{2}{*}{$\frac{\frac{1}{D}}{3}$} & \multirow{2}{*}{ 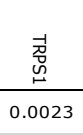 } & \multirow{2}{*}{$\frac{\text { 脋 }}{\vec{y}}$} & \multirow{2}{*}{$\frac{\prod_{\omega}^{J}}{0.031}$} & \multirow{2}{*}{ 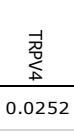 } \\
\hline \multirow{4}{*}{ 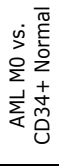 } & $\mathrm{p}$-value & & & & & & & & & & & & & & & & \\
\hline & Ratio & 0.9524 & 0.8041 & 3.1435 & 0.8529 & 1.0493 & 1.1174 & 1.3617 & 0.9897 & 1.3489 & 0.7882 & 1.2145 & 1.355 & 2.6641 & 1.016 & 1.1773 & 1.1689 \\
\hline & ld-Change & .05 & 2436 & 3.1435 & 1724 & 1.0493 & 1174 & 1.3617 & .0105 & 1.3489 & 1.2687 & 1.2145 & 1.355 & .6641 & 1.016 & 1773 & 1.1689 \\
\hline & Description & down & down & up & down & up & up & up & down & up & down & up & up & up & up & up & up \\
\hline \multirow{4}{*}{ 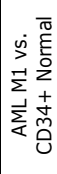 } & value & 0.3747 & 0.6852 & 0.0013 & 7874 & 0.4856 & 9362 & 0.2711 & .0511 & 8066 & 0.5428 & 1587 & 0.0067 & 0.0901 & 0.6088 & .0841 & 0.0242 \\
\hline & Ratio & 0.94 & 928 & 1.9007 & 0568 & 1.0605 & 9647 & 1.3901 & 4063 & 9551 & 1.2566 & 2225 & 1.4878 & 1.5865 & 0.9412 & .1188 & 1.1454 \\
\hline & Fold-Change & -1.0638 & -1.0776 & 1.9007 & 0568 & 1.0605 & .0365 & 1.3901 & .4063 & .047 & 1.2566 & 2225 & 1.4878 & 1.5865 & -1.0625 & 1.1188 & 1.1454 \\
\hline & Description & down & down & up & up & up & down & up & up & down & up & up & up & up & down & up & up \\
\hline \multirow{4}{*}{ 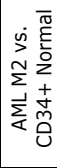 } & $\mathrm{p}$-value & 0.8822 & 0.3046 & 0.0023 & 0.8783 & 0.392 & 0.143 & 0.0677 & 0.3608 & 0.1835 & 0.5361 & 0.1311 & 0.0239 & 0.0575 & 0.9063 & 0.0545 & 0.012 \\
\hline & Ratio & 0.9898 & 0.828 & 1.8258 & 0.9693 & 1.0743 & 1.9293 & 1.7286 & 1.1704 & 0.7792 & 1.2596 & 1.2388 & 1.3868 & 1.6742 & 0.9862 & 1.1326 & 1.163 \\
\hline & Fold-Change & -1.0103 & -1.2077 & 1.8258 & -1.0317 & 1.0743 & 1.9293 & 1.7286 & 1.1704 & -1.2833 & 1.2596 & 2388 & 1.3868 & 1.6742 & -1.0139 & 1.1326 & 1.163 \\
\hline & Description & down & down & up & down & up & up & up & up & down & up & up & up & up & own & up & ip \\
\hline \multirow{4}{*}{ 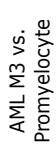 } & $\mathrm{p}$-value & 0.0002 & $=-14$ & 0.6006 & $=-05$ & 0.0094 & 8757 & 0.0206 & $=05$ & 0098 & $E-07$ & 0053 & $E-06$ & 5703 & $E-05$ & 1905 & $E-08$ \\
\hline & Ratio & 64 & 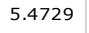 & & 476 & 581 & 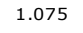 & 0617 & 635 & 647 & 28 & 5168 & 0778 & 3538 & 6743 & 913 & 4286 \\
\hline & Fold-Change & 1.3264 & 1729 & 1.11 & 2.5476 & 1.2581 & 1.075 & 2.0617 & 2.2635 & 1.6647 & 8.3628 & 1.5168 & 2.0778 & -1.1712 & 1.6743 & 1.0913 & 1.4286 \\
\hline & Description & up & up & up & up & up & up & up & up & up & up & up & up & down & up & up & up \\
\hline \multirow{4}{*}{ 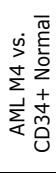 } & $p$-value & 0.166 & 0.7891 & 0.0128 & 0.0797 & 0.1446 & 0.0002 & 7E-05 & .6654 & 0.6972 & 0.7368 & 0.5198 & 0.0528 & 0.0395 & 0.4129 & 0.0721 & 0.0231 \\
\hline & Ratio & 0.9077 & 0.9519 & 1.6326 & 0.696 & 1.1314 & 7389 & 3.4757 & 1.0776 & 0758 & 0.8816 & 1.0956 & 1.3242 & 1.7561 & 0.9075 & .1241 & 1.1467 \\
\hline & Fold-Change & -1.1017 & -1.0506 & 1.6326 & -1.4368 & 1.1314 & 5.7389 & 3.4757 & 1.0776 & 1.0758 & -1.1343 & 1.0956 & 1.3242 & 1.7561 & -1.1019 & .1241 & 1.1467 \\
\hline & Description & 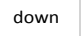 & & & & up & & P & & up & 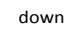 & & up & up & own & 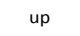 & up \\
\hline \multirow{4}{*}{ 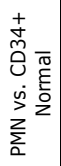 } & p-value & 0 & & 0.0926 & 7E-06 & 0.1122 & 1 & 0. & 3 & $5 E-05$ & 45 & 1 & $2 E-07$ & 21 & 04 & 92 & 0.1586 \\
\hline & Ratio & 0.8118 & 814 & 1.507 & 944 & 1.1833 & 25 & 0.6374 & 1.1536 & 58 & 3 & 73 & 49 & 86 & 11 & 02 & 11 \\
\hline & Fold-Change & -1.2318 & -12.292 & 1.507 & -3.3967 & 1.1833 & -1.3114 & -1.5688 & 1.1536 & -2.7262 & 1.103 & -1.0232 & -2.7404 & 2.2086 & -1.7208 & 1.0602 & .111 \\
\hline & & & & & & & & & & & & & & & ov & & up \\
\hline
\end{tabular}




\section{Appendix 3}

\section{Supplementary Table 4. Calcium channel gene information.}

\begin{tabular}{|c|c|c|}
\hline \multicolumn{3}{|c|}{ Under Expressed Gene Information } \\
\hline $\begin{array}{l}\text { Gene } \\
\text { Symbol }\end{array}$ & Gene Title & RefSeq Transcript ID \\
\hline ATP2A3 & ATPase, $\mathrm{Ca}++$ transporting, ubiquitous & $\begin{array}{l}\text { NM_005173 /// NM_174953 /// NM_174954 /// } \\
\text { NM_174955 /// NM_174956/// NM_174957 }\end{array}$ \\
\hline ATP2B2 & ATPase, Ca++ transporting, plasma membrane 2 & NM_001001331/// NM_001683 \\
\hline ATP2C2 & ATPase, Ca++ transporting, type 2C, member 2 & NM_014861 \\
\hline CACNA1C & $\begin{array}{l}\text { calcium channel, voltage-dependent, L type, alpha } \\
1 \mathrm{C} \text { subunit }\end{array}$ & $\begin{array}{l}\text { NM_000719 /// NM_001129827 /// NM_001129829 } \\
\text { /// NM_001129830/// NM_001129831 // }\end{array}$ \\
\hline CACNA1D & $\begin{array}{l}\text { calcium channel, voltage-dependent, L type, alpha } \\
\text { 1D subunit }\end{array}$ & NM_000720 /// NM_001128839 /// NM_001128840 \\
\hline CACNA1E & $\begin{array}{l}\text { Calcium channel, voltage-dependent, R type, } \\
\text { alpha } 1 \mathrm{E} \text { subunit }\end{array}$ & - \\
\hline CACNA1G & $\begin{array}{l}\text { calcium channel, voltage-dependent, } T \text { type, alpha } \\
1 \text { G subunit }\end{array}$ & $\begin{array}{l}\text { NM_018896 /// NM_198376 /// NM_198377 /// } \\
\text { NM_198378 /// NM_198379/// NM_198380 }\end{array}$ \\
\hline $\begin{array}{l}\text { CACNA2D } \\
1\end{array}$ & $\begin{array}{l}\text { calcium channel, voltage-dependent, alpha 2/delta } \\
\text { subunit } 1\end{array}$ & NM_000722 \\
\hline CACNB1 & subunit & NM_000723 /// NM_199247/// NM_199248 \\
\hline CACNB2 & $\begin{array}{l}\text { calcium channel, voltage-dependent, beta } 2 \\
\text { subunit }\end{array}$ & $\begin{array}{l}\text { NM_000724 /// NM_001167945 /// NM_201570 /// } \\
\text { NM_201571/// NM_201572/// NM_2015 }\end{array}$ \\
\hline CACNG1 & subunit 1 & NM_000727 \\
\hline CACNG4 & subunit 4 & NM_014405 \\
\hline CACNG5 & subunit 5 & NM_014404 /// NM_145811 \\
\hline KCNMA1 & $\begin{array}{l}\text { potassium large conductance calcium-activated } \\
\text { channel, subfamily } \mathrm{M} \text {, alpha member }\end{array}$ & $\begin{array}{l}\text { NM_001014797 /// NM_001161352 /// } \\
\text { NM_001161353 /// NM_002247 }\end{array}$ \\
\hline KCNMB2 & $\begin{array}{l}\text { potassium large conductance calcium-activated } \\
\text { channel, subfamily } M \text {, beta member }\end{array}$ & NM_005832 /// NM_181361 \\
\hline ORAI2 & 2 & NM_001126340 /// NM_032831 \\
\hline SLC24A4 & $\begin{array}{l}\text { (sodium/potassium/calcium exchanger), member } \\
4\end{array}$ & NM_153646 /// NM_153647 /// NM_153648 \\
\hline SLC24A5 & solute carrier family 24, member 5 & NM_205850 \\
\hline SLC8A1 & $\begin{array}{l}\text { solute carrier family } 8 \text { (sodium/calcium } \\
\text { exchanger), member } 1\end{array}$ & $\begin{array}{l}\text { NM_001112800 /// NM_001112801 /// } \\
\text { NM_001112802 /// NM_021097 }\end{array}$ \\
\hline TACSTD2 & tumor-associated calcium signal transducer 2 & NM_002353 \\
\hline TRPA1 & $\begin{array}{l}\text { transient receptor potential cation channel, } \\
\text { subfamily } A \text {, member } 1\end{array}$ & NM_007332 \\
\hline TRPC1 & $\begin{array}{l}\text { transient receptor potential cation channel, } \\
\text { subfamily C, member } 1\end{array}$ & NM_003304 \\
\hline TRPC4 & $\begin{array}{l}\text { transient receptor potential cation channel, } \\
\text { subfamily C, member } 4\end{array}$ & $\begin{array}{l}\text { NM_001135955 /// NM_001135956 /// } \\
\text { NM_001135957 /// NM_001135958/// NM_003306 // }\end{array}$ \\
\hline TRPC4AP & $\begin{array}{l}\text { transient receptor potential cation channel, } \\
\text { subfamily C, member } 4 \text { associated pr }\end{array}$ & NM_015638 /// NM_199368 \\
\hline TRPC6 & $\begin{array}{l}\text { transient receptor potential cation channel, } \\
\text { subfamily C, member } 6\end{array}$ & NM_004621 \\
\hline TRPM1 & $\begin{array}{l}\text { transient receptor potential cation channel, } \\
\text { subfamily } M \text {, member } 1\end{array}$ & NM_002420 \\
\hline TRPM2 & $\begin{array}{l}\text { transient receptor potential cation channel, } \\
\text { subfamily } M \text {, member } 2\end{array}$ & NM_003307 \\
\hline TRPM3 & $\begin{array}{l}\text { transient receptor potential cation channel, } \\
\text { subfamily } M \text {, member } 3\end{array}$ & $\begin{array}{l}\text { NM_001007470 /// NM_001007471 /// NM_020952 } \\
\text { /// NM_024971 /// NM_206944 /// NM_2 }\end{array}$ \\
\hline TRPM6 & $\begin{array}{l}\text { transient receptor potential cation channel, } \\
\text { subfamily } M \text {, member } 6\end{array}$ & NM_001177310/// NM_001177311/// NM_017662 \\
\hline TRPM8 & $\begin{array}{l}\text { transient receptor potential cation channel, } \\
\text { subfamily } M \text {, member } 8\end{array}$ & NM_024080 \\
\hline TRPV5 & $\begin{array}{l}\text { transient receptor potential cation channel, } \\
\text { subfamily } \mathrm{V} \text {, member } 5\end{array}$ & NM_019841 \\
\hline TRPV6 & $\begin{array}{l}\text { transient receptor potential cation channel, } \\
\text { subfamily } \mathrm{V} \text {, member } 6\end{array}$ & NM_018646 \\
\hline
\end{tabular}




\begin{tabular}{|c|c|c|}
\hline \\
\hline \multicolumn{3}{|c|}{\begin{tabular}{|l|l|} 
Over Expressed Gene Information \\
Gene & \\
\end{tabular}} \\
\hline ATP2A1 & twitch 1 & NM_004320 /// NM_173201 \\
\hline ATP2A2 & twitch 2 & NM_001135765 /// NM_001681/// NM_170665 \\
\hline ATP2B4 & ATPase, Ca++ transporting, plasma membrane 4 & NM_001001396 /// NM_001684 \\
\hline ATP2C1 & ATPase, $\mathrm{Ca}++$ transporting, type $2 \mathrm{C}$, member 1 & $\begin{array}{l}\text { NM_001001485 /// NM_001001486 /// } \\
\text { NM_001001487 /// NM_014382 }\end{array}$ \\
\hline CACNA1I & $\begin{array}{l}\text { calcium channel, voltage-dependent, T type, alpha } \\
1 \text { I subunit }\end{array}$ & NM_001003406 /// NM_021096 \\
\hline $\begin{array}{l}\text { CACNA2D } \\
3\end{array}$ & $\begin{array}{l}\text { calcium channel, voltage-dependent, alpha 2/delta } \\
\text { subunit } 3\end{array}$ & NM_018398 \\
\hline $\begin{array}{l}\text { CACNA2D } \\
4\end{array}$ & $\begin{array}{l}\text { calcium channel, voltage-dependent, alpha 2/delta } \\
\text { subunit } 4\end{array}$ & NM_172364 \\
\hline ORAI1 & ( & NM_032790 \\
\hline PANX1 & pannexin 1 & NM_015368 \\
\hline SLC24A3 & $\begin{array}{l}\text { (sodium/potassium/calcium exchanger), member } \\
3\end{array}$ & NM_020689 \\
\hline SLC8A3 & $\begin{array}{l}\text { solute carrier family } 8 \text { (sodium/calcium } \\
\text { exchanger), member } 3\end{array}$ & $\begin{array}{l}\text { NM_001130417 /// NM_033262 /// NM_058240 /// } \\
\text { NM_182932 /// NM_182936/// NM_1830 }\end{array}$ \\
\hline TRPM7 & $\begin{array}{l}\text { transient receptor potential cation channel, } \\
\text { subfamily M, member } 7\end{array}$ & NM_017672 \\
\hline TRPS1 & trichorhinophalangeal syndrome I & NM_014112 \\
\hline TRPT1 & tRNA phosphotransferase 1 & $\begin{array}{l}\text { NM_001033678 /// NM_001160389 /// } \\
\text { NM_001160390 /// NM_001160392 /// } \\
\text { NM_001160393 }\end{array}$ \\
\hline TRPV3 & $\begin{array}{l}\text { transient receptor potential cation channel, } \\
\text { subfamily } \mathrm{V} \text {, member } 3\end{array}$ & NM_145068 \\
\hline TRPV4 & $\begin{array}{l}\text { transient receptor potential cation channel, } \\
\text { subfamily } \mathrm{V} \text {, member } 4\end{array}$ & $\begin{array}{l}\text { NM_001177428 /// NM_001177431 /// } \\
\text { NM_001177433 /// NM_021625 /// NM_147204 }\end{array}$ \\
\hline
\end{tabular}




\section{Appendix 4}

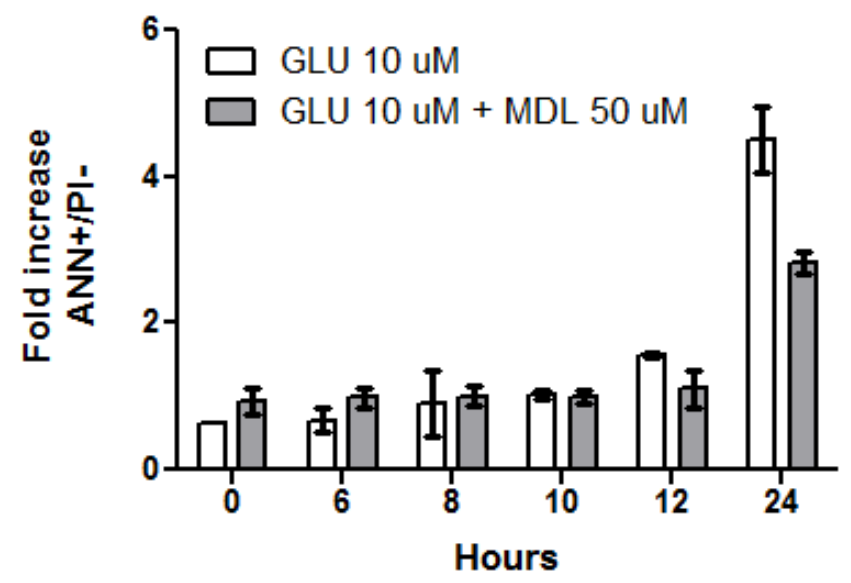

MDL28170 inhibits increases in apoptosis. Glucopsychosine was co-incubated with MDL28170 for increasing duration and apoptosis was measured by the ANN/PI assay. 


\section{Appendix 5}
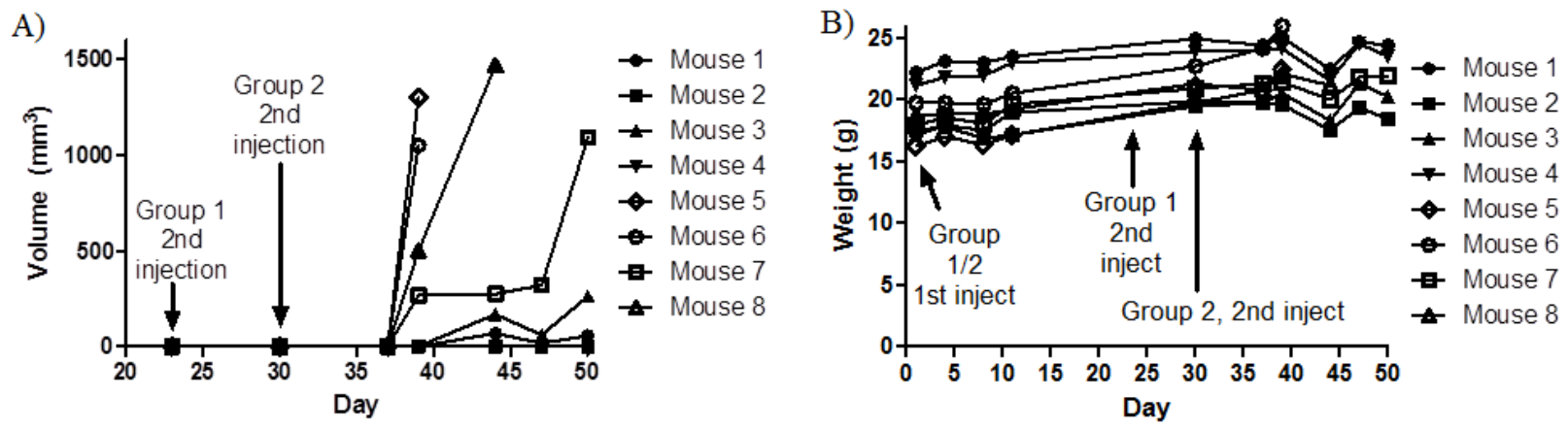

Eight NOD/SCID mice were injected with human leukemia cell lines and monitored for the presence of tumors and toxicity. Mice 1-4 comprised Group 1 and mice 5-8 comprised Group 2. (A) Tumor volumes were recorded three times weekly. Endpoint was determined when tumor volumes exceeded $1000 \mathrm{~mm}^{3}$. (B) Body weights of each mouse shows no sign of toxicity due to experiment. Subcutaneous cell line injections were performed by Julia Guan. Mouse weights and tumor measurements were done by Leonard Angka and Eric Lee. Cardiac puncture was performed by Leonard Angka and Julia Guan. 